\title{
Business cycle and policy effects on labour market transitions of older and disabled workers in Spain
}

Citation for published version (APA):

Vall Castello, J. (2010). Business cycle and policy effects on labour market transitions of older and disabled workers in Spain. [Doctoral Thesis, Maastricht University]. Boekenplan. https://doi.org/10.26481/dis.20100707jv

Document status and date:

Published: 01/01/2010

DOI:

10.26481/dis.20100707jv

Document Version:

Publisher's PDF, also known as Version of record

\section{Please check the document version of this publication:}

- A submitted manuscript is the version of the article upon submission and before peer-review. There can be important differences between the submitted version and the official published version of record.

People interested in the research are advised to contact the author for the final version of the publication, or visit the DOI to the publisher's website.

- The final author version and the galley proof are versions of the publication after peer review.

- The final published version features the final layout of the paper including the volume, issue and page numbers.

Link to publication

\footnotetext{
General rights rights.

- You may freely distribute the URL identifying the publication in the public portal. please follow below link for the End User Agreement:

www.umlib.nl/taverne-license

Take down policy

If you believe that this document breaches copyright please contact us at:

repository@maastrichtuniversity.nl

providing details and we will investigate your claim.
}

Copyright and moral rights for the publications made accessible in the public portal are retained by the authors and/or other copyright owners and it is a condition of accessing publications that users recognise and abide by the legal requirements associated with these

- Users may download and print one copy of any publication from the public portal for the purpose of private study or research.

- You may not further distribute the material or use it for any profit-making activity or commercial gain

If the publication is distributed under the terms of Article $25 \mathrm{fa}$ of the Dutch Copyright Act, indicated by the "Taverne" license above, 


\title{
Business Cycle and Policy Effects on Labour Market Transitions of Older and Disabled Workers in Spain
}

\author{
Dissertation
}

To obtain the degree of Doctor at Maastricht University, on the authority of the Rector Magnificus Prof. Dr.

G.P.M.F.Mols in accordance with the decision of the Board of Deans to be defended in public on Wednesday 7 July, at 16.00 hours

By

Judit Vall Castello 
Supervisors:

Prof. Dr. C.J.N. de Neubourg

Prof. Dr. S. Jimenez-Martin

Assessment Committee:

Prof. Dr. A. De Grip (chairman)

Dr. F. Cörvers

Dr. A. Dupuy

Prof. Dr. J.I. Garcia-Perez, Universidad Pablo de Olavide, Spain

Prof. Dr. F. Felgueroso, Universidad Oviedo, Spain

ISBN 9789086661534

Publisher: Boekenplan, Maastricht 


\section{Acknowledgements}

This is the best part of the thesis for me as I get to thank everybody that, in one form or another, has accompanied me in this three and a half year process of writing a PhD. Following my personal approach of "going to the point", I will be very quick and concise, incurring in the risk of forgetting to mention somebody (but I am sure they will understand).

First of all, I want to thank everybody at the Maastricht Graduate School of Governance for making the School such a great place to be. Its multi-cultural character and friendly environment are extraordinary and make it a truly nice and appealing place to study. From the School, my first big thank you goes to Chris, Mindel and Franziska for having selected me among many applicants and for trusting and supporting me at ALL times. I am truly indebted to them and this is something I will never forget. Second, I have to thank the colleagues of my cohort (Nicola, Treena, Manuel, Jinjing, Victor, Metka and particularly Robert, Henry, Maha and Marina). I immediately connected with them and we created a great and fun group to do whatever there was to be done in Maastricht). When thinking about my time in Maastricht I also have to thank Semih, Eze, Jake, Olga and, of course, Abraham for sharing many lunches, dinners, teas, beers and parties in Maastricht.

Having covered the Maastricht chapter, I have to thank my long-time friends Nuria, Anna, Cristina, Pili and Laura for always being there for me and for making me remember at all times what is most important in this life (yes, above the PhD).

During the PhD, I had one main supervisor but I had 3 other professors who really helped and supported me during difference phases of my thesis; Nacho read many versions of my papers and hosted me in Sevilla for one week (apart from meeting him in several conferences and always having a laugh), Thierry Magnac invited and hosted me at the Toulouse School of Economics for one year and continuously revised and directed my work every two weeks during that year and Hugo Benitez Silva gave me the opportunity to do a 6-month visiting research period at Stony Brook University and provided me with help, advice and contacts in the USA, apart from many other good economic and non-economic conversations. I also need to thank people at ROA for giving me the opportunity to work with them.

Thinking about the relationship with my supervisor, I believe that it was truly uncommon for a supervisor-student relation. Usually, when you listen to students commenting on their supervisors, the story begins really nice with lots of projects and good intentions and, at some point, it deteriorates and it usually ends up pretty bad. In our case, I first meet Sergi Jimenez at Pompeu Fabra and we talked for (at most) 30 minutes before deciding that he would be my supervisor. I am 
positive when I say that, at that point, neither of us was quite sure about how this would work out. However, little by little, we managed to find common interests and (most importantly) an honest and friendly way to talk and work together which created a link of trust between us. Looking back, I really thank you Sergi for always being supportive and minimizing what I thought were big problems, always replying to my emails (even if in a different language) and sharing with me the road to become a doctor. I am sure that our friendship will continue after my PhD.

And to end, I only need to thank my family, which is very big so that I cannot enumerate all the members of it. In particular, I need to thank my grandparents (for their support and their desire to take part of everything I do in my life), my father (and his family), my "other" father Carles (and his family) but MOST OF ALL the three most important persons in my life: my sister Berta, my mother Montse and my partner (now also husband and soon-to-be father of my child) Marc. They know me better than myself and they have always been there and will always be there for me. This, after all, is what really makes my life full and gives me the strength to do anything in this world!! (even finishing a PhD). 


\section{Contents}

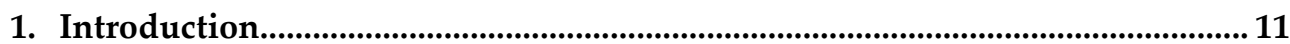

1.1 Business Cycle Effects on Labour Force Transitions for Older

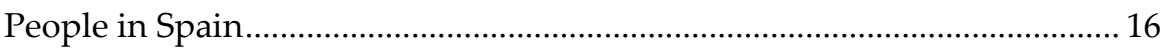

1.2 Promoting Employment of Disabled Women in Spain: Evaluating a Policy

1.3 Employment Effects of Increasing Disability Benefits: A Regression Discontinuity Approach ……………………………………..... 19

1.4 The Database; Muestra Continua de Vidas Laborales..................................... 20

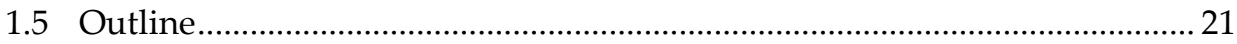

2. Business Cycle Effects On Labour Force Transitions For Older People In Spain........................................................................................................ 23

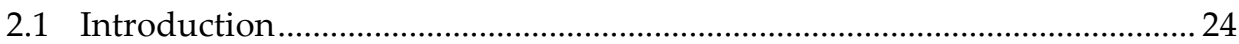

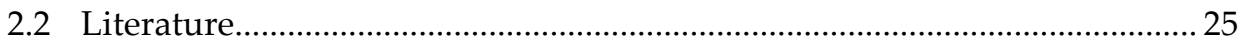

2.3 Determinants of labour force transitions for workers aged 45-59

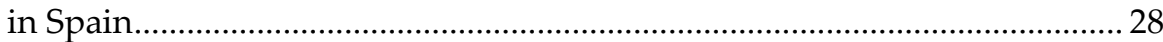

2.4 The Spanish Social Security rules for older people:

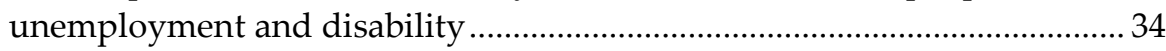

2.5 Modelling framework: The hazard regression model .................................... 35

2.5.1 Single exit logistic hazard model ............................................................. 35

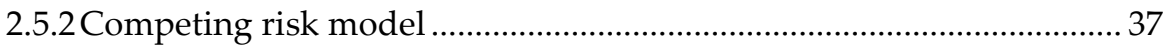

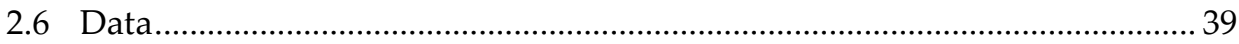

2.6.1 Sample selection criteria and variables ................................................... 40

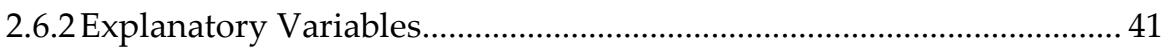

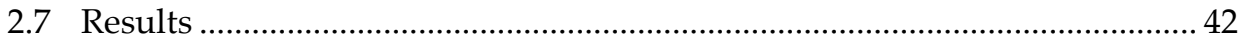

2.7.1 Non-parametric analysis ................................................................... 42

2.7.2 Results: Hazard Regression analysis .................................................... 47

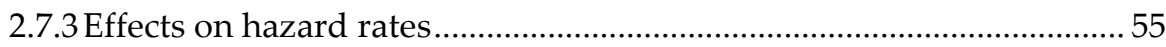

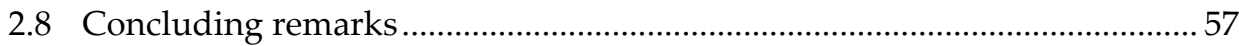

2.9 Appendix: Tables and Figures …………………………………………........ 59

3. Promoting Employment of Disabled Women in Spain; Evaluating a

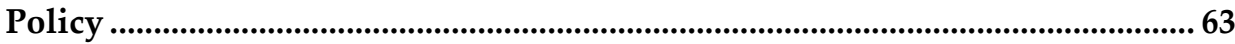

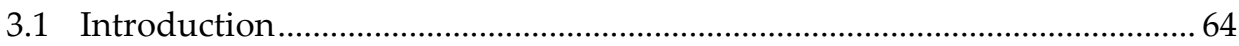

3.2 Types of disability benefits \& compatibility with a job ……............................. 69

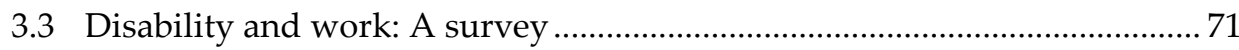

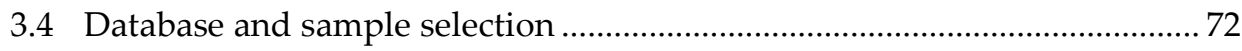

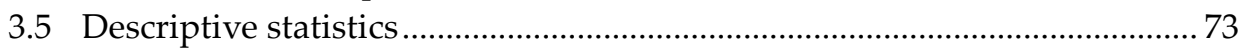




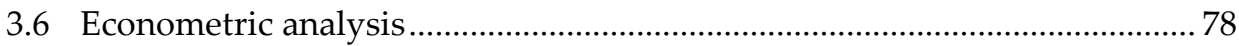

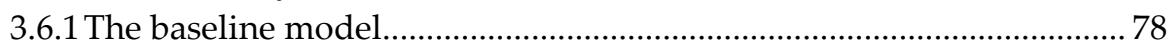

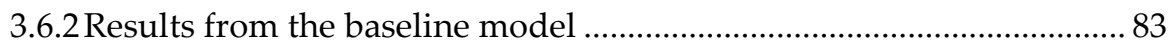

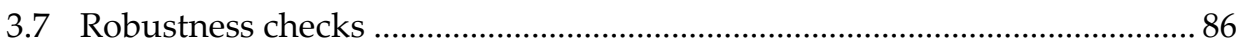

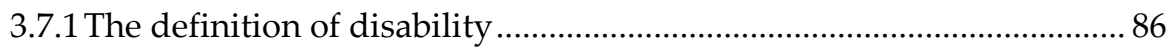

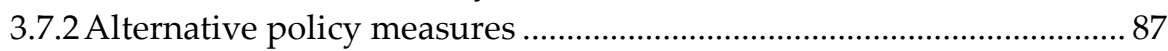

3.8 Conclusions and policy recommendations ……............................................ 89

3.9 Appendix: Tables and figures ...................................................................... 91

4. The Employment Effect of Increasing Disability Benefits: A Regression Discontinuity Approach ...................................................................... 95

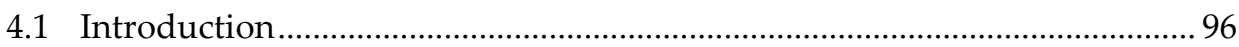

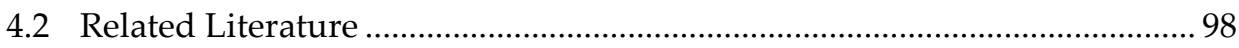

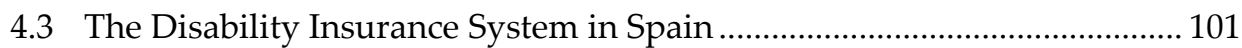

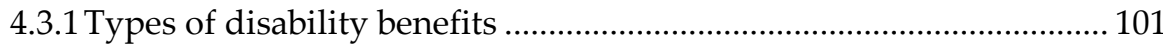

4.3.2Elegibility and Pension Amount ......................................................... 102

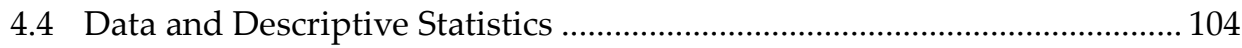

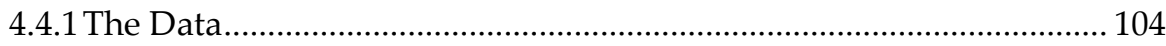

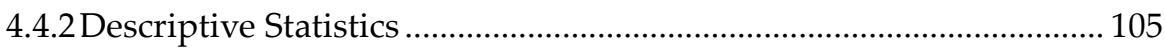

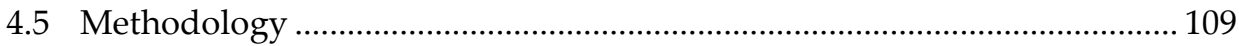

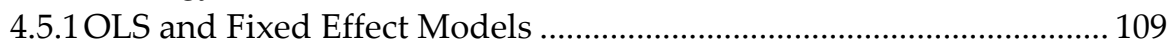

4.5.2 Regression Discontinuity Models ........................................................ 110

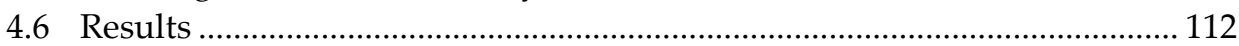

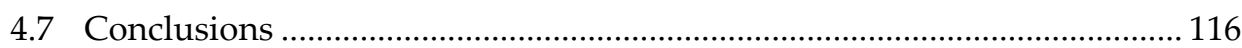

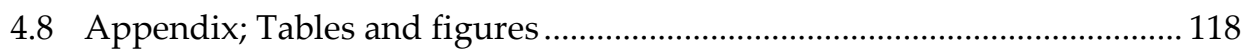

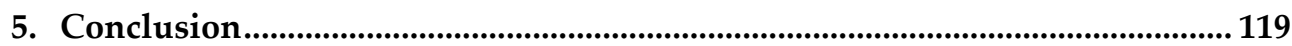

5.1 Business Cycle Effects on Labour Force Transitions for Older

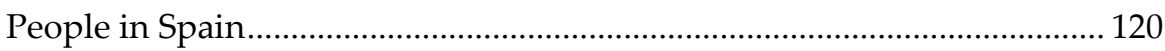

5.2 Promoting Employment of Disabled Women in Spain: Evaluating

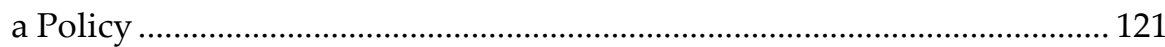

5.3 The Employment Effect of Increasing Disability Benefits: A Regression Discontinuity Approach ........................................................ 123

5.4 Main Policy Implications and Further Work ............................................... 124

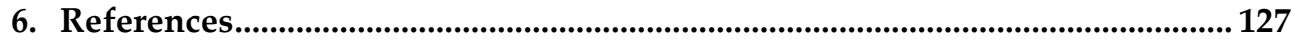

7. Nederlandse Samenvatting ................................................................................... 136

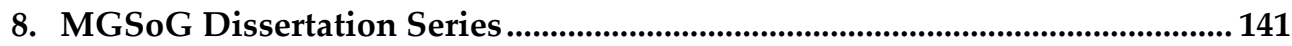

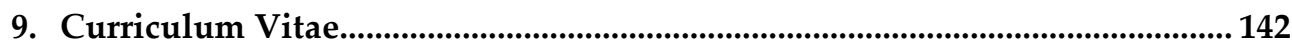




\section{List of Figures}

Figure 1 Disability benefit recipiency rates: disability benefit recipients in percent of the population aged 20-64 in 28 OECD countries, mid-1990s and latest available year.

Figure 2 Employment rates of the working-age population with disability in 27 OECD countries, mid-1990s and mid-2000s.

Figure 3 Unemployment and labour force participation for men aged 45-

59 in Spain, from 1987-2007.

Figure 4 Unemployment and labour force participation for women aged

45-59 in Spain, from 1987-2007..

Figure 5 Unemployment rate and new disability benefits granted each

year to individuals aged 45-59 in Spain, from 1980-2008.

Figure 6 GDP growth and new disability benefits granted each year to individuals aged 45-59 in Spain, from 1980-2008.

Figure 7 GDP growth and rate of new disability benefits to employment

(individuals of all ages) in Spain, from 1978-2006

Figure 8 Unemployment rate and rate of new disability benefits to employment (individuals of all ages) in Spain, from 1987-2006.

Figure 9 Interval hazard rate men aged 45-59 in Spain.

Figure 10 Interval hazard rate women 45-59 in Spain.

Figure 11 Interval hazard rate by temporary/permanent contract of employment, men aged 45-59 in Spain.

Figure 12 Interval hazard rate by temporary/permanent contract of employment, women aged 45-59 in Spain

Figure 13 Interval hazard rate by level of education, men aged 45-59 in

Spain.

Figure 14 Interval hazard rate by level of education, women aged 45-59 in

Spain.

Figure 15 Predicted hazard rate men $45-59$ by temporary/permanent contract of employment 56

Figure 16 Predicted hazard rate men $45-59$ by maximum/minimum level of GDP growth. 56

Figure 17 Predicted hazard rate men $45-59$ by maximum/minimum level of unemployment rates 57

Figure 18 Interval hazard rate exit to Unemployment; men \& women 4559 59

Figure 19 Interval hazard rate exit to Disability; men \& women 45-59. 59

Figure 20 Interval hazard rate exit to Inactivity; men \& women 45-59. 60 
Figure 21 Calibration of the magnitude of several challenges in disability policies.

Figure 22 Disability recipients by age and gender as a share of total disabled individuals, 2005

Figure 23 Employment rates of disabled individuals

Figure 24 Evolution of the percentages of women and total disability pensioners in the sample

Figure 25 Evolution of the probability of working for disabled individuals in our sample. 77

Figure 26 Evolution of the probability of working for disabled women in our sample

Figure 27 Evolution of the probability of working for disabled men in our sample. 78

Figure 28 Proportion of disability recipients receiving the increase in disability benefits by age. 106

Figure 29 Proportion of disabled individuals who are female in the sample by age.

Figure 30 Proportion of disabled individuals with secondary education or above.

Figure 31 Age started claiming DI by age 108

Figure 32 EMP of disability recipients by age 108

Figure 33 Distribution of age started claiming DI. 115

Figure 34 Description of the claiming process to access permanent disability benefits 


\section{List of Tables}

Table 1 Trends in expenditure on disability and sickness programs, in percentage of GDP, 1999, 2000 and 2005, and in percentage of unemployment benefit spending and total public spending, 2005.

Table 2 Regression results: Dependent Variable: rate of new disability benefits to employment.

Table 3 Determinants of the probability of leaving employment, Spanish male aged 45-59 (logistic hazard regression model)

Table 4 Determinants of the probability of leaving employment, Spanish female aged 45-59 (logistic hazard regression model)...

Table 5 Determinants of the probability of going to disability benefits, unemployment and inactivity Spanish male aged 45-59 (competing-risk hazard regression model).

Table 6 Business cycle coefficients, Spanish male 45-59 conditional on working for two years before entering the sample (competing risk hazard regression model)

Table 7 Determinants of the probability of going to disability benefits, unemployment and inactivity, Spanish female aged 45-59 (competing risk hazard regression model).

Table 8 Business cycle coefficients, Spanish female 45-59 conditional on working for two years before entering the sample (competing risk hazard regression model)

Table 9 Means and standard deviations. Sample of men 45-59. 61

Table 10 Means and standard deviations. Sample of women 45-59 ............................. 62

Table 11 Summary statistics selected variables. ........................................................... 74

Table 12 Summary statistics selected variables by working status............................. 75

Table 13 Legislative reforms in firm's incentives in Spain.......................................... 80

Table 14 Estimation bivariate probit model, all years all ages. .................................... 84

Table 15 Estimation bivariate probit model with covariates and exclusion

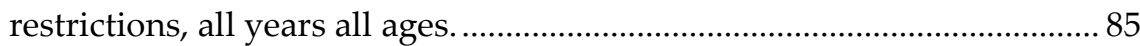

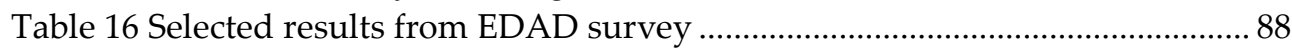

Table 17: Probabilities of working and number of individuals in the sample

Table 18 Rules for the determination of the pension amount.................................... 93

Table 19 OLS and fixed effects results ................................................................... 113

Table $20 \mathrm{RD}$ results for different age windows around the eligibility age threshold. 
Table 21 RD results +/-1 year around eligibility age threshold with individual controls.

Table 22 RD results $+/-1$ year around eligibility age threshold with individual controls for individuals who started claiming before age 55 116 


\section{Introduction}


Disability policies have recently gained a lot of attention in OECD countries as the disability insurance system has become one of the main obstacles in the attempts of raising (or preventing the fall of) labour force participation rates in developed economies. Many reforms have been introduced across the OECD in order to activate the unemployed and to abolish early retirement schemes, which coupled with the sustained economic growth has led to decreases in unemployment rates. However, these positive developments have translated in increases in the disability rolls, particularly so for older workers. Figure 1 shows that, on average, $6 \%$ of the OECD working-age population was receiving disability benefits in 2007 but, for some countries like Sweden or Norway disability recipiency rates reach the $10 \%$, which is a higher number than unemployment rates for these countries. Only the countries that have introduced policy changes which successfully managed to tighten access to disability benefits like The Netherlands, Poland or Luxemburg have experienced significant declines in beneficiary rates in recent years.

Figure 1 Disability benefit recipiency rates: disability benefit recipients in percent of the population aged 20-64 in 28 OECD countries, mid-1990s and latest available year1.

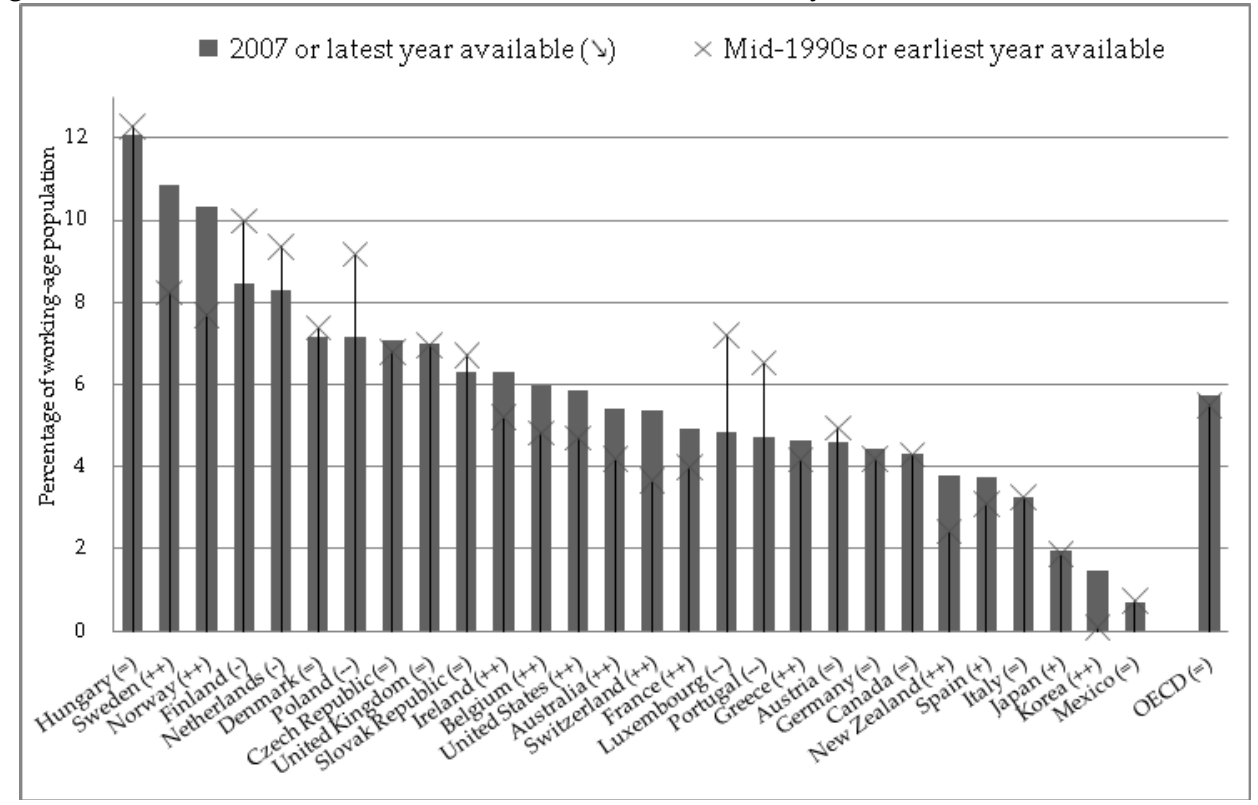

Source: OECD high-level forum on Sickness, Disability and Work, May 2009.

${ }^{1} 2004$ for France, 2005 for Luxembourg, 2006 for Denmark, Italy, Japan, the Slovak Republic and the United States. 1996 for Belgium and Canada, 1999 for The Netherlands, 2000 for Hungary and Italy, 2001 for Ireland, 2003 for Japan and 2004 for Poland. 
As a parallel development to this increase in recipiency rates, it has been extensively documented that employment rates of disabled individuals have remained at very low levels despite increases in the GDP during the past decade in most OECD countries. In Figure 2 we observe that, on average across the OECD in the mid-2000s, employment rates of people with disability only managed to reach $42 \%$ compared to the $75 \%$ level of people without disability. Despite some attempts in a number of countries to implement employment integration measures for individuals with disabilities, their employment rates have not substantially improved.

Figure 2 Employment rates of the working-age population with disability in 27 OECD countries, mid-1990s and mid-2000s.

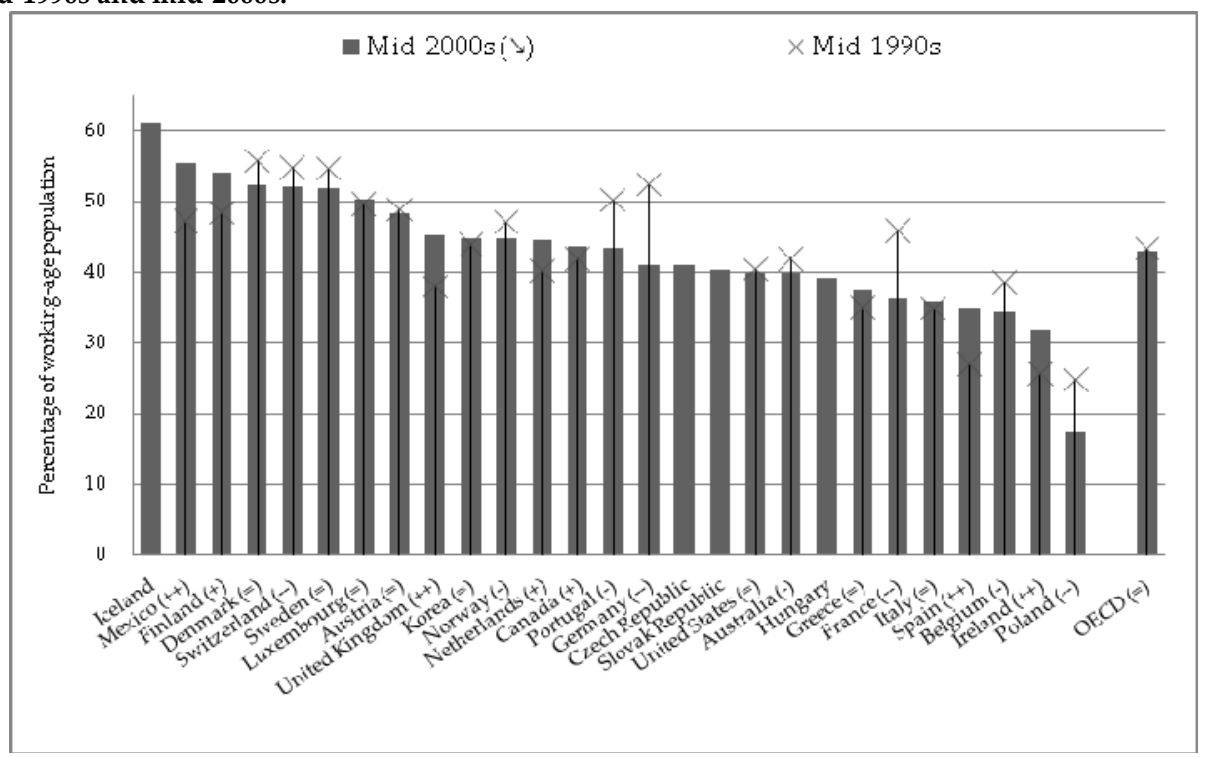

Source: OECD high-level forum on Sickness, Disability and Work, May 2009.

Therefore, both national and international authorities have recognized the need to control the inflow into disability benefit programs and to introduce policies that prove effective in promoting the reintegration in the labour market of those beneficiaries that keep some remaining capacity to work.

The immediate consequence of these high inflow rates into disability benefits and the low employment and outflow rates from the system, is the extremely high benefit spending on disability. We can see in Table 1 that, on average, OECD countries spend $1.2 \%$ of GDP on disability benefits but this figure more than doubles for countries like Sweden $(2.5 \%)$, Norway $(2.6 \%)$ or The Netherlands (2.4\%). If we add sickness expenditures to spending on disability benefits, the figure can reach the 5\% level of the GDP and it more than doubles what is spent on unemployment benefits. 
Table 1 Trends in expenditure on disability and sickness programs, in percentage of GDP, 1999, 2000 and 2005, and in percentage of unemployment benefit spending and total public spending, 2005.

\begin{tabular}{|c|c|c|c|c|c|c|c|c|c|c|c|}
\hline & \multicolumn{3}{|c|}{ Disability } & \multicolumn{3}{|c|}{ Sickness } & \multicolumn{5}{|c|}{ Disability and sickness } \\
\hline & \multicolumn{3}{|c|}{$\begin{array}{c}\% \\
\text { GDP }\end{array}$} & \multicolumn{3}{|c|}{$\begin{array}{c}\% \\
\text { GDP }\end{array}$} & \multicolumn{3}{|c|}{$\begin{array}{c}\% \\
\text { GDP }\end{array}$} & \multirow{2}{*}{$\begin{array}{c}\begin{array}{c}\% \text { Unem- } \\
\text { ployment }\end{array} \\
2005\end{array}$} & \multirow{2}{*}{$\begin{array}{c}\begin{array}{c}\% \text { Public } \\
\text { social } \\
\text { spend }\end{array} \\
2005\end{array}$} \\
\hline & 1990 & 2000 & 2005 & 1990 & 2000 & 2005 & 1990 & 2000 & 2005 & & \\
\hline Australia & 1.1 & 1.2 & 1.3 & 0.5 & 1.8 & 1.3 & 1.6 & 3.0 & 2.5 & 463 & 15 \\
\hline Austria & 1.8 & 1.1 & 1.3 & 1.3 & 1.1 & 1.0 & 3.1 & 2.3 & 2.4 & 221 & 9 \\
\hline Belgium & 1.4 & 1.2 & 1.4 & 1.4 & 0.7 & 0.7 & 2.8 & 1.9 & 2.1 & 72 & 8 \\
\hline $\begin{array}{l}\text { Canada } \\
\text { Czech }\end{array}$ & 0.4 & 0.4 & 0.4 & 0.0 & 0.0 & 0.0 & 0.4 & 0.4 & 0.4 & 65 & 2 \\
\hline Republic & 1.2 & 1.1 & 1.1 & 1.0 & 1.2 & 1.0 & 2.3 & 2.3 & 2.1 & 355 & 11 \\
\hline Denmark & 1.6 & 1.5 & 1.8 & 1.4 & 1.1 & 1.3 & 2.9 & 2.6 & 3.1 & 231 & 11 \\
\hline Finland & 2.1 & 1.8 & 1.9 & 1.5 & 1.2 & 1.2 & 3.6 & 3.0 & 3.1 & 194 & 12 \\
\hline France & 0.9 & 0.8 & 0.9 & 0.6 & 0.7 & 0.8 & 1.6 & 1.5 & 1.6 & 99 & 6 \\
\hline Germany & 0.8 & 1.0 & 0.9 & 1.9 & 1.6 & 1.3 & 2.7 & 2.5 & 2.2 & 148 & 8 \\
\hline Greece & 1.0 & 0.7 & 0.7 & 0.8 & 0.7 & 0.6 & 1.9 & 1.4 & 1.3 & 329 & 6 \\
\hline Hungary & .. & 0.2 & 0.2 & .. & 0.7 & 0.7 & .. & 1.0 & 0.9 & 190 & 4 \\
\hline Iceland & 0.9 & 1.7 & 2.2 & 1.5 & 1.4 & 1.5 & 2.3 & 3.1 & 3.6 & 1.183 & 22 \\
\hline Ireland & 0.5 & 0.6 & 0.7 & 0.8 & 0.6 & 0.7 & 1.3 & 1.1 & 1.5 & 163 & 9 \\
\hline Italy & 1.2 & 0.9 & 0.8 & 0.9 & 0.7 & 0.5 & 2.1 & 1.6 & 1.3 & 324 & 5 \\
\hline Japan & 0.3 & 0.3 & 0.3 & 0.1 & 0.1 & 0.1 & 0.4 & 0.4 & 0.4 & 125 & 2 \\
\hline Korea & 0.1 & 0.1 & 0.1 & 0.1 & 0.1 & 0.1 & 0.2 & 0.2 & 0.2 & 104 & 3 \\
\hline Luxemb. & 2.0 & 1.7 & 1.6 & 0.6 & 0.6 & 0.9 & 2.6 & 2.3 & 2.5 & 324 & 11 \\
\hline Mexico & 0.0 & 0.0 & 0.0 & 0.0 & 0.0 & 0.0 & 0.0 & 0.0 & 0.0 & .. & .. \\
\hline $\begin{array}{l}\text { Netherls. } \\
\text { New }\end{array}$ & 4.7 & 2.7 & 2.4 & 2.9 & 2.2 & 2.3 & 7.6 & 4.9 & 4.6 & 303 & 22 \\
\hline Zealand & 0.6 & 0.9 & 1.0 & 0.3 & 0.3 & 0.3 & 0.9 & 1.2 & 1.3 & 302 & 7 \\
\hline Norway & 2.5 & 2.3 & 2.6 & 2.6 & 2.7 & 2.4 & 5.1 & 5.1 & 4.9 & 960 & 23 \\
\hline Poland & 2.1 & 2.2 & 1.6 & 0.7 & 0.7 & 0.6 & 2.8 & 3.0 & 2.3 & 821 & 11 \\
\hline $\begin{array}{l}\text { Portugal } \\
\text { Slovak }\end{array}$ & 1.7 & 1.8 & 1.8 & 0.0 & 0.0 & 0.0 & 1.7 & 1.8 & 1.8 & 157 & 8 \\
\hline Republic &.. & 0.9 & 0.9 & .. & 1.0 & 0.3 & .. & 1.9 & 1.2 & 672 & 7 \\
\hline Spain & 1.2 & 1.2 & 1.1 & 1.0 & 1.0 & 1.1 & 2.2 & 2.2 & 2.2 & 103 & 11 \\
\hline Sweden & 1.9 & 2.1 & 2.5 & 3.1 & 2.0 & 1.7 & 5.0 & 4.1 & 4.2 & 353 & 14 \\
\hline Switz. & 1.0 & 1.8 & 2.1 & 1.2 & 1.1 & 1.0 & 2.2 & 2.8 & 3.2 & 339 & 16 \\
\hline $\begin{array}{l}\text { Turkey } \\
\text { United }\end{array}$ & 0.1 & 0.2 & 0.1 & 0.1 & 0.0 & 0.0 & 0.1 & 0.2 & 0.1 & 232 & 1 \\
\hline $\begin{array}{l}\text { Kingdom } \\
\text { United }\end{array}$ & 1.6 & 2.1 & 1.8 & 0.6 & 0.7 & 0.5 & 2.2 & 2.8 & 2.3 & 904 & 11 \\
\hline States & 0.5 & 0.6 & 0.7 & 0.8 & 0.6 & 0.7 & 1.3 & 1.2 & 1.4 & 483 & 9 \\
\hline OECD & 1.3 & 1.2 & 1.2 & 1.0 & 0.9 & 0.8 & 2.3 & 2.1 & 2.0 & 248 & 10 \\
\hline
\end{tabular}

Source: OECD high-level forum on Sickness, Disability and Work, May 2009. 
Moreover, spending on disability benefits has, in general, either been kept at a relatively constant level or it has been increasing during recent years as a result of the permanent nature of this kind of benefits, which adds extra difficulties when trying to reduce this source of public expenditure. This is a very important observation to take into account in times of economic crisis like the current ones as reductions of spending on disability benefits are only possible through strong reorganization of the access and revision process of the benefit structure (some of these reforms are analyzed and suggested in the $3^{\text {rd }}$ and $4^{\text {th }}$ chapter of this thesis for the Spanish case).

With the objective of reducing expenditures on disability benefits in mind, several countries have begun to introduce policy changes in their disability systems and the OECD has created a "Sickness, Disability and Work" group that publishes evaluations of these policy changes and recommendations about the main challenges for each of the OECD countries in terms of disability policies.

For the case of Spain, the OECD highlights the success obtained in keeping recipiency rates under the $4 \%$, a level which is well below the OECD average of $6 \%$. However, at the same time, the OECD also confirms the failure of employment integration policies for workers with disabilities, which have been unable to significally modify the high unemployment and low employment rates of disability beneficiaries in Spain (despite a small increase in employment rates in recent years as can be observed in Figure 2).

This study addresses three issues in understanding the labour market situation of disabled individuals in Spain and the sources of this situation as well as assessing the effect of two policy initiatives on the labour market prospects and behavior of disabled individuals.

The first part of the study focuses on the inflow into disability benefits for older individuals approaching retirement age. More precisely, it analyzes the determinants of labour market transitions from employment to unemployment, inactivity and disability for individuals aged 45-59 in Spain. The aim of this first part is to determine the extent to which the business cycle, both at the local and national level, affects transitions from employment to disability benefits for individuals approaching retirement age. The second and third parts focus only on the group of individuals in the disability rolls and they try to assess the effect of two policies. The policy analyzed in the second part was introduced in 2004 in order to promote the labour market integration of disabled women and it granted deductions to the social security contributions for employers that hired disabled women. On the other hand, the policy that is the object of study of the third part allows for a $36 \%$ increase in the amount of benefits to partially disabled individuals who are older than 55 years old and for which it is deemed to be difficult to find a 
job. The aim of this third part is to assess the disincentives to work introduced by the increase in the benefits.

Starting from the little that was know from previous publications about the labour market situation of disabled individuals in Spain², this study addresses three specific issues related to the steps specified above:

- The impact of the business cycle at the local and national level on entries into the disability system for older individuals approaching retirement age in Spain.

- The effectiveness of using deductions to the Social Security contributions for employers as a labour market integration policy targeted to a specific part of the disabled population, in this case disabled women.

- The disincentives to work embedded in increases in the levels of benefits given to partially disabled individuals.

Each issue is tackled in an independent chapter which contributes to a specific literature. The following sections explain in further detail the methodology used in the analysis and the contribution of each of the parts to the academic debate.

\subsection{Business Cycle Effects on Labour Force Transitions for Older People in Spain}

During the 1970s and 1980s governments focused on the promotion of early retirement schemes in an attempt to increase employment for younger workers. As a result of this policy, labour force participation rates of older individuals dropped and the authorities realized that there was a need to change this strategy in order to preserve the financial stability of the Social Security systems and to compensate for the graying of the labour force. Consequently, activation policies were introduced as well as limitations to access the early retirement schemes. However, activity rates of older people did not recover as alternative routes were found by these workers to exit the labour market, mainly through the unemployment and disability schemes.

If we take into consideration that in Spain $70 \%$ of individuals receiving disability benefits are older workers, the need to study these alternative routes of leaving the labour force before reaching the retirement age (as a source of covered pre-retirement) becomes of major importance for the planning and designing of activation policies for older individuals.

\footnotetext{
${ }^{2}$ A complete literature review from previous publications is given in each chapter. 
Although exits from employment occur throughout the business cycle, it is a known fact that, in times of economic downturns, more people lose their jobs and one way for firms to adjust to the changing economic environment is through (voluntary or involuntary) restructuration of the older part of the labour force. Therefore, this exogenous variation in business cycle conditions represents a very useful tool for us to analyze the relative use of these alternative routes of leaving the labour force before retirement for the case of older workers. The results of this study will also be important to be incorporated by policy-makers when designing policy changes to the unemployment and disability benefit schemes, as some unforeseen secondary effects of these changes could occur if the connection between these exits routes is not included in the policy analysis.

Therefore, in this chapter we analyze the determinants of observed exits from employment for people aged 45-59 years old in the context of the Spanish labour market in 1981-2006. The main aim of the paper is to identify the effect of the business cycle (BC) at the regional and national level on the timing and the type of exit route out of the labour force.

We proceed in two stages. In the first stage, we study the determinants of exits from employment to non-employment. In the second, we take into account the fact that there are three competing exit routes (unemployment, inactivity and disability) and estimate a competing risk duration model to evaluate the importance of $\mathrm{BC}$ conditions in determining the respective exit probabilities. We make use of the recently released Muestra Continua de Vidas Labourales to estimate discrete time hazard regression models. We match this information with a number of variables constructed with macroeconomic data derived from the Instituto Nacional de Estadística to measure growth and employability performance of different economic sectors and regions in Spain in order to capture the variation in the business cycle between times, sectors and regions. Timevarying covariates are also included in the analysis to model the monetary incentives provided by the system. Finally, we also include some age dummies to capture the effect of a number of special schemes included in the unemployment and disability legislation in order to check whether they have an impact on the timing and the choice of route out of the labour market. 


\subsection{Promoting Employment of Disabled Women in Spain: Evaluating a Policy}

The Social Security system in Spain provides four different types of permanent disability benefits which are granted according to the severity of the disabling condition and the remaining capacity to work that is left for these individuals. Therefore, the system is designed to allow for a certain part of the disabled individuals to work while receiving the disability pension. However, data reveals that the majority of these individuals do not effectively work and employment rates for this group of people have remained very low since 1996. Among the policy initiatives in place that aim to promote the labour market integration of disabled individuals in Spain we can highlight an antidiscrimination law that dates from the 1983, an employment quota of $2 \%$ of the working force covered by individuals with disabilities for firms of more than 50 employees and deductions to the Social Security contributions paid by the employer that hires a disabled worker. Isolating and identifying the effect of antidiscrimination policies on employment of disabled individuals is rather complicated and, on the other hand, it is widely acknowledged that the $2 \%$ employment quota is not enforced in the Spanish market. Therefore, the aim of this research is to evaluate the results of an employment promotion policy introduced in 2004 which increased the deductions to the Social Security contributions paid by the employer that hire a disabled woman.

In order to do that, we first analyze employment rates of disabled individuals in Spain from 1996 until 2007 followed by the estimation of a bivariate probit model to evaluate the existence of shifts in employment trends in the women relative to the men sample conditioning on the existence of preexisting trends. We choose a bivariate probit model to fit our data in order to take into account the crucial role played by the different degrees of disability benefits available in the system and, apart from the dependent variable that captures the labour market situation of the individual, we also include another equation that captures the type of disability pension (partial or total) received by the individual. As the residuals in both equations are not independent, we model them simultaneously and allow for the correlation in the unobserved factors of the two equations. 


\subsection{Employment Effects of Increasing Disability Benefits: A Regression Discontinuity Approach}

The availability and generosity of disability insurance systems has increased in recent decades in most OECD countries but with sustained economic growth in most of these economies, the raise in the financial resources targeted to these programs did not translate into a political problem for a long time ${ }^{3}$. However, this situation will certainly change as a result of the financial crisis of the last three years and the constraints placed on government's budgets due to increases in unemployment insurance schemes and other social assistance programs. Disability systems have, nonetheless, received continuous criticism as they are blamed for introducing disincentives to work for part of the disabled population. A large literature has emerged in countries like the USA and The Netherlands ${ }^{4}$ that tried to quantify these disincentives and there is nowadays a certain degree of agreement about the existence of disincentive effects to work provided by the disability schemes. However, there is still some disagreement on the size of these effects.

For the case of Spain, a report from the OECD published in 2007 clearly defined the improvement of the work incentives for older workers with partial disability as one of the four main recommendations to the Spanish authorities in the area of disability policies (OECD 2007). However, no reform in this direction has been implemented since this recommendation was issued in 2007. Moreover, the disincentives to work embedded in the Spanish disability system have never been properly analyzed in the literature, primarily due to the lack of data availability.

Therefore, the aim of this research is to analyze the employment effects of a law that provides for a $36 \%$ increase in the generosity of disability benefits in Spain for claimants who are, as a result of their lack of skills and of the labour market conditions they face, deemed unlikely to find a job.

The main problem in analyzing the existence of employment effects resides in the fact that disabled individuals with the lowest probability of being employed are also the ones that are more likely to be given the increase in the benefit amount (treatment). Therefore, this selection issue makes it more complicated to obtain unbiased results of the size of the disincentive effects introduced by the policy.

\footnotetext{
3 However, it must be noted that some countries (such as Denmark, Luxemburg or The Netherlands) started implementing reforms to the sickness and disability systems a few years ago in an attempt to reduce the generosity of these systems. For a description and revision of the main changes implemented in OECD countries, refer to OECD, 2009.

4 See, for example, Börsch-Supan, 1998 and Autor and Duggan, 2003. More detailed information on the literature on the topic is given in the literature review of chapter 4 .
} 
Simple models that do not take into account this selection will result in overestimation of the policy effect. On the other hand, models that control and match on observable characteristics of the disabled individuals and the region in which they live will reduce the bias of the estimated coefficients, as part of the selection into the policy depends on these observables features. However, if disabled individuals are also selected into the policy following a number of characteristics that are not observable by the researcher (such as attachment to the labour market or relative degree of disability) these models will still present biased results.

For these reasons, we exploit the discontinuity of the policy implementation at the age of 55 which allows us to use regression discontinuity models to take into account the influence and selection on both observable and unobservable variables. This technique relies on the simple assumption that the distribution of disabled individuals around this eligibility threshold is relatively random in order to get the impact of the increase in the disability benefits on re-employment rates (Marie and Machin forthcoming; Chen and Van Der Klaauw, 2008). We use both traditional regression discontinuity models and we also include some specifications in which we restrict the sample to individuals who joined the disability rolls before turning 55 years old. We introduce these new specifications of the model due to the existence of non-linearities in the covariate age at which individuals enter the disability insurance system.

\subsection{The Database; Muestra Continua de Vidas Laborales}

For the three chapters of this thesis, we make use of the same database for the empirical analysis. It is an administrative dataset called Muestra Continua de Vidas Laborales based on a random draw from the Spanish Social Security records, which contains a sample of $4 \%$ of all affiliated employed and unemployed workers and pensioners for the year 2007. For this group of people, it reproduces the entire work and pensions experience so that the dataset contains information for approximately 1.2 million people and covers their entire labour and pension history.

This sampling exercise has been repeated in 2004, 2005, 2006 and 2007 with the aim of keeping the panel structure of the database so that for each new year, there is an actualization of the information of the individuals included in the wave of the previous year. Therefore, for these individuals, the potential problem of selection bias is reduced and the representativeness of the sample is maintained with new individuals being added each year. However, at the same time, individuals that die or that stop having a job or receiving unemployment or 
pension benefits from the Social Security administration for the whole year, will disappear from the sample 5 .

\subsection{Outline}

In addition to this introductory chapter, this dissertation comprises three more chapters (chapters 2 to 4), a concluding chapter (chapter 5) and a reference list.

In the conclusion we highlight the main findings of each paper and the way in which they provide new information on the labour market situation of disabled individuals in Spain. We also point out the potential policy implications derived from this study and the issues that are left for future work.

\footnotetext{
${ }^{5}$ Some recent studies have focused on the analysis of these attrition cases in order to provide an assessment of the potential importance for the maintenance of the representativeness of the sample (see García-Perez, 2008).
} 

2. Business Cycle Effects on Labour Force Transitions for Older People in Spain 


\subsection{Introduction ${ }^{6}$}

Labour market policies and legislation are evolving over time in response to changing economic and demographic conditions around the world and, for a long time, European governments focused on promoting early retirement for older workers, particularly during the 1970s and 1980s, in order to generate job opportunities and reduce unemployment for younger workers.

However, because of the huge number of older workers taking advantage of the early retirement option and because of the consequent substantial decrease in both the activity and labour force participation rates of the older population, this policy soon proved to have a number of problematic and unforeseen effects. At the same time, society was ageing due to increased life expectancy and reduced fertility rates, and this only exacerbated the problem (Fischer et al. 2006).

As a result of these two parallel developments, there was an increase in the financial pressure of the social security system and on taxes of the working population in relation to the non-working one.

As the ageing of society is being regarded as one of the most important social and economic challenges for Europe in recent times, these developments have prompted a shift in policy focus towards ways of delaying retirement and of keeping older workers economically active in the labour market. To achieve this goal, governments introduced several policies such as incentives for the firms that hire older workers or limitations in the accession rules to these early retirement schemes. However, these efforts have not translated into increases in activity rates of older workers because many of these workers are able to find alternative programs to leave the labour market, such as the disability or unemployment schemes, before reaching the retirement or early retirement age. Therefore, these other possibilities of leaving employment should be studied and understood so that they can be integrated in the analysis when designing policies to keep older workers active in the labour market.

The literature analyzing labour market transitions usually identifies a collection of factors as potential determinants of these transitions, ranging from individual-specific determinants, employer, firm and industry characteristics or business cycle conditions to incentives embedded in the Social Security institutions (See for example Garcia-Perez et al.2007, 2008, Blanco 2000). It is important to understand the incentives to withdraw from the labour force provided by each of these factors in order to devise effective labour market policy reforms.

\footnotetext{
${ }^{6}$ This chapter is based on: Jimenez-Martin, S. \& J. Vall-Castello (2009). Business cycle effects on labour force transitions for older people in Spain. FEDEA Working Paper 2009-25, Madrid, Spain.
} 
Therefore, our aim in this paper is to identify the different incidence of each of these factors on labour force exit behaviour among Spanish workers aged 45-59 distinguishing between exits to unemployment, disability benefits or inactivity. We will pay special attention to the role of the business cycle on the inflow into disability benefits, the monetary incentives provided by the system and the relative power of age-based legislation schemes in inducing transitions between these labour force states.

The current study contributes to the body of literature that focuses on labour market transitions through the analysis of transitions from employment to unemployment, disability benefits and inactivity of Spanish workers aged 45-59 and incorporating as regressors a rich set of variables describing the firm and sector in which the individual is employed, business cycle indicators both at the sector and regional level and age-specific dummies in order to capture the incentives provided by some special schemes included in the Social Security legislation. The analysis is conducted separately for men and women due to the different evolution of the main labour market variables, such as participation rates, between the two genders.

Our results show the strategic use of disability benefits by older workers approaching retirement as an alternative means of leaving the labour market when the economic situation of the country deteriorates and economic growth slows down.

The chapter proceeds as follows: Section 2 revises the literature on the topic while section 3 describes and analyzes the evolution of the main labour market and economic indicators in Spain during the last 30 years paying special attention to the group of workers with ages comprised between 45-59 years old. Section 4 describes the Spanish legislation on unemployment and disability benefits focusing on those schemes specifically applicable to older people. Section 5 presents the two econometric models that are used for the analysis, which are the single exit logistic hazard model and the competing risk model. Section 6 explains the database used for the analysis, the sample selection criteria and the variables included. In part 7, we present the results of both the non-parametric analysis, in terms of empirical hazard rate graphs, and the parametric analysis. Finally, some concluding remarks are included in the last section of the chapter.

\subsection{Literature}

The issue of the effect of the business cycle on labour force participation behaviour has not received much attention in the Spanish literature mainly because of the difficulty of combining macroeconomic and microeconomic data in a coherent way. However, workers' participation decisions during expansionary 
or recessionary periods are crucial for understanding how labour markets adjust to macroeconomic fluctuations (Darby et al, 1998). At the same time, the economic environment also affects the performance of the firms operating in the labour market which make their decisions on labour demand needs partly based on the economic conditions of the country. Furthermore, the effect of the business cycle on firm performance is usually heterogeneous among economic sectors and regional units of a single country. In this paper, we try to capture these differences with a number of variables that describe labour market conditions and economic and industrial growth at the sector and regional level.

Most of the literature that analyzes the effect of the business cycle on labour market participation rates approaches the topic from a macroeconomic point of view. These studies usually choose the unemployment rate as a proxy for the business cycle and they evaluate its effects on participation rates in a panel data setting using a pool of different countries. Their findings usually suggest that participation rates are lower during recessionary times. However, macroeconomic time-series data are not enough to identify the causal effect behind an individual's behaviour, as information on workers' characteristics and choices is not available. At the same time, the problem with microeconomic surveys is that they are not long enough so as to capture the effect of the business cycle. Therefore, studies using this kind of microeconomic survey data usually include one additional regressor (calendar time) to control for the business cycle ${ }^{7}$ (Van den Berg et al, 2000). In this chapter, our data (administrative records) allows us to reconstruct the entire working history of the individuals, which we combine with a number of business cycle indicators constructed with macroeconomic data. This process results in a better identification of the causal effects of the economic conditions on individual's behaviour.

The effects of labour market institutions on labour market transitions at advanced ages have been widely studied in the literature (see Gruber and Wise, 1999, for a cross-country comparison). In the case of Spain, Boldrin et al. (1999, 2004) show the strong incentives to retire early provided by the Spanish Social Security legislation for individuals with below average working histories and/or low wages. This finding explains the strong increase in the number of early retirees in Spain during the 1990s. Two more papers by Kugler et al. (2003) and GarciaPerez et al. (2007) focus on the impact of a reform in 1997 of the labour market legislation on transitions into a permanent contract. In the spirit of Boldrin et al. (2004), Argimon et al. (2007) find that the Social Security Wealth variable has a positive impact on retirement decisions using a reduced-form duration model and Cairo (2007) employs a competing risk model to study transitions to early and

\footnotetext{
7 With microeconomic data, it is usually assumed that the duration of employment is independent of business cycle conditions when the number of periods analyzed is relatively small.
} 
partial retirement for men between 60 and 70 years old in 2005. She includes two variables, Social Security Wealth and Social Security Accrual, to model monetary incentives and finds evidence that Social Security incentives do affect retirement decisions.

The effects of the Spanish unemployment legislation on re-employment probabilities and on the duration of the spell of unemployment have been studied by Bover at al. (2002) and Jenkins et al. (2004). The paper by Bover et al. analyzes the effects of both unemployment benefits and the business cycle on unemployment durations for the period 1987-1994 using the Spanish Labour Force Survey (EPA) for men aged 20 to 64 . Their conclusions suggest that the hazard rate of leaving unemployment is higher with favourable business cycle conditions and lower for individuals receiving unemployment benefits (as opposed to unemployed individuals who are not entitled to benefits). The paper by Jenkins et al. (2004) focuses on the effects of the unemployment benefit level on the reemployment probabilities of Spanish men aged 20 to 59 between 1987 and 1991 and finds that benefits do affect unemployment durations but that the level of these benefits has only a small disincentive effect on re-employment probabilities. Business cycle conditions are also found to have an impact on re-employment rates of unemployed workers.

On the other hand, Garcia-Perez and Sanchez-Martin (2007) restrict their analysis to older people and their paper explores the monetary incentives embedded in the Social Security institutions to stay unemployed. They use Spanish data to estimate the parameters of a theoretical model of job search behaviour and conclude that both labour market conditions and institutional incentives play a very important role in explaining the search behaviour of unemployed individuals between 55-65 years old in Spain. For people in this age range, remaining unemployed is found to be the best strategy given the level of unemployment benefits and the penalties associated with the early retirement option.

Another strand of the literature has focused on the alternative of leaving employment and claiming a disability pension. The paper by Jimenez-Martin et al. (2006) investigates the effects of permanent disability benefits on labour market behaviour of people aged 45-59 in Spain. The results seem to prove that the disability option has been used as a form of exit from the labour market for individuals substantially close to the early retirement age who do not fulfil the requirements to access this route, as some of these individuals are found to receive disability benefits without deserving them.

Blanco (2000) estimates a competing risk duration model to study the decision of individuals between 50 and 64 years of age to leave the labour force and either take early retirement benefits or claim disability benefits. In her paper, Blanco does not include a variable to measure the monetary incentives of the Social 
Security System but she incorporates a number of labour demand variables describing the firm and sector in which the individual is employed. Her findings suggest that both the decision to retire and the decision to claim disability benefits are very much affected by the type of job and the level of income of the last job. In that sense, she finds that individuals with higher levels of income in the last job try to delay both the date of retirement and entries into the disability system as they try to remain active in the labour market. On the other hand, workers in the manufacturing and public sector have higher hazard rates to early retirement while self-employed and public sector workers exhibit higher hazard rates into disability benefits.

\subsection{Determinants of labour force transitions for workers aged 45-59 in Spain}

Figure 3 and Figure 4 show Spanish labour force participation rates and unemployment rates for men and women aged 45-59 from 1987 to 2007. Figure 3 shows dramatic falls in the labour force participation rate for men during the late eighties and mid nineties following, to some extent, the business cycle and resulting in strong increases in the unemployment rate for this group of workers during this period. Since 1995 labour participation rates have recovered somewhat ${ }^{8}$ but participation has not been as high as it was in the late 1980's, while unemployment rates have been steadily decreasing since the mid nineties. In 2001, and for the first time since the 1980's, a decrease in participation rates is not followed by an increase in the unemployment rate (although, as can be seen in Figure 5, there is an increase in the number of disability benefits granted to individuals aged 45-59 from 2001). Figure 4 shows a very different trend for women in the age bracket 45-59: in a comparable period of time the labour force participation rate for women has increased steadily whereas the unemployment rate has followed a similar pattern than the unemployment rate for men aged 4559. This increase in the participation rate can be explained by the generational change that resulted in a replacement of low educated older women by more educated younger women in the same age bracket ${ }^{9}$.

\footnotetext{
8 The jump in 2002 is due to a methodological change in the Spanish labour force survey.

9 This is the explanation that seems to prevail in the literature for the case of Spain. However, some studies conducted in other European countries have found that cohort effects are also very relevant in explaining the rise in women's participation rates as younger cohorts of women tend to have more liberal social norms with respect to paid employment and to face more favorable child care facilities (see Vendrik and Cörvers, 2009; Balleer et al. 2009 and Euwals et al. 2007).
} 
Figure 3 Unemployment and labour force participation for men aged 45-59 in Spain, from 1987$2007^{10}$.

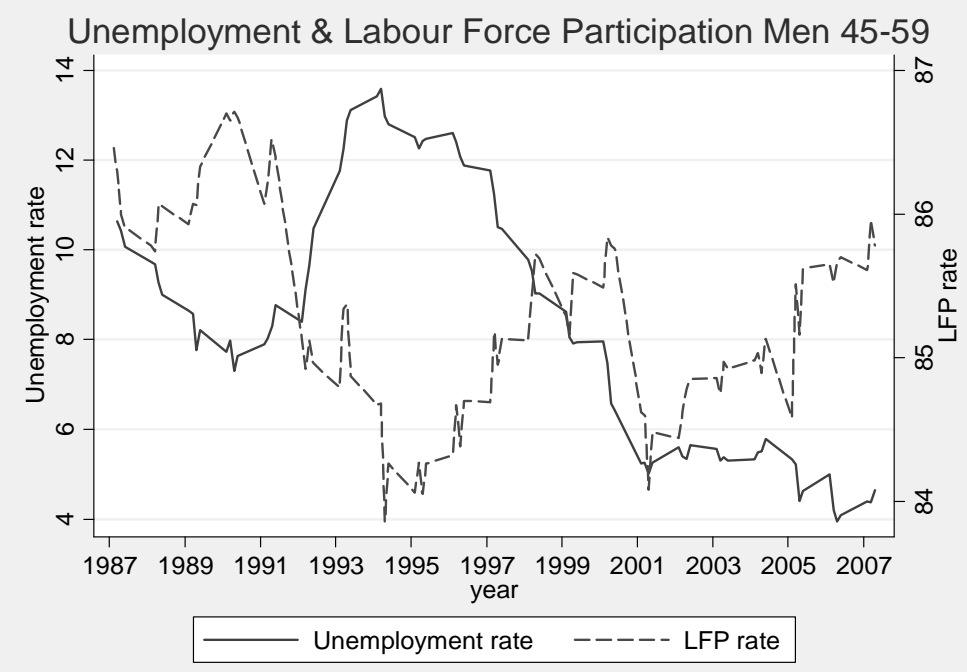

Figure 4 Unemployment and labour force participation for women aged 45-59 in Spain, from 1987$2007^{11}$.

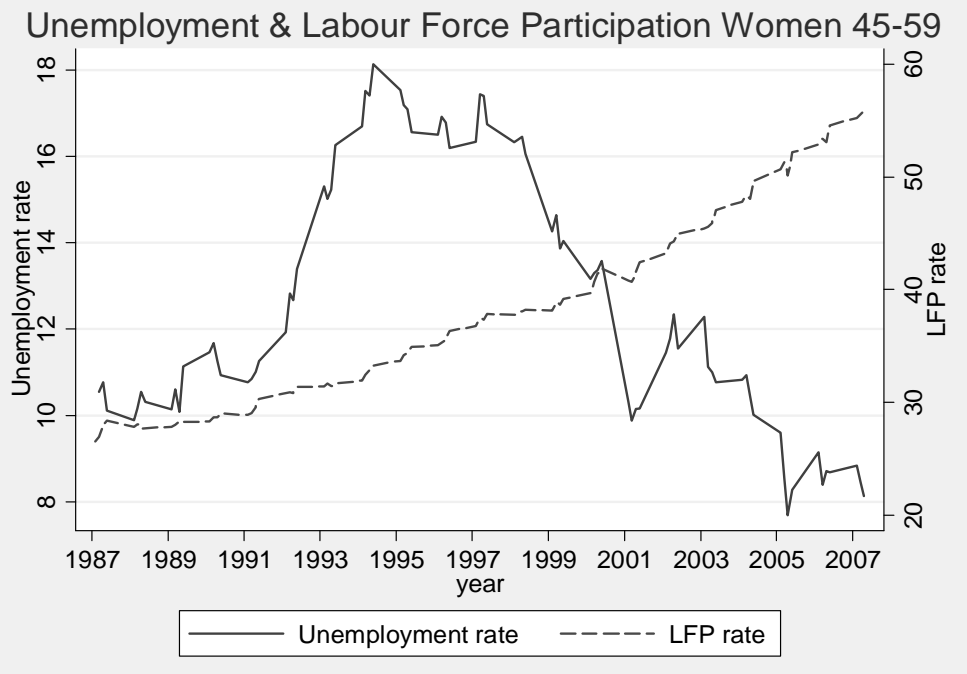

Source: Spanish National Institute of Statistics: "Encuesta Poblacion Activa" (EPA).

${ }^{10}$ This is 3-month interval data.

${ }^{11}$ Although the scale of the graph of labour force participation rate for women is greater than that for men, the evolution is much less erratic than it is for men. Even if we decrease the scale of the graph of women, there is no different pattern observed during the crisis years (as it is the case for men). 
Figure 5 and Figure 6 show the way in which both the unemployment rate and the inflow into disability benefits react to business cycle conditions. In Figure 5 , we can see that both the unemployment rate and the number of new disability benefits granted to workers aged 45-59 strongly increased during the first half of the nineties when the GDP growth dropped to negative numbers for the first time since the 1980's. However, since 2000 these two variables have showed an opposite evolution with the unemployment rate remaining reasonable constant between $6 \%$ and $8 \%$ and the number of new disability benefits granted to this group of workers increasing steadily until 2007.

Figure 5 Unemployment rate and new disability benefits granted each year to individuals aged 45-59 in Spain, from 1980-2008.

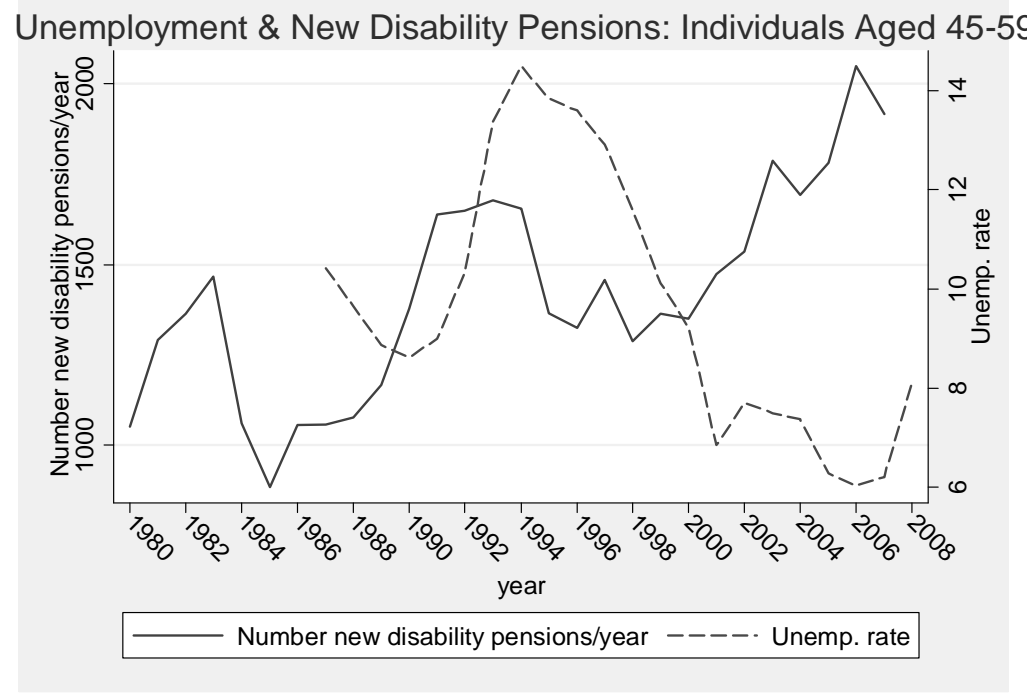

Source: Unemployment rate of individuals aged 45-59: Spanish National Institute of Statistics (EPA), Number disability benefits granted each year to individuals aged 4559: Own calculations from MCVL.

Figure 6 reflects the relation between the number of benefits granted to workers aged 45-59 and the business cycle. It can be observed that there is a quite surprising perfect negative relation between these two variables so that whenever the GDP increases, the number of disability benefits for this group of workers decreases and vice versa. 
Figure 6 GDP growth and new disability benefits granted each year to individuals aged 45-59 in Spain, from 1980-2008.

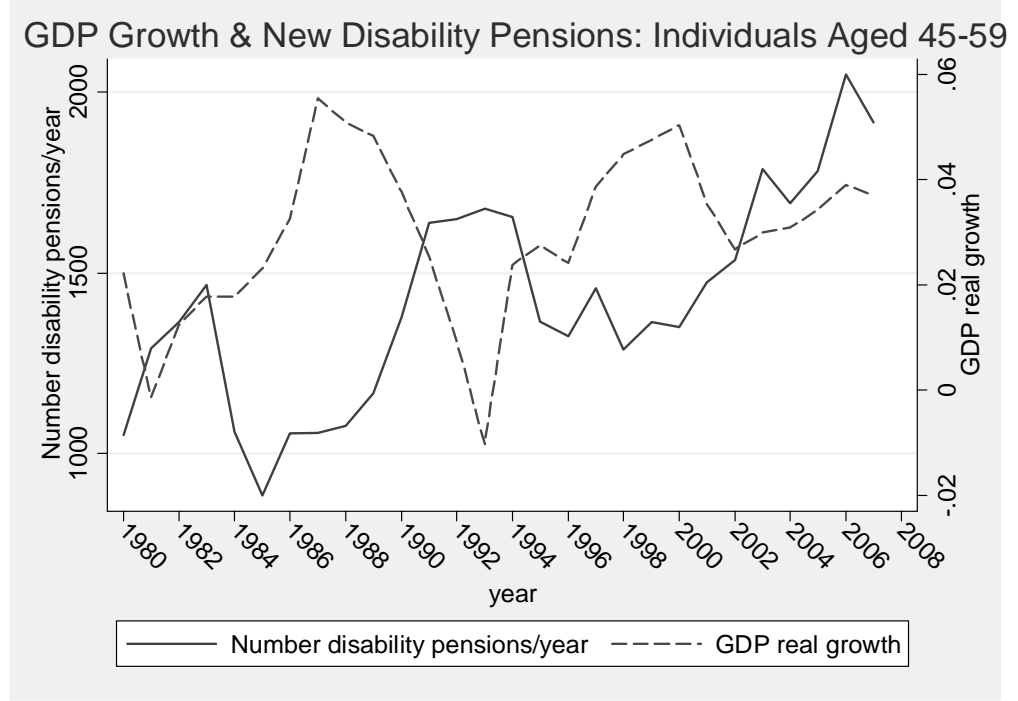

Source: GDP growth: Spanish National Institute of Statistics, Number of disability benefits granted each year to individuals aged 45-59: Own calculations from MCVL.

Therefore, it seems clear that, at the aggregate level, changes in the number of disability benefits granted to this group of pre-retirement workers and changes in their unemployment rate seem to respond to adjustments in the speed of economic growth. This relationship is also maintained if we broaden the analysis to include all working age individuals, as can be seen in Figure 7 and Figure 8 that plot both the GDP growth and the unemployment rate with the rate of new disability benefits to employment for all Spanish workers between 1977 and 2008. 
Figure 7 GDP growth and rate of new disability benefits to employment (individuals of all ages) in Spain, from 1978-2006.

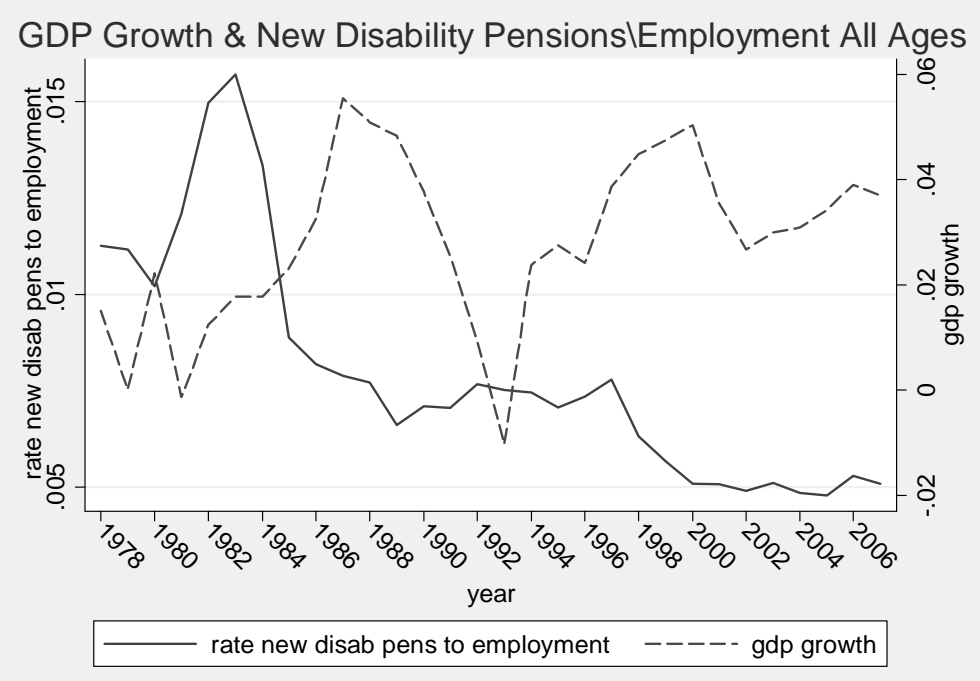

Figure 8 Unemployment rate and rate of new disability benefits to employment (individuals of all ages) in Spain, from 1987-2006.

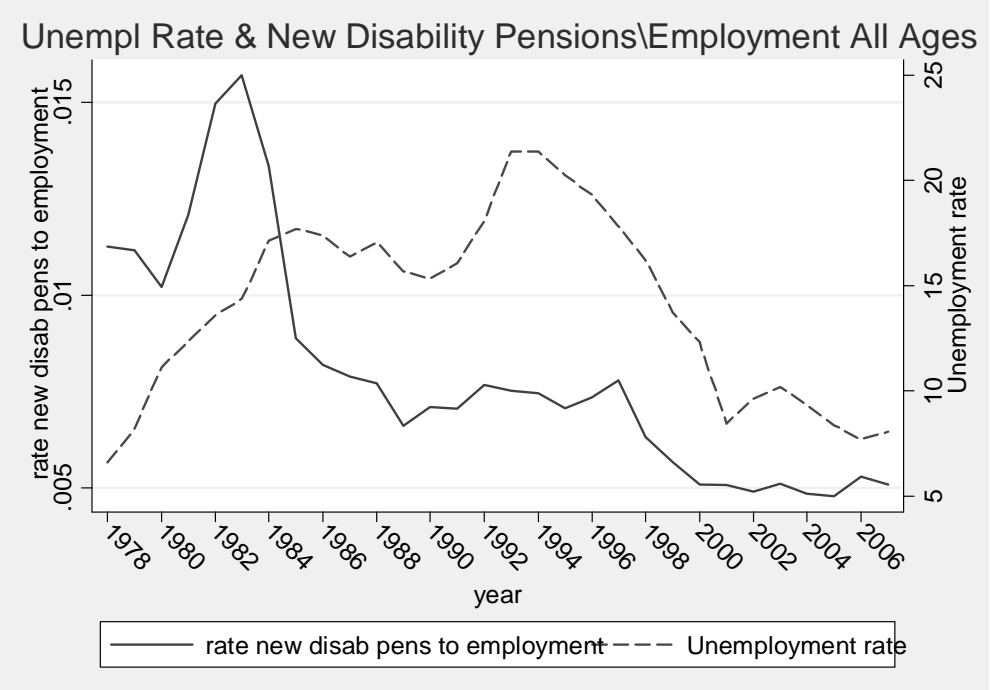

Source: Spanish National Institute of Statistics (EPA).

Finally, if we take this aggregate data from 1977 until 2008 and perform a simple regression of the rate of new disability benefits to employment including as explanatory variables the GDP growth and yearly dummies, the results show a negative and significant relation between the GDP growth and the rate of new disability benefits to employment that remains significant when we include other 
explanatory variables such as the unemployment rate and the GDP per capita (see Table 2) ${ }^{12}$.

Consequently, this seems to suggest that workers may be strongly affected by business cycle conditions and that their decisions on labour market transitions (particularly from employment to unemployment and disability) may be affected by the level of economic growth ${ }^{13}$.

Table 2 Regression results: Dependent Variable: rate of new disability benefits to employment

\begin{tabular}{|c|c|c|c|c|}
\hline & Model1 & Model2 & Model3 & Model4 \\
\hline GDP Growth & $\begin{array}{r}-0.03960 \\
(-1.98)\end{array}$ & & & $\begin{array}{r}-0.03467 \\
(-1.94)\end{array}$ \\
\hline Year & $\begin{array}{r}-0.00026 \\
(-7.34)\end{array}$ & $\begin{array}{r}-0.00010 \\
(-0.50)\end{array}$ & $\begin{array}{r}-0.00029 \\
(-8.51)\end{array}$ & $\begin{array}{r}0.00071 \\
(2.23)\end{array}$ \\
\hline GDP capita & & $\begin{array}{l}-0.00052 \\
(-1.02)\end{array}$ & & $\begin{array}{l}-0.00267 \\
(-3.05)\end{array}$ \\
\hline Unemp. rate & & & $\begin{array}{r}-0.00002 \\
(-0.37)\end{array}$ & $\begin{array}{r}-0.00033 \\
(-2.91)\end{array}$ \\
\hline Cons & $\begin{array}{l}0.51967 \\
(7.49)\end{array}$ & $\begin{array}{l}0.20599 \\
(0.56)\end{array}$ & $\begin{array}{l}0.57980 \\
(8.62)\end{array}$ & $\begin{array}{l}-1.36081 \\
(-2.20)\end{array}$ \\
\hline $\mathrm{N}$ & 31 & 31 & 31 & 31 \\
\hline$r 2$ & 0.75423 & 0.72991 & 0.72119 & 0.82034 \\
\hline F & 42.96417 & 37.83363 & 36.21391 & 29.67977 \\
\hline
\end{tabular}

\footnotetext{
12 Please note that, in this case and unlike in the regressions, the unemployment rate used is at the national level and it is only included to introduce more controls on the regression, as the variable of interest is the GDP growth. In the coming sections, we introduce in the regressions the unemployment rate of the region in order to capture the effect of local labour market conditions on transitions out of employment.

13 These decisions on labour market transitions might be taken jointly by the employee and the employer or might be unilateral by one of the sides.
} 


\subsection{The Spanish Social Security rules for older people: unemployment and disability}

According to the current unemployment rules, there are two kinds of unemployment benefits, an unemployment insurance system (UI) for those workers that contributed while employed but that have been fired from the previous job ${ }^{14}$, and unemployment assistance (UA) for individuals who do not qualify for the unemployment insurance benefits. Individuals entering the UI scheme are entitled to receive $70 \%$ of the wages of the last job during the first six months and $60 \%$ after that. These quantities are subject to a minimum and a maximum amount. The minimum corresponds to $75 \%$ of the minimum wage and the maximum is not fixed and is proportional to the number of dependents in the household. These benefits are paid for a period of one-third of the accumulated job tenure and are only paid for a maximum period of two years ${ }^{15}$. The UA benefits are only paid to individuals with dependents and with an average family income below $75 \%$ of the minimum wage. There is a fixed amount paid which corresponds to $75 \%$ of the minimum wage. This benefit is only paid for a maximum period of two years ${ }^{16}$ (Bover et al., 2002).

There is, however, an exception to this rule for people aged 52 and more. They can receive $75 \%$ of the minimum wage until they reach the official retirement age and the years spent under this scheme are counted as contributive years towards an old-age pension (as the public employment agency, INEM, pays the contributions of the unemployed $)^{17}$.

There are also two schemes of disability benefits, depending on whether the disability is temporary or permanent. If the disability is temporary and the risk covered is "common illness", a period of 180 days of contribution to the system during the last 5 years is required and benefits are granted for a maximum period of 18 months. After that, the individual has to either return to work or enter the scheme of permanent disability ${ }^{18}$. No minimum contribution is required for disabilities resulting from "work-related accidents".

\footnotetext{
${ }^{14}$ They must have held the job for at least one year.

${ }^{15}$ After these two years of contributory unemployment benefits, unemployed individuals who are still not working can have access to social assistance benefits.

16 There is also a special scheme in Andalucía and Extremadura for agricultural workers who have been employed for 40 days during the year. They are entitled to receive $75 \%$ of the minimum wage for 90 to 300 days each year. The number of days depends on their age and number of dependents.

17 This rule was introduced in 1989.

${ }^{18}$ Provided on passing a medical examination that determines the "permanent disability" condition. 
For permanent disability situations, three levels of disability are identified which depend on the severity of the injury/illness and which involve different eligibility requirements and pension amounts. Included in the first level (inability to perform the usual job), there is a special provision for which workers with few qualifications from disadvantaged socio-economic circumstances who are older than 55 years ${ }^{19}$ are eligible to receive a higher amount of disability benefits $(75 \%$ of the regulatory base as opposed to $55 \%$, which is the regular amount paid by this type of disability benefits).

Between 5 and 15 years of contribution are required when the source of the disability is an ordinary illness and the benefit base is calculated in a similar way as old-age benefits ${ }^{20}$. No contributive requirement is needed if the disability is caused by a work related or unrelated accident or by a professional illness. In the case of a work-related accident or professional illness, the benefit base corresponds to the average wage in the last year of work and for a work-unrelated accident the benefit is calculated as the average annual wage for a 24 month-period that the individual can choose from the last seven years of work. All three schemes are automatically converted to old-age benefits when the individual turns 65 (JimenezMartin et al., 2006).

\subsection{Modelling framework: The hazard regression model}

The analysis is divided into two stages. In the first one, we estimate a single exit logistic hazard model to study transitions from employment to nonemployment with a particular focus on the duration of employment spells. In the second part of the paper, a competing risk model is estimated in order to distinguish between the various routes out of employment: disability benefits, unemployment or inactivity. The idea of fitting these two different models is to first analyze the overall impact of $\mathrm{BC}$ conditions on exits from employment before going into more detail about the effect of the $\mathrm{BC}$ for each of the different available routes of doing these transitions.

\subsubsection{Single exit logistic hazard model}

We apply the logistic model to analyze single exit transitions from employment to non-employment for Spanish workers aged 45-59. We have chosen this discrete time model because our data is recorded in monthly intervals and, as we are dealing with employment contracts, exits are usually observed at the

\footnotetext{
19 The argument behind this special arrangement is the fact that this group of workers is considered to be in a particularly difficult position for finding a new job.

${ }^{20}$ The way in which the regulatory base is calculated is explained in detail in chapter 4 .
} 
beginning, the middle or the end of the interval. Therefore, the logistic model seemed more appropriate than the complementary log-log model (which is the discrete time representation of a continuous time hazard model). However, a number of tests conducted with the cloglog model provide very similar results to our logistic results so that, for our analysis, both models could be used.

The logistic hazard model estimates the probability that an individual will leave employment at time $t$ given the fact that he has been employed for, at least, $t$ periods (where $t$ is the discrete time duration variable).

We observe a person's spell until the end of the $t$ month, at which point we observe that the spell is either complete or right censored. Therefore, for each individual in our sample, the probability of a spell being completed at time $t$ given that it has continued, at least, until time $t$ takes the form of:

$$
\begin{aligned}
& h_{i}\left(t, x_{i}(t), z_{i}(t)\right)=\operatorname{Pr}\left(T_{i}=t \mid T_{i} \geq t, x_{i}(t), z_{i}(t)\right)= \\
& F\left[\alpha_{0}+\alpha_{1}(t) x_{i}(t)+\alpha_{2}(t) z_{i}(t)+\theta_{i}(t)\right]
\end{aligned}
$$

(Equation 1)

Where,

$h_{i}\left(t, x_{i}(t), z_{i}(t)\right)$ is the discrete time hazard rate for month $\mathrm{t}$ conditional on a vector of exogenous variables; $x_{i}(t)$ describing personal characteristics of the individual such as age or education level and $z_{i}(t)$ which include the variables that describe the economic situation of the sector and the region in which the individual works. $\theta_{i}(t)$ are the variables that represent duration dependence and depend on the number of months spent in employment. For the purposes of this paper, we characterize duration dependence as a cubic polynomial function of time:

$$
\theta_{1} t+\theta_{2} t^{2}+\theta_{3} t^{3}
$$

(Equation 2)

Where $\theta_{1}, \theta_{2}$ and $\theta_{3}$ are the shape parameters, which are estimated together with the slope parameters and the constant.

Therefore, the likelihood contribution of a censored spell is given by:

$$
\mathrm{L}_{\mathrm{i}}=\operatorname{Pr}\left(T_{i}>t\right)=\prod_{k=1}^{t}\left(1-h_{i k}\right)
$$

(Equation 3) 
Whereas the contribution to the likelihood function of a complete spell is:

$$
\mathrm{L}_{\mathrm{i}}=\operatorname{Pr}\left(T_{i}=t\right)=\frac{h_{i t}}{1-h_{i t}} \prod_{k=1}^{t}\left(1-h_{i k}\right)
$$

(Equation 4)

And the log-likelihood function for the sample as a whole is represented by:

$$
\log \mathrm{L}=\sum_{i=1}^{n} c_{i} \log \left(\frac{h_{i t}}{1-h_{i t}}\right)+\sum_{i=1}^{n} \sum_{k=1}^{t} \log \left(1-h_{i k}\right)
$$

(Equation 5)

Where $\mathrm{Ci}_{\mathrm{i}}$ is the censoring indicator:

$$
c_{i}\left\{\begin{array}{l}
1 \text { if spell is complete } \\
0 \text { if spell is right censored }
\end{array}\right.
$$

If we define $Y_{t i}$ as a $(0,1)$ variable that is 1 when the observed duration equals $t$ :

$$
Y_{t i}=1\left(T_{i}=t\right)
$$

\section{(Equation 6)}

Then, the log-likelihood function of the sample for $Y_{\text {ti }}$ takes the same form as the likelihood function of a standard binary dependent variable model (Jenkins, 1995):

$$
\begin{aligned}
& \log \mathrm{L}=\sum_{i=1}^{n} \sum_{k=1}^{t} y_{i k} \log \left(\frac{h_{i k}}{1-h_{i k}}\right)+\sum_{i=1}^{n} \sum_{k=1}^{t} \log \left(1-h_{i k}\right) \\
& =\sum_{i=1}^{n} \sum_{k=1}^{t}\left[y_{i k} \log h_{i k}+\left(1-y_{i k}\right) \log \left(1-h_{i k}\right)\right]
\end{aligned}
$$

\section{(Equation 7)}

Thus, the model is estimated by Maximum Likelihood where the hazard rate $h_{i}(t)$ corresponds to a logit probability; estimation is the same as estimating a sequence of logit models defined on the surviving population at each duration, where the dependent variable equals 1 whenever an exit from employment is observed and 0 otherwise.

\subsubsection{Competing risk model}

We further consider the possibility of exit from employment to one of the three following destination states: unemployment; disability benefits and 
inactivity. With the assumption of independence of the destination-specific hazard rates $^{21}$, the discrete hazard rate for exit at time $t$ to any of the three destinations is simply the sum of the destination-specific discrete hazard rates, $h_{u}(t), h_{i}(t)$ and $h_{d}(t)$ :

$$
h(t)=h_{u}(t)+h_{i}(t)+h_{d}(t)
$$

(Equation 8)

where

$h_{u}(t)$ is the hazard rate of experiencing a transition from employment to unemployment

$h_{i}(t)$ is the hazard rate of a transition to inactivity and,

$h_{d}(t)$ is the hazard rate to disability benefits.

The discrete time hazard into one of the $m$ states is equal to the probability of making a transition in interval $t$, conditional upon surviving up to the beginning of the interval.

We assume a specific form for the conditional destination-specific hazard rate $h_{i t}^{m}$ for individual $i$ to destination $m$ in interval $t$ such that ${ }^{22}$ :

$$
\mathrm{h}_{\mathrm{it}}^{\mathrm{m}}=\frac{\exp \left(\beta_{0}^{m}+\beta_{1}^{m} X_{i t}+\beta_{2}^{m} Z_{i t}+\theta_{t}^{m}\right)}{1+\sum_{m=1}^{3} \exp \left(\beta_{0}^{m}+\beta_{1}^{m} X_{i t}+\beta_{2}^{m} Z_{i t}+\theta_{t}^{m}\right)}
$$

(Equation 9)

Where, as before, $X_{i t}$ is a vector of personal characteristics, $Z_{\text {it }}$ include the variables that describe the economic situation of the sector and the region in which the individual works and $\theta_{t}^{n}$ is the baseline hazard function which is modelled as a cubic polynomial.

\footnotetext{
${ }^{21}$ The assumption of independence may be questionable in the context of our analysis but it is still reasonable.

${ }^{22}$ We assume that the conditional destination-specific hazard rate is independent from the other competing risks and can be derived from a latent variable model in which the error term has a standard logistic distribution 
For the given hazard rate described above, the individual worker's likelihood contribution has the same form as the likelihood of a standard multinomial logit model (Allison, 1982).

$$
L_{i}=\left[\prod_{m=1}^{3} h_{i t}^{m}\right]^{c_{t i}^{m}}\left[h_{i t}^{0}\right]^{1-\sum_{m=1}^{3} c_{i i}^{m}}\left[\prod_{\tau=1}^{t-1} h_{i \tau}^{0}\right]
$$

(Equation 10)

where $c_{i t}^{m}$ is a destination-specific censoring indicator which equals 1 if worker $\mathrm{i}$ exits to state $\mathrm{m}$ in interval $\mathrm{t}$, and $h_{i t}^{0}$ is the conditional probability of making no transition (reference category).

$$
h_{i t}^{0}=\frac{1}{1+\sum_{m=1}^{3} \exp \left(\beta_{0}^{m}+\beta_{1}^{m} X_{i t}+\theta_{t}^{m}\right)}
$$

(Equation 11)

$$
c_{i t}^{m}=\left\{\begin{array}{l}
1 \text { if } c_{i t}=m \\
0 \text { if } c_{i t}=0
\end{array} \Rightarrow c^{m}\right.
$$

(Equation 12)

\subsection{Data}

The study will use the Continuous Sample of Working Lives (Muestra Continua de Vidas Laborales, MCVL) which is a microeconomic data set based on administrative records compiled from three sources; the Spanish Social Security Administration, the Tax Office and the National Census. There have been four waves until now, 2004, 2005, 2006, and 2007 and it is envisaged that the information will be updated annually. We have used the 2007 wave. It contains a random sample of $4 \%$ of all the individuals who, at some point during 2007 , had contributed towards the social security system (either by working or being in an unemployment scheme) or had received a contributory pension. The random sample selected contains over one million people.

There is information available on the entire employment history of the workers, including the exact duration of employment, unemployment and pension spells, and for each spell, the firm's sector and region of activity, the type of contract held, the wages measured as contribution bases, the level of pension and 
unemployment benefits, among others. There is also some information on personal characteristics such as age, gender, nationality and level of education.

The macroeconomic variables used to capture the economic business cycle are constructed with information derived from the Spanish Instituto Nacional de Estadistica.

We measure growth and employability performance of different economic sectors and regions in Spain to capture the variation in the business cycle between times, sectors and regions.

\subsubsection{Sample selection criteria and variables}

We select employment spells of individuals in the sample between 45 and $59^{23}$ years old and we follow them until their first exit from employment or until they are censored (last month of age 59 or 2006), whichever occurs earlier. We don't consider spells of individuals who are unemployed, inactive or receiving disability benefits, as our focus is on transitions out of employment. The analysis is conducted separately for women and men.

There is a maximum of 180 periods of time (15 years* 12 months) for each individual and the sample selected contains 26.556 women, of which 9.451 leave the labour market (5.163 to unemployment, 653 to disability, 3.635 to inactivity) and 58.684 men, of which 24.883 leave the labour market (14.549 to unemployment, 1.814 to disability, 8.520 to inactivity). We also used a variant of this sample in which we applied the same sample selection criteria laid out above with the extra requirement that the individuals selected need to have been continuously working for the two years prior to entering the sample. With this restriction we exclude from our sample individuals with short temporary contracts (which can be signed for one to three years) and with a more unstable job situation who probably have a different labour market behaviour than workers with longer term contracts. At the same time, we want to test whether these workers are affected in a different way by the business cycle.

\footnotetext{
${ }^{23}$ We don't include individuals aged 60 because, at that age, they can already access some early retirement schemes and this would constitute another possible exit route which is not the focus of our paper. 


\subsubsection{Explanatory Variables}

First, we have included three variables that capture duration dependence. The baseline hazard is modelled as a cubic polynomial function of duration. The level of education obtained is incorporated with three dummies: The first one captures individuals who cannot read or write or who dropped out of education before finishing high school. The second one includes individuals holding a high school diploma (or equivalent) whereas the third one is for people with a bachelor's degree and other higher education. Regional and cohort dummies are also included as regressors as well as dummies for ages 52,55 and 58 to capture the effect of the special unemployment and disability schemes available at these ages on transitions out of employment. The dummy variable at age 58 is introduced in order to capture the effect of individuals who have contributed for enough years to receive two years of unemployment benefits at the age of 58 before joining the early retirement scheme when they turn 60 . The dummy at age 52 is introduced to capture the special scheme in unemployment benefits whereas the dummy at age 55 captures the increase from $55 \%$ to $75 \%$ in disability benefits available at this age. Both of these schemes are explained in detail in section 2.4 above.

There are six dummy variables that represent the economic activity of the firm in which the individual is working, one for each sector of activity (primary, secondary and tertiary sectors, public administration, education and social services). There is also a variable that describes the number of workers in the firm and three dummy variables that account for partial/full time employment, temporary(short-term)/permanent contract of employment and voluntary/involuntary termination of the contract ${ }^{24}$. Two more variables describe the employment history of the worker. The first one captures the number of years that the individual worked from age 15 until the last month of age 44 . The second one represents the tenure of the worker and is calculated as the number of years spent working in the employment spell with which the individual enters the sample.

\section{Monetary variables:}

The variable that we include in order to capture the monetary incentives of the worker is the contributions to the social security administration, which is a double censored (from below and above) version of the wages (see Boldrin et al., 2004 , for a procedure to recover wages from contributions). We have information

\footnotetext{
${ }^{24}$ Partial Contract: A dummy variable which is 1 if the contract of employment is a part-time contract. Temporary Contract: Is a dummy variable constructed from a variable describing the type of contract and equals 0 if the contract is temporary or short-term and 1 if the contract is permanent.
} 
about this variable for each month that the individual is contributing to the Social Security Administration.

Macroeconomic variables:

In order to capture the macroeconomic conditions at each point in time, we use three macroeconomic variables derived from the Spanish National Institute of Statistics. The first variable represents the unemployment rate of each of the 18 autonomous communities in Spain and we assign this value to each individual according to the autonomous community in which they work. Depending on the economic sector in which the individual is reported to work, we also assign them the value of two variables that capture both the unemployment rate and the average number of hours worked in each of the 17 economic sectors in which the National Institute of Statistics divides the Spanish economy. These macroeconomic variables vary over time. We also include an interaction term of these variables with the logarithm of duration. Finally, we include the GDP growth at the national level in order to capture national business cycle trends that are not captured by the regional or sector variables ${ }^{25}$.

\subsection{Results}

\subsubsection{Non-parametric analysis}

If we take a look at the empirical hazard rates derived from our sample, we can already see the strong impact on the hazard rate of some of the explanatory variables included in the analysis. The empirical hazard for a given number of months is calculated as the total number of exits from employment in each month divided by the population in employment at the beginning of that month. This summarizes the sample probability of leaving employment at each particular point in time. However, for simplicity purposes, we present this information compiled by age instead of months.

Figure 9 and Figure 10, show the interval hazard rates for men and women respectively. Both figures show three peaks of the hazard rate at ages 52, 55 and 58, which could be attributable to the special schemes on the unemployment and disability benefits legislation. However, in the case of women, the effect at age 58 is considerably stronger than the two effects at ages 52 and 55 which are approximately of the same size. For Spanish men, the increase in the hazard rate is more progressive and higher at each of the three age intervals.

\footnotetext{
${ }^{25}$ Apart from these variables, we have also done some tests with regional employment rates, regional employment growth and the employment rate of the sector. Results don't differ that much and we found it more interesting in terms of interpreting the results to use unemployment rates.
} 
Figure 9 Interval hazard rate men aged 45-59 in Spain.

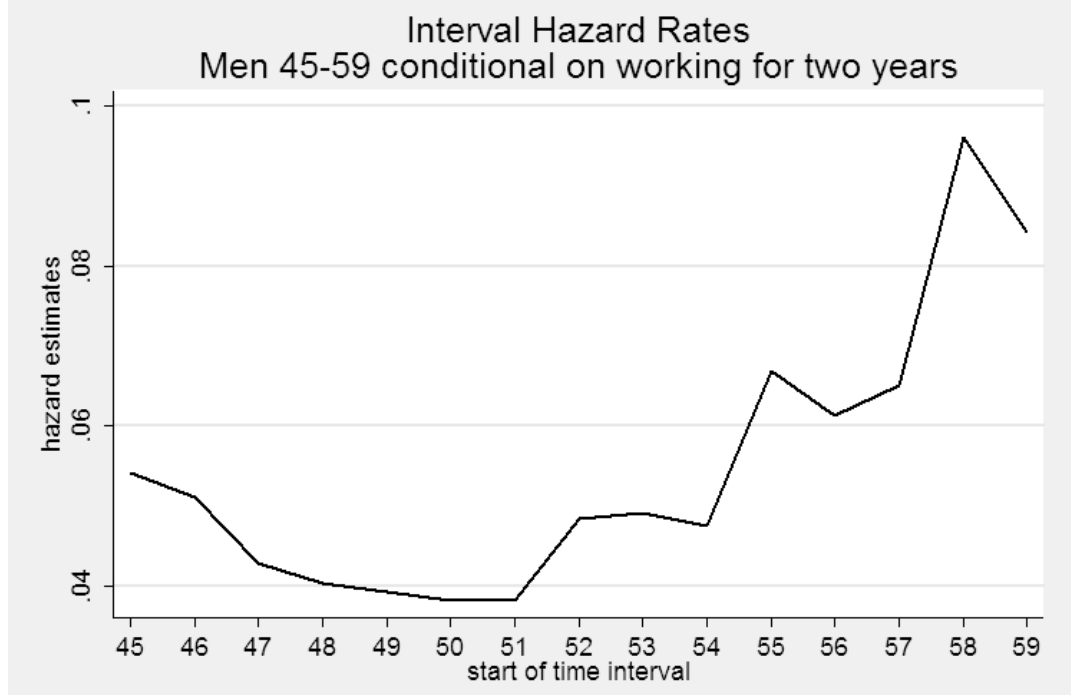

Figure 10 Interval hazard rate women 45-59 in Spain.

Interval Hazard Rates

Women 45-59 conditional on working for two years

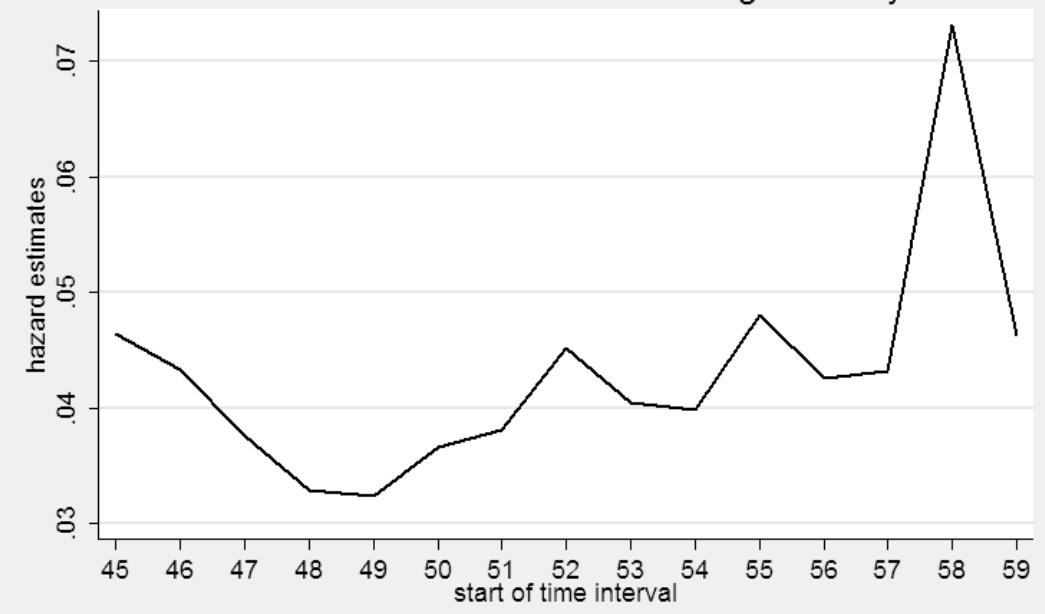


Figure 11 Interval hazard rate by temporary/permanent contract of employment, men aged 45-59 in Spain.

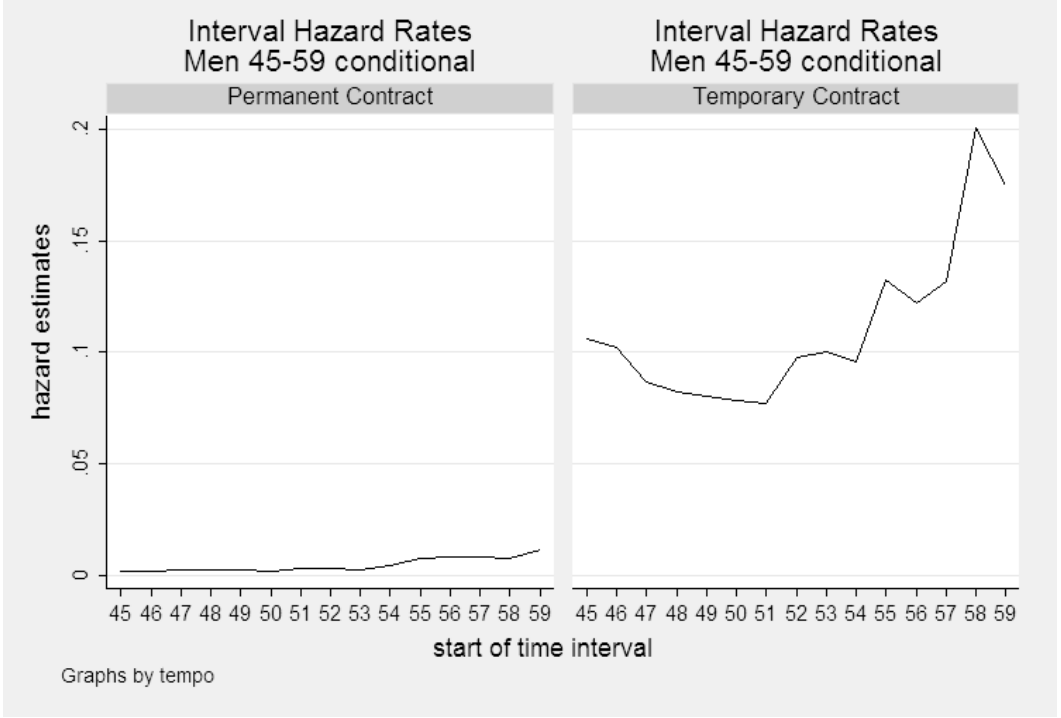

Figure 11 and Figure 12 plot the empirical hazard rates according to temporary/permanent contract and it becomes clear that it is workers with a temporary contract (men and women) the ones leaving employment between ages 45 and 59.

Individuals with a permanent contract tend to leave less the labour force before reaching the retirement age. This tendency for temporary workers to leave the labour market could be interpreted as a means of escaping from a very uncertain and unstable job situation, as it is probably very difficult for these older workers to find a job once their temporary contract expires. 
Figure 12 Interval hazard rate by temporary/permanent contract of employment, women aged 45-59 in Spain.

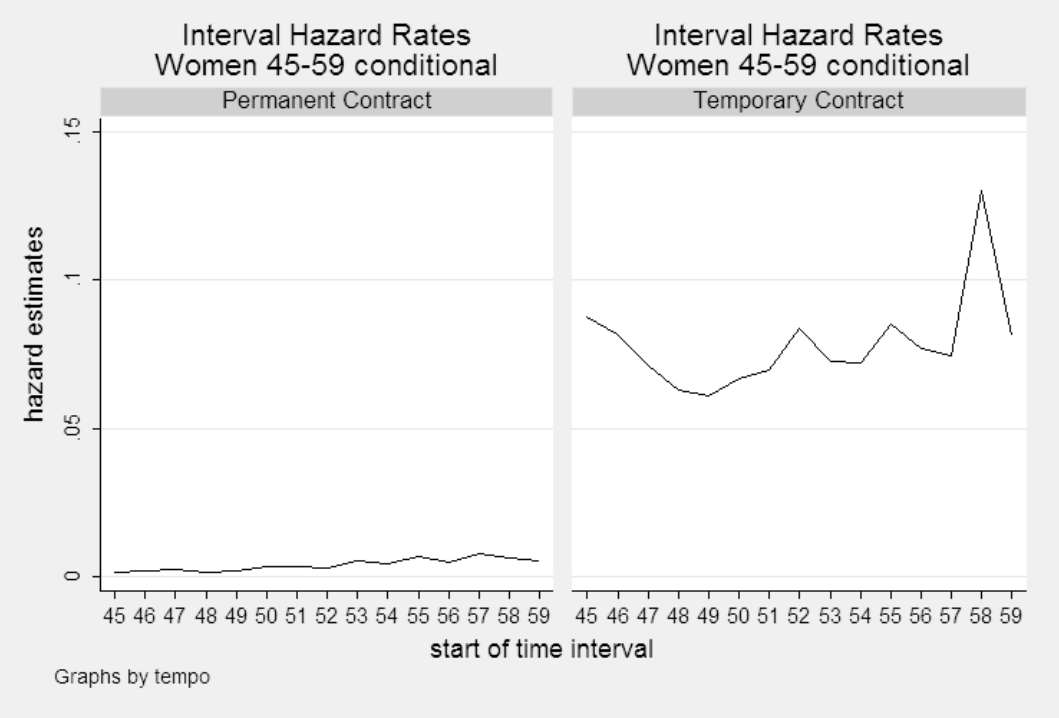

In fact, as stressed above, the special unemployment and disability schemes at ages 52 and 55 were already introduced in an attempt to provide a minimum degree of income stability for older workers who are unable to find a job after being fired due to industrial relocation or modernization plans. However, there is another possible interpretation; the choice to work under a temporary contract might already be a lifestyle choice indicating increased preference for leisure time. Unfortunately, we don't have information on preferences or the difficulties of these workers to find a new job.

Finally, Figure 13 and Figure 14 show the hazard rates for men and women with different educational levels. For women, the hazard rate clearly decreases according to the level of education and the peak at age 58 is higher for those with a level of education below a bachelor degree. For men, there is not much difference in the hazard rates for individuals with or without a high-school diploma although hazard rates for those with bachelor's degrees are slightly lower. 
Figure 13 Interval hazard rate by level of education, men aged 45-59 in Spain.

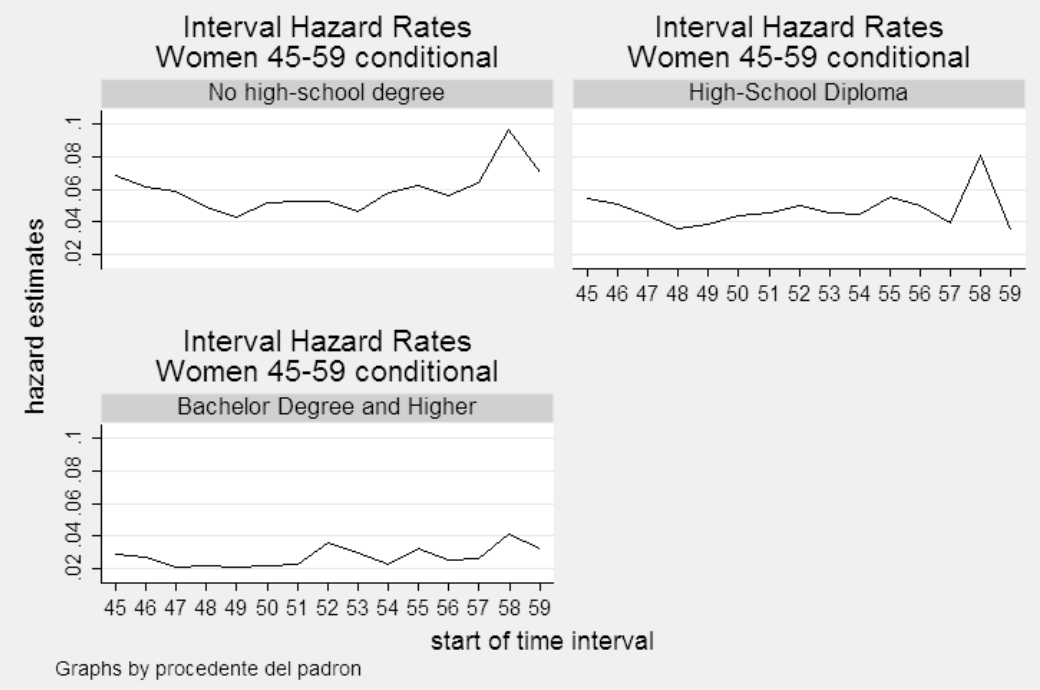

Figure 14 Interval hazard rate by level of education, women aged 45-59 in Spain.

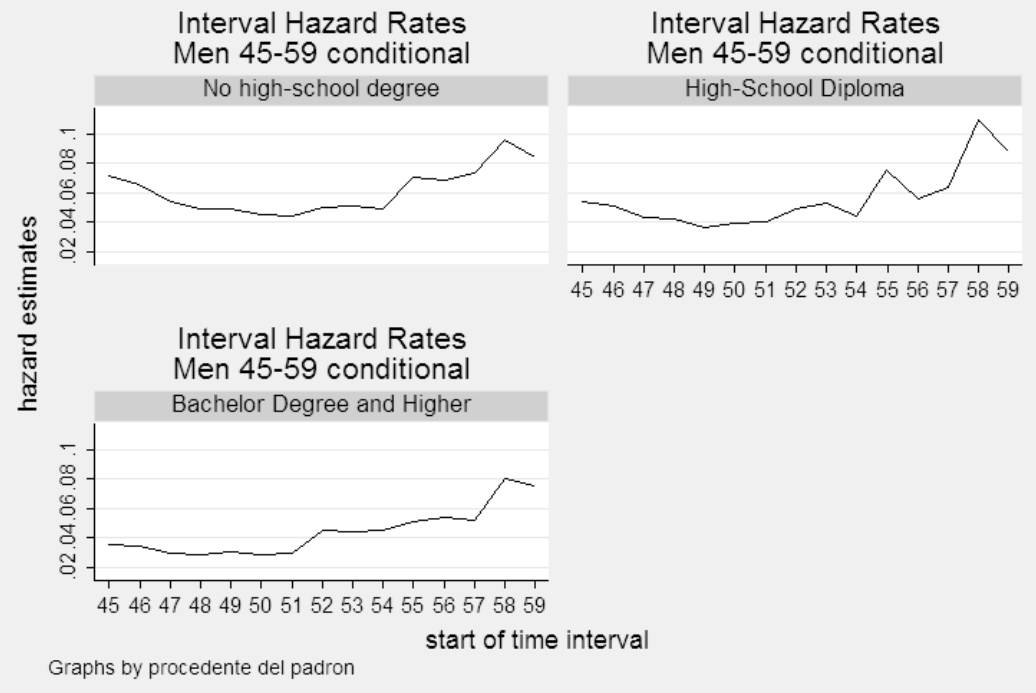




\subsubsection{Results: Hazard Regression analysis}

In this section we estimate the effect of personal and job-related characteristics, business cycle and age dummy variables on the hazard of leaving employment, while controlling for duration dependence through a cubic polynomial function of time.

The results are shown in Table 3, Table 5 and Table 6 for the case of men and Table 4, Table 7 and Table 8 for women.

We have estimated two models for each gender, a logistic hazard regression model for single exit from employment to a non-employment situation and a competing risk model to assess the differences between exits from employment to either unemployment, disability benefits or inactivity. As a result of the nonlinearity of the model estimated and the inclusion of interaction terms in the regression, we only discuss the results of the regressions in terms of sign and statistical significance of the coefficients of the explanatory variables. The size of these effects is discussed in the subsequent section through calibration of the effects of changes in selected variables on the predicted hazard rates. 
Table 3 Determinants of the probability of leaving employment, Spanish male aged 45-59 (logistic hazard regression model)

\begin{tabular}{|c|c|}
\hline & Coefficients \\
\hline $\begin{array}{l}\text { Contributions SS } \\
\text { Contributions SS * (log dur) } \\
\text { High School } \\
\text { Bachelor's and Higher } \\
\text { Bachelor's and Higher * (log dur) } \\
\text { Number Workers Firm } \\
\text { Catalonia Region } \\
\text { Mediterranean Region } \\
\text { Northern Region (excl Catalonia) } \\
\text { Castilla: Centre (excl Madrid) } \\
\text { South Region } \\
\text { duration } \\
\text { duration1 } \\
\text { duration2 } \\
\text { Voluntary Termination Empl } \\
\text { Sector empl: Primary Sector } \\
\text { Sector empl: Secondary Sector } \\
\text { Sector empl: Tertiary Sector } \\
\text { Sector empl: Education } \\
\text { Sector empl: Social Services } \\
\text { Part-time Contract } \\
\text { Number Years Contributed 15-45 } \\
\text { Tenure } \\
\text { Temporary Contract } \\
\text { Temporary Contract * (log dur) } \\
\text { Cohort born in 1941-1946 } \\
\text { Cohort born in 1947-1951 } \\
\text { Cohort born in 1952-1956 } \\
\text { Cohort born in 1957-1961 } \\
\text { Unem Rate CCAA } \\
\text { (Unem Rate CCAA) (log dur) } \\
\text { Unem Rate Sector } \\
\text { (Unem Rate Sector)* (log dur) } \\
\text { Av Hours Worked Sector } \\
\text { (Av Hours Worked)*(log dur) } \\
\text { GDP growth } \\
\text { age52 } \\
\text { age55 } \\
\text { age58 } \\
\text { Constant }\end{array}$ & $\begin{array}{c}-.0027228 * * * \\
.0002589 * * * \\
-.288038 * * * \\
-1.333674 * * * \\
.0635003 * \\
.0003305 * * * \\
.5101453 * * * \\
.2057207 * * \\
1.97327 * * * \\
1.746574 * * * \\
1.14097 * * * \\
-.0362429 * * * \\
.0004224 * * * \\
-1.194-06 * * * \\
1.493615 * * * \\
-3.71105 * * * \\
-3.468923 * * * \\
-3.508407 * * * \\
-4.148343 * * * \\
-5.449722 * * * \\
-2.324987 * * * \\
.0330285 * * * \\
-.0100746 * * * \\
3.698862 * * * \\
-.4062714 * * * \\
.7321382 * * * \\
1.18961 * * * \\
1.64788 * * * \\
2.174096 * * * \\
.0264608 * * * \\
-.0034779 \\
-.2677416 * * * \\
.032374 * * * \\
-.0455558 * \\
.0126749 * * * \\
-.2728114 * * * \\
.4501008 * * * \\
.2571083 * \\
.7658007 * * * \\
-4.986807 * * *\end{array}$ \\
\hline $\begin{array}{l}\mathbf{N} \\
11\end{array}$ & $\begin{array}{c}3302709 \\
-26165.35\end{array}$ \\
\hline
\end{tabular}


Table 4 Determinants of the probability of leaving employment, Spanish female aged 45-59 (logistic hazard regression model)

\begin{tabular}{|c|c|}
\hline & Coefficients \\
\hline Contributions ss & $-.0033717 * * *$ \\
\hline Contributions SS * (log dur) & $.000273 * * *$ \\
\hline High School & $-.4455875 * * *$ \\
\hline Bachelor's and Higher & $-1.528574 * * *$ \\
\hline Bachelor's and Higher * (log dur) & $.0975434 *$ \\
\hline Number Workers Firm & $.0003608 * * *$ \\
\hline Catalonia Region & $1.21007 * * *$ \\
\hline Mediterranean Region & -.0833553 \\
\hline Northern Region (excl Catalonia) & $2.148691 * * *$ \\
\hline Castilla: Centre (excl Madrid) & $1.944586 * * *$ \\
\hline South Region & $1.490959 * * *$ \\
\hline duration & $-.0583406 * * *$ \\
\hline duration 1 & $.0007447 * * *$ \\
\hline duration2 & $-2.38 e-06 * * *$ \\
\hline Voluntary Termination Empl & $1.549265 * * *$ \\
\hline Sector empl: Primary sector & $-3.102886 * *$ \\
\hline Sector empl: secondary sector & $-2.312497 * * *$ \\
\hline Sector empl: Tertiary Sector & $-2.724112 * * *$ \\
\hline Sector empl: Education & $-2.312423 * * *$ \\
\hline Sector empl: Social Services & $-4.146849 * * *$ \\
\hline Part-time Contract & $-2.814936 * * *$ \\
\hline Number Years Contributed 15-45 & $-.037407 * * *$ \\
\hline Tenure & $.0192176 * * *$ \\
\hline Temporary Contract & $3.510437 * * *$ \\
\hline Temporary Contract * (log dur) & $-.4075445 * * *$ \\
\hline Cohort born in 1941-1946 & $.9632839 * * *$ \\
\hline Cohort born in 1947-1951 & $1.678875 * * *$ \\
\hline Cohort born in 1952-1956 & $2.418431 * * *$ \\
\hline Cohort born in 1957-1961 & $3.186847 * * *$ \\
\hline Unem Rate CCAA & .0062434 \\
\hline (Unem Rate CCAA)*(log dur) & -.0050866 \\
\hline Unem Rate Sector & $-.4780831 * * *$ \\
\hline (Unem Rate Sector)* (log dur) & $.1041583 * * *$ \\
\hline Av Hours Worked Sector & $-.0730138 *$ \\
\hline (Av Hours Worked) $*(\log$ dur $)$ & .0068292 \\
\hline GDP growth & $-.1328065 * * *$ \\
\hline age 52 & $.5298079 * *$ \\
\hline age55 & .194174 \\
\hline age 58 & .1803018 \\
\hline Constant & $-3.380862 *$ \\
\hline $\mathbf{N}$ & 1215877 \\
\hline 11 & -8594.184 \\
\hline
\end{tabular}




\subsubsection{Duration dependence}

We have modelled the baseline hazard as a cubic polynomial function of duration because, together with the age dummies, this specification reproduces the shape of the empirical interval hazard rate reasonably closely.

We have also tried to estimate the model with a piece-wise constant specification of the baseline hazard in order to allow for greater flexibility as we don't have to assume any functional form for the baseline hazard. However, in the competing risk case, when duration was represented by time dummies (one for each month), several of these dummy variables were not identified as for certain months there was no exit observed to one of the exit routes ${ }^{26}$. Furthermore, in this specification, age dummies could not be included as they caused multicollinearity problems with the duration variables. On the other hand, if we increase the number of months included in each dummy variable to reduce the number of these variables and allow for a better identification of the model, we are unable to capture age effects.

In order to keep consistency between the two specifications that we use (logistic and competing risk models) and to be able to test the effects of some unemployment and disability schemes through age dummies, we decided to represent duration dependence with a cubic polynomial function of time.

In addition, the coefficients of the explanatory variables are very similar in the model in which duration dependence is modelled as a piece-wise constant and the model with a cubic polynomial baseline hazard so that the results that we report correspond to the model with the cubic polynomial baseline hazard.

\subsubsection{Individual features and employer, firm and industry characteristics}

Our findings confirm that the effect of personal characteristics is similar to what the literature on the topic suggests. Individuals with higher education and individuals with a part-time contract show lower hazard rates. Therefore, the idea of introducing partial retirement schemes in order to keep older workers active in the labour market would seem like a positive alternative as part-time workers leave employment less than full-time workers. On the other hand, temporary contracts are not a good policy to retain workers in employment, as the hazard rate increases substantially for individuals with a temporary contract. This result

\footnotetext{
${ }^{26}$ The same problem occurred if we grouped the time dummies in small groups of 3 or 4 months for each time dummy representing duration. 
implies that temporary contracts usually run out without leading to a permanent contract so that temporary contracts in Spain are not used as stepping-stones to reach a more stable employment situation.

In terms of regions, Madrid has the lowest hazard rate, followed by the Mediterranean region, Catalonia, Southern Spain and the Centre (Castilla), while the Northern region has the highest hazard rate.

Social security contributions (our proxy for wages) show a negative sign so that employees with higher salaries have a lower hazard rate as the monetary incentives to stay employed are stronger compared to receiving unemployment or disability benefits. This effect increases with elapsed duration.

The coefficient for the number of years contributed between ages 15 and 45 is positive and significant suggesting that individuals who have been contributing for a longer period to the social security administration have a higher hazard to leave the labour force possibly because they fulfil the contributory eligibility conditions to receive unemployment or disability benefits. On the other hand, individuals who have been working for longer in the current job at the time of entering the sample have a lower hazard rate, which could be interpreted as having a stronger attachment to the employer the longer you work for the same firm.

\subsubsection{Business cycle conditions and age effects}

Business cycle effects are measured in terms of the unemployment rate of the autonomous community in which the individual is working, the unemployment rate of that firm's sector of activity, the average number of hours worked in the sector of activity and, finally, the GDP growth rate to capture national business cycle trends that are not captured by the regional or sector variables.

The first variable, the unemployment rate of the autonomous community shows the anticipated positive sign for both males and females, but it is stronger and more significant in the case of men. The negative sign of the interaction term with duration suggests that the effect of the unemployment rate is lower for individuals who remain employed for a longer period of time.

However, the coefficient of the unemployment rate of the sector of activity of the firm has a negative sign, which is unexpected and is very significant for both genders while the interaction term displays a positive and significant sign. A possible interpretation of this result is the idea that the negative consequences (in terms of increased unemployment) of idiosyncratic shocks that affect only one sector of the economy can be absorbed by other sectors of the economy that might be experiencing a growth path. Therefore, this fact points to the existence of opportunities for workers to move to other sectors of the economy when 
unemployment in the sector of activity is high compared to overall unemployment in other sectors.

The higher the number of hours worked in the sector, the lower the hazard rate of leaving employment and this effect is stronger for individuals who have been employed for longer.

The GDP growth rate has the expected negative (and very significant) sign reinforcing the idea that workers tend to leave employment at times when the economy is at its lowest rate of growth.

For men, the three age peaks at 52, 55 and 58 have a higher and very significant hazard rate whereas for the case of women only the 52 variable turns out to be significant. However, all of them have a positive coefficient.

The results of the competing risk model present a very interesting finding for the disability option. If we take a look at Table 5, the coefficient for the unemployment rate of the autonomous community is positive and significant and the GDP growth coefficient is negative and also very significant suggesting that exit to disability is very much influenced by the economic cycle of both the region and the country as a whole. The medical requirements needed to access this route are not as strict as to prevent workers from using this route as an alternative to claiming unemployment benefits during bad economic times. In this case, a higher sector unemployment rate is also reflected in an increased hazard rate of leaving employment to receive disability benefits.

We have also estimated the same competing risk model using the sample of people observed as working continuously for the two years prior to entering the sample. The aim is to test whether the results are any different for workers with a more stable job situation (as we exclude workers with very short-term contracts). 
Table 5 Determinants of the probability of going to disability benefits, unemployment and inactivity Spanish male aged 45-59 (competing-risk hazard regression model).

\begin{tabular}{|c|c|c|c|}
\hline & Disability & Unemployment & Inactivity \\
\hline $\begin{array}{l}\text { Contributions SS } \\
\text { (Contribution SS)*(log dur) }\end{array}$ & $-0.00203 * * *$ & $-0.00305 * * *$ & $-0.00298 * * *$ \\
\hline $\begin{array}{l}\text { High School } \\
\text { Higntrof }\end{array}$ & 0.06564 & $-0.19058 * * *$ & 0.22083 \\
\hline Bachelor's and Higher & 0.20879 & $-1.60031 * * *$ & $0.78750 *$ \\
\hline (Bachelors's and Higher)*(log dur) & -0.05496 & $0.06682 *$ & -0.09064 \\
\hline Number Workers Firm & $0.00008 * * *$ & $0.00046 * * *$ & $-0.00013 * *$ \\
\hline Catalonia Region & $0.25374 *$ & $2.12555 * * *$ & $-0.46312 * *$ \\
\hline Mediterranean Region & 0.23144 & $-0.23275 * *$ & $-0.67753 * * *$ \\
\hline Northern Region (excl Catalonia) & $0.59395 * * *$ & $4.09505 * * *$ & $-0.35994 *$ \\
\hline Castilla: Centre (excl Madrid) & $0.28579 *$ & $3.99653 * * *$ & $-0.56086 * *$ \\
\hline South Region & $0.81876 * * *$ & $2.27052 * * *$ & $-0.58518 * *$ \\
\hline duration & -0.03112 & $-0.05939 * * *$ & $-0.05650 * *$ \\
\hline duration 1 & $0.00032 *$ & $0.00062 * * *$ & $0.00067 * *$ \\
\hline duration2 & -0.00000 & $-0.00000 * * *$ & $-0.00000 * *$ \\
\hline Voluntary Termination Empl & $-1.51588 * * *$ & $2.12595 * * *$ & $0.36774 * *$ \\
\hline Part-time Contract & $-1.13919 * * *$ & $-5.60529 * * *$ & $-0.61262 *$ \\
\hline Number Years Contributed 15-45 & $0.01558 *$ & $-0.01048 * * *$ & $-0.02436 *$ \\
\hline Tenure & 0.00401 & $-0.01632 * * *$ & 0.01130 \\
\hline Cohort born in 1941-1946 & $0.68599 * * *$ & $0.36473 * * *$ & $0.90093 * * *$ \\
\hline Cohort born in 1947-1951 & $1.19878 * * *$ & $0.75943 * * *$ & $1.24030 * * *$ \\
\hline Cohort born in 1952-1956 & $1.43072 * * *$ & $1.26949 * * *$ & $0.97528 * * *$ \\
\hline Cohort born in 1957-1961 & $1.94947 * * *$ & $1.96465 * * *$ & -0.09233 \\
\hline Unem Rate CCAA & $0.06457 *$ & $0.08015 * * *$ & -0.01746 \\
\hline (Unem Rate CCAA)*(log dur) & $-0.01449 *$ & $-0.01557 * * *$ & 0.01308 \\
\hline Unem Rate Sector & 0.05904 & $-0.46275 * * *$ & -0.01514 \\
\hline (Unem Rate Sector)* (log dur) & -0.01002 & 0.00496 & 0.00039 \\
\hline $\begin{array}{l}\text { Av Hours Worked Sector } \\
(\text { Av Hours Worked }) *(\text { log dur })\end{array}$ & $\begin{array}{l}-0.08587 * \\
0.03097 * * *\end{array}$ & $\begin{array}{r}-0.21426 * * * \\
0.00877 * * *\end{array}$ & $\begin{array}{r}-0.00104 \\
0.00647\end{array}$ \\
\hline GDP growth & $-0.08667 * * *$ & $-0.34260 * * *$ & $-0.05652 *$ \\
\hline age 52 & -0.35493 & $0.61324 * * *$ & 0.09696 \\
\hline age 55 & 0.08273 & $0.39656 * * *$ & -0.41544 \\
\hline age58 & 0.39408 & $0.98238 * * *$ & 0.60168 \\
\hline Constant & $-8.58850 * * *$ & $2.21552 * * *$ & $-6.42835 * * *$ \\
\hline $\mathbf{N}$ & 3302709 & & \\
\hline 11 & -36164.43 & & \\
\hline$* \mathrm{p}<0.05, * * \mathrm{p}<0.01, * * * \mathrm{p}<0.001$ & & & \\
\hline
\end{tabular}

Table 6 Business cycle coefficients, Spanish male 45-59 conditional on working for two years before entering the sample (competing risk hazard regression model)

\begin{tabular}{l|c|c|c|}
\hline & Disability & Unemployment & Inactivity \\
\hline Unem Rate CCAA & 0.02547 & $0.05662 * * *$ & -0.05389 \\
(Unem Rate CCAA)*(log dur) & -0.00537 & $-0.01091 * * *$ & $0.02868 * *$ \\
Unem Rate Sector & $0.13678 * *$ & $-0.46747 * * *$ & -0.05693 \\
(Unem Rate Sector)*(log dur) & $-0.03113 * *$ & 0.01013 & 0.00958 \\
Av Hours Worked Sector & $-0.08597 *$ \\
(Av Hours Worked)*(log dur) & $0.03204 * *$ & $-0.22578 * * *$ & 0.005960 \\
GDP growth & $-0.07817 * * *$ & $-0.39401 * * *$ & -0.00411 \\
\hline $\mathbf{N}$ & 2986084 & & -0.03106 \\
\hline 1 & -29486.682 & & \\
$* \mathrm{p}<0.05, * * p<0.01, * * * p<0.001$ & & & \\
\hline
\end{tabular}


Table 7 Determinants of the probability of going to disability benefits, unemployment and inactivity, Spanish female aged 45-59 (competing risk hazard regression model)

\begin{tabular}{|c|c|c|c|}
\hline & Disability & Unemployment & Inactivity \\
\hline Contributions ss & $-0.00214 * * *$ & $-0.00417 * * *$ & $-0.00426 * * *$ \\
\hline (Contribution SS)*(log dur) & 0.00003 & $0.00050 * * *$ & 0.00015 \\
\hline High School & -0.15942 & $-0.53211 * * *$ & 0.08196 \\
\hline Bachelor's and Higher & -0.39680 & $-1.60398 * * *$ & 0.08995 \\
\hline (Bachelors's and Higher)*(log dur) & 0.10779 & 0.05362 & 0.06782 \\
\hline Number Workers Firm & $0.00006 * *$ & $0.00049 * * *$ & 0.00001 \\
\hline Catalonia Region & 0.16061 & $2.69987 * * *$ & $-0.54284 *$ \\
\hline Mediterranean Region & 0.13876 & -0.23809 & $-0.76888 *$ \\
\hline Northern Region (excl Catalonia) & $0.51579 * *$ & $4.13433 * * *$ & $-0.95251 * *$ \\
\hline Castilla: Centre (excl Madrid) & 0.05444 & $3.89641 * * *$ & -0.15090 \\
\hline South Region & $0.94122 * * *$ & $1.78955 * * *$ & $-1.01541 * *$ \\
\hline duration & -0.03212 & $-0.11759 * * *$ & 0.00925 \\
\hline duration1 & 0.00029 & $0.00129 * * *$ & 0.00016 \\
\hline duration2 & -0.00000 & $-0.00000 * * *$ & -0.00000 \\
\hline Voluntary Termination Empl & $-1.60678 * *$ & $2.26171 * * *$ & 0.02614 \\
\hline Part-time Contract & $-1.72939 * * *$ & $-7.17703 * * *$ & $-0.95575 * * *$ \\
\hline Number Years Contributed 15-45 & 0.01821 & $-0.07915 * * *$ & 0.00044 \\
\hline Tenure & -0.00947 & 0.00055 & -0.00219 \\
\hline Cohort born in 1941-1946 & $0.66024 * *$ & $0.68751 * * *$ & 0.28962 \\
\hline Cohort born in 1947-1951 & $1.16505 * * *$ & $1.45295 * * *$ & 0.19621 \\
\hline Cohort born in 1952-1956 & $1.29205 * * *$ & $2.22800 * * *$ & 0.27253 \\
\hline Cohort born in 1957-1961 & 0.97322 & $3.10912 * * *$ & -0.60145 \\
\hline Unem Rate CCAA & -0.10062 & $0.04539 * * *$ & 0.03042 \\
\hline (Unem Rate CCAA)*(log dur) & 0.01740 & $-0.02222 * * *$ & 0.01198 \\
\hline Unem Rate Sector & -0.09578 & $-0.62136 * * *$ & -0.08130 \\
\hline (Unem Rate Sector)*(log dur) & 0.02280 & $0.05250 * * *$ & 0.02335 \\
\hline Av Hours Worked Sector & -0.04407 & $-0.08528 * * *$ & 0.04072 \\
\hline (Av Hours Worked) * (log dur) & 0.01204 & $0.01249 * * *$ & -0.01588 \\
\hline GDP growth & $-0.16146 * * *$ & $-0.13096 * * *$ & -0.01816 \\
\hline age 52 & -1.51549 & $0.80914 * * *$ & 0.06362 \\
\hline age55 & $0.80955 *$ & -0.12329 & -0.21635 \\
\hline age58 & -0.26143 & $0.71663 *$ & -28.02658 \\
\hline Constant & $-5.94766 * * *$ & $-2.20807 * * *$ & $-6.98773 * * *$ \\
\hline $\begin{array}{l}\mathbf{N} \\
11\end{array}$ & $\begin{array}{r}1215877 \\
-11330.2\end{array}$ & & \\
\hline$* \mathrm{p}<0.05, * * \mathrm{p}<0.01, * * * \mathrm{p}<$ & & & \\
\hline
\end{tabular}

Table 8 Business cycle coefficients, Spanish female 45-59 conditional on working for two years before entering the sample (competing risk hazard regression model)

\begin{tabular}{|c|c|c|c|}
\hline & Disability & Unemployment & Inactivity \\
\hline $\begin{array}{l}\text { Unem Rate CCAA } \\
\text { (Unem Rate CCAA)*(log dur) } \\
\text { Unem Rate Sector } \\
\text { (Unem Rate Sector)*(log dur) } \\
\text { Av Hours Worked Sector } \\
\text { (Av Hours Worked)*(log dur) } \\
\text { GDP growth }\end{array}$ & $\begin{array}{r}-0.08366 \\
0.01733 \\
-0.03119 \\
0.00032 \\
-0.05555 \\
0.01893 \\
-0.15665 * * *\end{array}$ & $\begin{array}{r}0.10781 * * * \\
-0.03371 * * * \\
-0.56614 * * * \\
0.03890 * \\
-0.11256 * * * \\
0.01739 * * * \\
-0.21273 * * *\end{array}$ & $\begin{array}{r}0.05129 \\
0.00886 \\
0.07138 \\
-0.03381 \\
-0.11459 \\
0.01211 \\
-0.02763\end{array}$ \\
\hline $\begin{array}{l}\mathbf{N} \\
11 \\
\end{array}$ & $\begin{array}{r}1069059 \\
-7685.83 \\
\end{array}$ & & \\
\hline$* \mathrm{p}<0.05, * * \mathrm{p}<0.01, * * * \mathrm{p}<0.001$ & & & \\
\hline
\end{tabular}


The results of this estimation are shown in Table 6 and Table 8. The sign of the coefficients do not change with respect to the original sample but the sector unemployment rate has now a stronger effect on hazard rates than the unemployment rate of the autonomous community and the GDP growth. Therefore, a deterioration of the economic conditions in a particular economic sector increases the hazard rate of making a transition to disability benefits for individuals employed in that sector. As a result, individuals with a more stable employment situation are more affected by the economic situation of the sector of activity and by the economy-wide business cycle conditions than by the economic situation of the autonomous community in which they work.

\subsubsection{Effects on hazard rates}

We finish by analyzing the relative size of the effects outlined in the previous section. Of all the variables, we have chosen to concentrate on the macroeconomic variables, as they are the main focus of this chapter, and on the variable that describes the type of temporary/permanent contract, so as to illustrate the size of the differences on the hazard rates of these two groups of workers. Comparisons of size are complicated as they depend on the reference group of individuals and the values chosen for the evaluation. In Figure 15 we compare the predicted hazard rates of a representative individual ${ }^{27}$ with either a temporary or a permanent contract of employment. For that comparison, we keep macroeconomic variables at their sample means: $15.75 \%$ unemployment rate for the autonomous community; $6.84 \%$ unemployment rate for the sector of activity; 40.31 average number of hours worked and $2.96 \%$ GDP growth.

According to our predictions, a person in our sample has a 1.3 percentage point higher hazard rate of leaving employment if he has a temporary contract of employment than if he has a permanent contract.

\footnotetext{
27 The representative individual has the values of the reference category of the regressions for the explanatory variables that are dummies and the mean values of the sample for the other explanatory variables such as contributions (wages), number of workers in the firm, etc...
} 
Figure 15 Predicted hazard rate men $45-59$ by temporary/permanent contract of employment

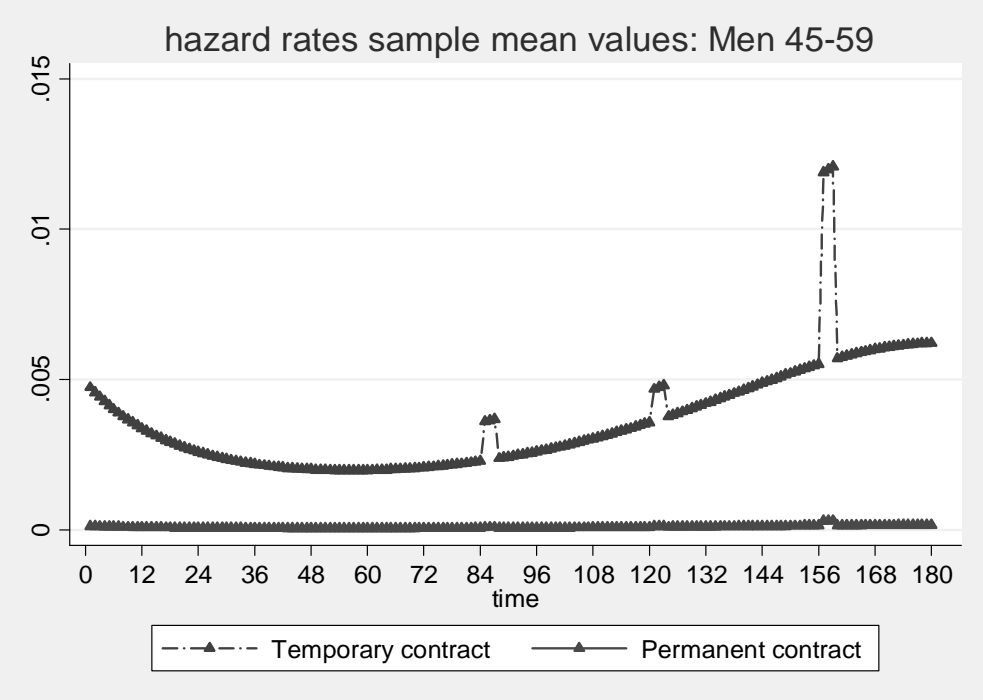

Figure 16 Predicted hazard rate men 45-59 by maximum/minimum level of GDP growth.

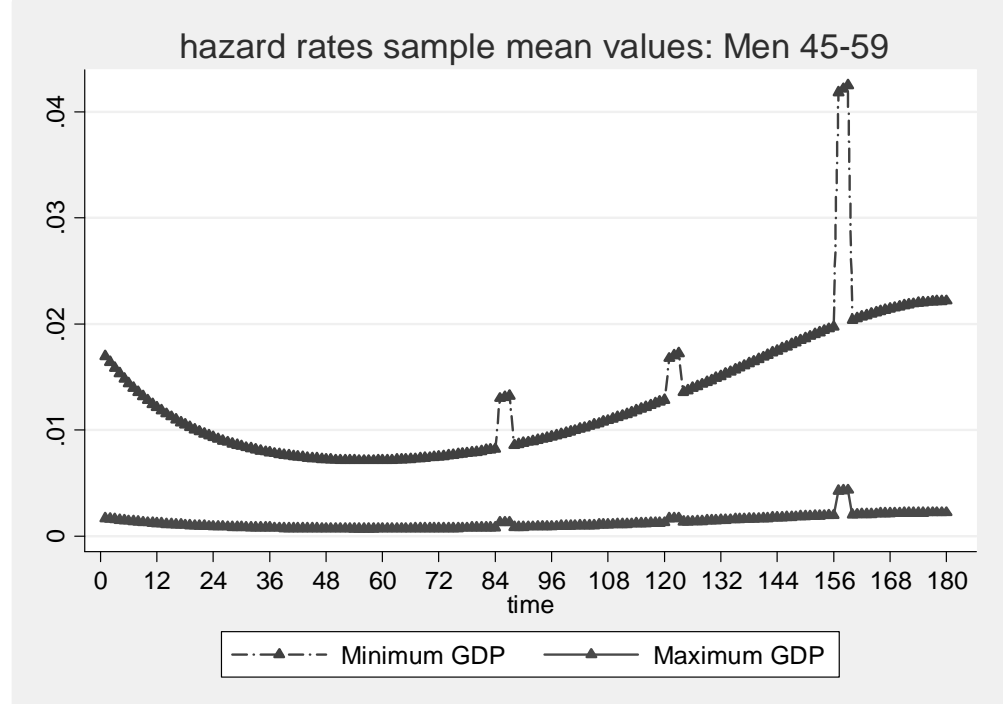

Figure 16 shows that when GDP growth is at the lowest point of our sample period $(-1.8 \%)$ the hazard of a 58 year-old men leaving employment is 4 percentage points higher than at times of maximum GDP growth $(6.7 \%)$. For a 59 year-old men the difference is of 2 percentage points.

The effect of changing the unemployment rate to the maximum and minimum value of the sample period is not as strong as the effect of the GDP growth but it is still important: for a 58 year-old men the hazard rate is 1 
percentage point higher when the unemployment rate is at its maximum $(34.9 \%)$ than when it is at its minimum rate (3.47\%) (Figure 17$)$.

Figure 17 Predicted hazard rate men 45-59 by maximum/minimum level of unemployment rates

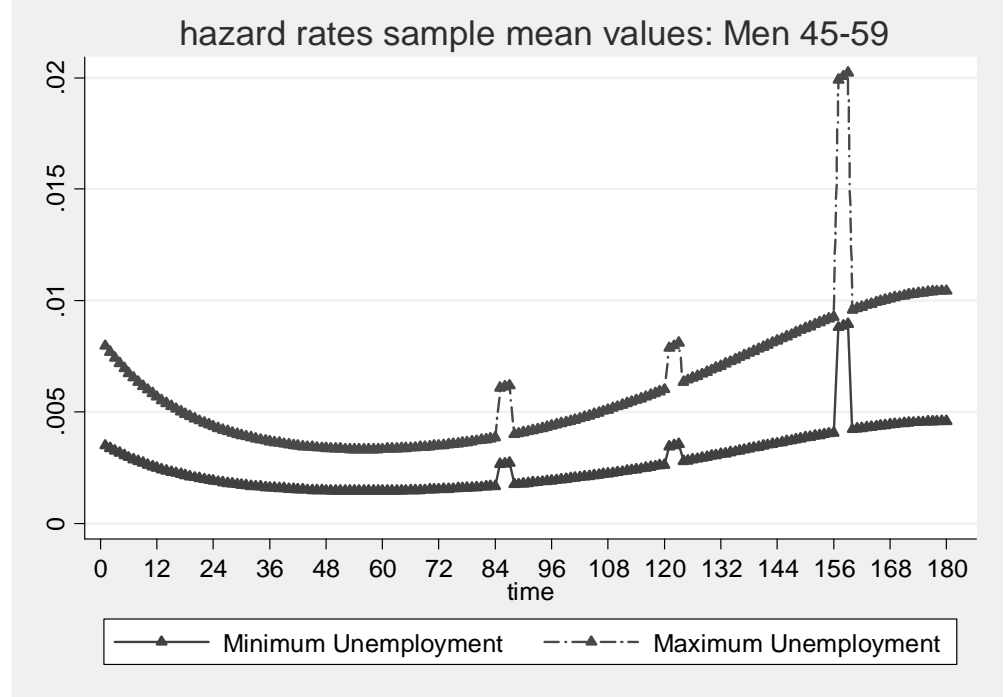

\subsection{Concluding remarks}

In this chapter we have investigated the effect of business cycle conditions in Spain on labour market transitions from employment to disability benefits, unemployment and inactivity for men and women aged 45-59.

We have also described two special schemes in the unemployment and disability legislation which induce people to make the transitions when they reach a certain age.

For this analysis, we have estimated two kinds of duration models, a logistic hazard model for single exit transitions from employment to all the other nonemployment situations and a competing risk model for transitions from employment to each of the other three states: unemployment, disability and inactivity.

We have used two databases for our analysis: on the one hand, the so-called "Muestra Continua de Vidas Laborales", which is an administrative database, obtained from a random draw of the Spanish Social Security records and, on the other hand, from the Spanish National Institute of Statistics we have derived the macroeconomic information on the business cycle conditions. 
Our main findings can be listed as following:

- Business cycle conditions are found to affect not only transitions from employment to unemployment, but also transitions from employment to disability. This effect holds both for men and women. Individuals are more likely to leave employment to receive disability benefits when the economic situation of the country is less favourable. Disability benefits are being used as an alternative means of leaving the labour market for individuals who find it difficult to get a new job (because of age) and who (most probably) do not fulfil the requirements to receive unemployment benefits.

- For exits to disability benefits, the effect of the economic environment in the sector of activity proves to be stronger than the effect of the economic environment in the region. However, the opposite can be said for the unemployment option, as a higher unemployment rate in the sector of activity in which the individual is working reduces the hazard of leaving employment to receive unemployment benefits. Furthermore, this effect is stronger than the effect of the unemployment rate of the autonomous community.

- The special schemes in the unemployment and disability legislation mentioned in this paper that relax the conditions to access these benefits at ages 52,55 and 58 , trigger specific age effects in transitions, particularly so for exits to unemployment. 


\subsection{Appendix: Tables and Figures}

Figure 18 Interval hazard rate exit to Unemployment; men \& women 45-59

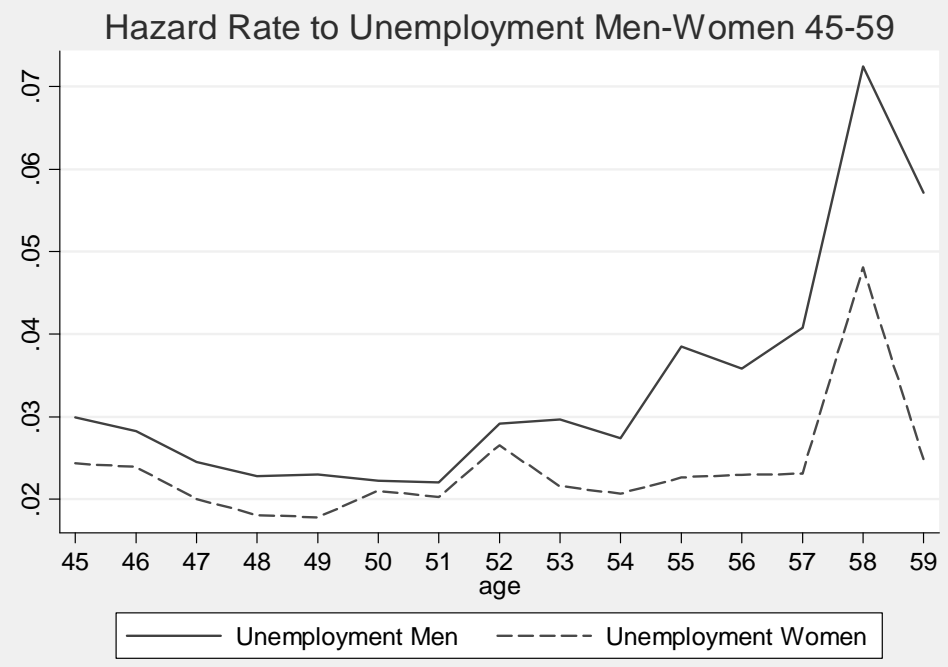

Figure 19 Interval hazard rate exit to Disability; men \& women 45-59

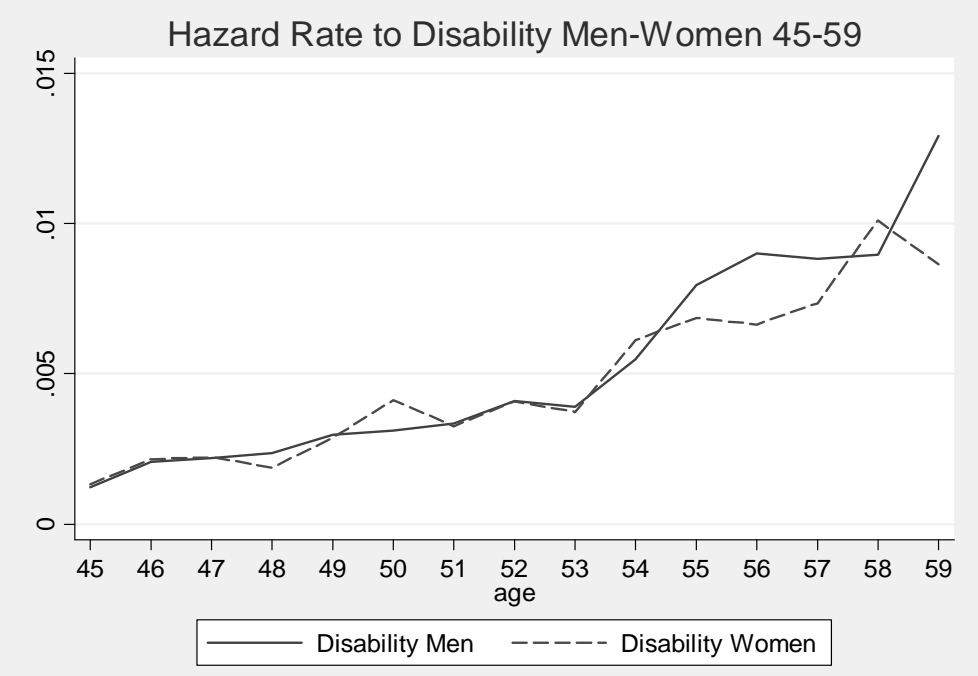


Figure 20 Interval hazard rate exit to Inactivity; men \& women 45-59

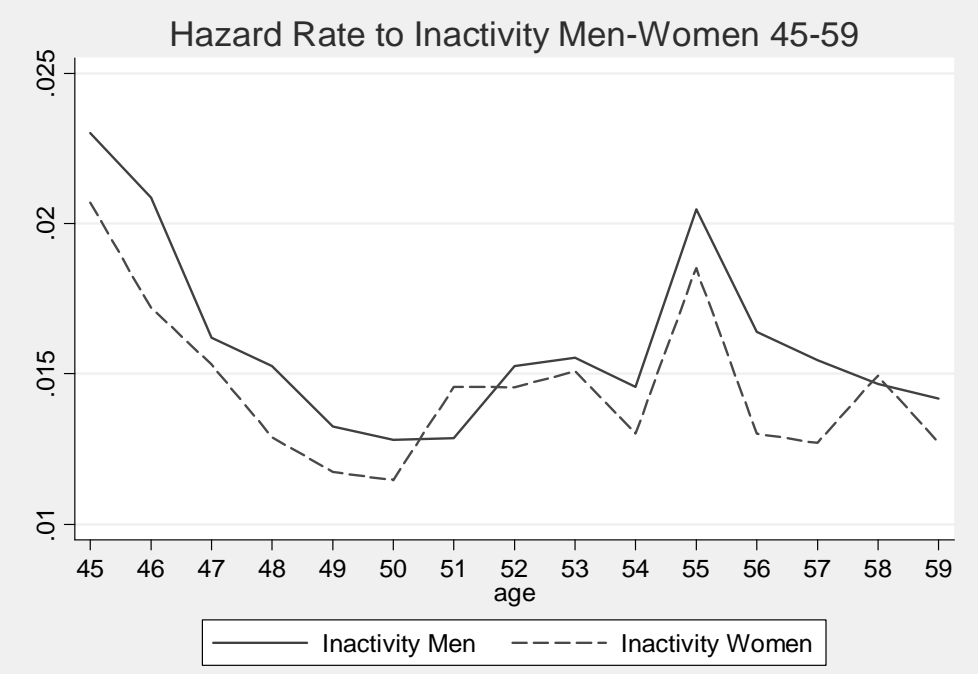


Table 9 Means and standard deviations. Sample of men 45-59

\begin{tabular}{|c|c|c|}
\hline & mean & sd \\
\hline Contributions ss & 1510.265 & 674.6356 \\
\hline Contributions SS * ( $\log$ dur $)$ & 5793.033 & 3263.335 \\
\hline High School & .2909938 & .4542208 \\
\hline Bachelor's and Higher & .3222576 & .4673411 \\
\hline Bachelor's and Higher * (log dur) & 1.193649 & 1.836985 \\
\hline Number Workers Firm & 866.6959 & 3829.889 \\
\hline Catalonia Region & .2218119 & .4154653 \\
\hline Mediterranean Region & .1146653 & .3186176 \\
\hline Northern Region (excl Catalon) & .2068248 & .4050288 \\
\hline Castilla: Centre (excl Madrid) & .1272828 & .3332895 \\
\hline South Region & .1506106 & .357669 \\
\hline duration & 64.41215 & 46.51883 \\
\hline duration1 & 6312.927 & 7543.53 \\
\hline duration2 & 742651.2 & 1185394 \\
\hline Voluntary Termination Empl & .0695484 & .2543844 \\
\hline Sector empl: Primary sector & .0120259 & .1090012 \\
\hline Sector empl: Secondary sector & .4632791 & .4986498 \\
\hline Sector empl: Tertiary Sector & .3535964 & .4780858 \\
\hline Sector empl: Education & .0195552 & .1384657 \\
\hline Sector empl: Social Services & .0675391 & .2509534 \\
\hline Part-time Contract & .0299512 & .1704527 \\
\hline Number Years Contributed 15-45 & 14.58961 & 6.203472 \\
\hline Tenure & 8.450237 & 7.114126 \\
\hline Temporary Contract & .4736366 & .4993046 \\
\hline Temporary Contract * (log dur) & 1.756559 & 2.004741 \\
\hline Cohort born in 1941-1946 & .3314358 & .4707294 \\
\hline Cohort born in 1947-1951 & .2714572 & .4447114 \\
\hline Cohort born in 1952-1956 & .1925386 & .3942937 \\
\hline Cohort born in 1957-1961 & .0452426 & .2078357 \\
\hline Unem Rate CCAA & 15.75695 & 6.314089 \\
\hline (Unem Rate CCAA)*(log dur) & 58.94927 & 29.52057 \\
\hline Unem Rate Sector & 6.845021 & 4.145969 \\
\hline (Unem Rate Sector)*(log dur) & 25.75916 & 17.90896 \\
\hline Av Hours Worked Sector & 40.31725 & 2.020348 \\
\hline (Av Hours Worked)*(log dur $)$ & 151.5127 & 44.2845 \\
\hline GDP growth & 2.969093 & 1.474075 \\
\hline age 52 & .0169558 & .1291057 \\
\hline age 55 & .0112629 & .1055274 \\
\hline age 58 & .0064744 & .0802027 \\
\hline $\mathbf{N}$ & 3302709 & \\
\hline
\end{tabular}


Table 10 Means and standard deviations. Sample of women 45-59

\begin{tabular}{|c|c|c|}
\hline & mean & sd \\
\hline Contributions ss & 1337.592 & 665.8197 \\
\hline Contributions SS * (log dur) & 4889.283 & 3013.761 \\
\hline High School & .3118268 & .4632397 \\
\hline Bachelor's and Higher & .4017133 & .4902448 \\
\hline Bachelor's and Higher * (log dur) & 1.42292 & 1.875155 \\
\hline Number Workers Firm & 1160.565 & 4109.105 \\
\hline Catalonia Region & .2588675 & .4380129 \\
\hline Mediterranean Region & .0995981 & .2994635 \\
\hline Northern Region (excl Catalonia) & .1894797 & .3918894 \\
\hline Castilla: Centre (excl Madrid) & .1087075 & .3112721 \\
\hline South Region & .1420168 & .3490675 \\
\hline duration & 56.50742 & 44.24135 \\
\hline duration 1 & 5150.384 & 6863.411 \\
\hline duration2 & 580455.7 & 1053404 \\
\hline Voluntary Termination Empl & .0522693 & .2225696 \\
\hline Sector empl: Primary sector & .0026746 & .0516475 \\
\hline Sector empl: Secondary sector & .1563661 & .3632023 \\
\hline Sector empl: Tertiary Sector & .3441236 & .4750818 \\
\hline Sector empl: Education & .0833686 & .2764387 \\
\hline Sector empl: Social Services & .2569224 & .4369364 \\
\hline Part-time Contract & .0962745 & .2949675 \\
\hline Number Years Contributed 15-45 & 13.67125 & 7.886595 \\
\hline Tenure & 7.387752 & 7.285841 \\
\hline Temporary Contract & .5133439 & .4998221 \\
\hline Temporary Contract * (log dur) & 1.828531 & 1.963227 \\
\hline Cohort born in 1941-1946 & .236746 & .4250853 \\
\hline Cohort born in 1947-1951 & .3105076 & .4627016 \\
\hline Cohort born in 1952-1956 & .2807694 & .4493752 \\
\hline Cohort born in 1957-1961 & .0779363 & .2680715 \\
\hline Unem Rate CCAA & 14.62729 & 6.14194 \\
\hline (Unem Rate CCAA) *(log dur) & 52.20523 & 27.98231 \\
\hline Unem Rate Sector & 4.837684 & 3.403539 \\
\hline (Unem Rate Sector)*(log dur) & 17.1973 & 13.66126 \\
\hline Av Hours Worked Sector & 38.95804 & 2.566424 \\
\hline (Av Hours Worked)*(log dur) & 139.5169 & 44.39457 \\
\hline GDP growth & 2.980086 & 1.303055 \\
\hline age 52 & .0150097 & .1215914 \\
\hline age55 & .0087953 & .0933699 \\
\hline age 58 & .0046567 & .0680811 \\
\hline $\mathbf{N}$ & 1215877 & \\
\hline
\end{tabular}


3. Promoting Employment of Disabled Women in Spain; Evaluating a Policy 


\subsection{Introduction ${ }^{28}$}

During the last years, disability policies have attracted particular attention in OECD countries both because they represent an important source of government expenditure and because societies are becoming more and more concerned about the need to strengthen the integration of disabled individuals in the society.

Countries in the OECD have tightened the conditions to access the unemployment and social assistance schemes introducing several work requirements while, at the same time, early retirement schemes have been limited (or even abolished) because of their well-documented work disincentives. These events have resulted in increasing numbers of pre-retirement individuals entering the disability schemes which, together with the ageing process of developed societies, raises concerns about the mid-term effects of disability expenses on the government's budget (OECD, 2007a, 2007b).

On the other hand, several studies and organizations of people with disabilities have stressed the need to promote the labour market integration of disabled individuals as a way of facilitating their broader integration in the society. The pre-conception that disability completely disables the individual for any kind of job is totally unfounded and some effort should be made in order to analyze how their abilities can be matched with labour market opportunities (OECD, 2003).

For these reasons, the possibility of increasing the number of disabled people that work is regarded as a good way to decrease the pressures on the financial stability of the social security system as well as to reach the social integration of disabled individuals.

As the OECD puts it; "Helping (disabled) people to work is potentially a "win-win" policy: it helps people avoid exclusion and have higher incomes while raising the prospect of more effective labour supply and higher economic output in the long term" (OECD, 2007a).

This seems to be a reasonable policy objective specially if we take into account two current developments that will provide new opportunities; on the one hand, medical advances will open up the possibilities for disabled people to stay healthier at older ages while, on the other hand, technological innovations will facilitate the adaptation of the working environment to the special requirements of the disabled.

\footnotetext{
${ }^{28}$ This chapter is based on: Vall-Castello, J. (2010). Promoting Employment of Disabled Women in Spain: Evaluating a Policy. FEDEA Working Paper 2010-10, Madrid, Spain.

64
} 
However, there are several entry barriers to the labour market that individuals with disabilities face, which partially explain the low employment rates of this group of people:

1. Physical barriers: adaptation of the working space.

2. Stigma: prevents disabled individuals from receiving job offers.

3. Mismatch: the job search process is more complicated as it is more difficult to receive the "adequate" job offer; employers don't know the specificities of the disabling condition nor the way in which they will affect the type of job that they offer.

Therefore, there is a need for new specific policies that take into account all the specificities explained above in order to ensure their effectiveness and the real integration of the disabled into the labour market and into society.

The promotion of employment of disabled individuals is particularly relevant for the Spanish case and, in 2007, the OECD identified it as the most "formidable" challenge facing the Spanish government with respect to disability policies (see Figure 21). This is mainly due to two reasons: the significantly lower employment rates of disabled individuals in Spain with respect to other OECD countries and the higher proportion of older workers in the disability scheme. In that sense, $70 \%$ of all disabled individuals receiving disability benefits in Spain are on the age range of 50-64 years old (see Figure 22).

In terms of employment rates of disabled individuals, they have remained quite low at a $30 \%$ level ${ }^{29}$ even if GDP growth has been quite high at around 2-6\% during the last ten years and the general unemployment rate has dropped from $20 \%$ to $9,2 \%{ }^{30}$. This employment rate of $30 \%$ is one of the lowest in the OECD, where employment rates for disabled individuals are $45 \%$ in the UK, $40 \%$ in Australia, $50 \%$ in Luxembourg, $45 \%$ in Norway or $52 \%$ in Switzerland (see Figure 23).

\footnotetext{
${ }^{29}$ The general employment rate has increased by $7 \%$ in the last 5 years. Employment rates stand at $65 \%$ (at the OECD average). 3,5\% of the Spanish population is receiving disability benefits.

${ }^{30}$ Unemployment rates of disabled individuals have also remained constant at $15 \%$.
} 
Figure 21 Calibration of the magnitude of several challenges in disability policies.

\begin{tabular}{|c|c|c|c|c|}
\hline \multicolumn{5}{|c|}{ The magnitude of the policy challenge in Australia, Luxembourg, Spain and the United Kingdom, 2007} \\
\hline Seven key policy challenges ${ }^{a, b}$ & Australia & Luxembourg & Spain & $\begin{array}{c}\text { United } \\
\text { Kingdom } \\
\end{array}$ \\
\hline 1) Controlling incapacity-related public spending & ++ & +++ & ++ & ++ \\
\hline $\begin{array}{l}\text { 2) Raising employment rates for people with health } \\
\text { problems }\end{array}$ & +++ & + & ++++ & ++ \\
\hline $\begin{array}{l}\text { 3) Tackling lower incomes of households with disabled } \\
\text { people }\end{array}$ & +++ & + & ++ & ++ \\
\hline $\begin{array}{l}\text { 4) Reducing the inflow into sickness and disability } \\
\text { benefits }\end{array}$ & ++ & ++ & ++ & ++++ \\
\hline $\begin{array}{l}\text { 5) Addressing the increasing medicalisation of labour } \\
\text { market problems }\end{array}$ & ++ & ++ & + & +H \\
\hline $\begin{array}{l}\text { 6) Raising the outflow from usually permanent } \\
\text { disability benefits }\end{array}$ & +++ & +++ & ++ & ++ \\
\hline $\begin{array}{l}\text { 7) Strengthening co-ordination across different benefit } \\
\text { schemes }\end{array}$ & ++ & +++ & +++ & ++ \\
\hline \multicolumn{5}{|c|}{$\begin{array}{l}\text { a) The scales should be interpreted as follows: }+\ldots \text { minor challenge; }++\ldots \text { moderate challenge; }+++\ldots \text { substantial } \\
\text { challenge; and }++++\ldots \text { formidable challenge. } \\
\text { b) Public spending on sickness and disability benefits excludes employer-paid wage payments in the first weeks } \\
\text { of absence. Relative poverty is defined as the share of persons with incomes below } 50 \% \text { of the median income of } \\
\text { the entire population. } \\
\text { Source: OECD, } 2007 \text { a. }\end{array}$} \\
\hline
\end{tabular}

Figure 22 Disability recipients by age and gender as a share of total disabled individuals, 2005

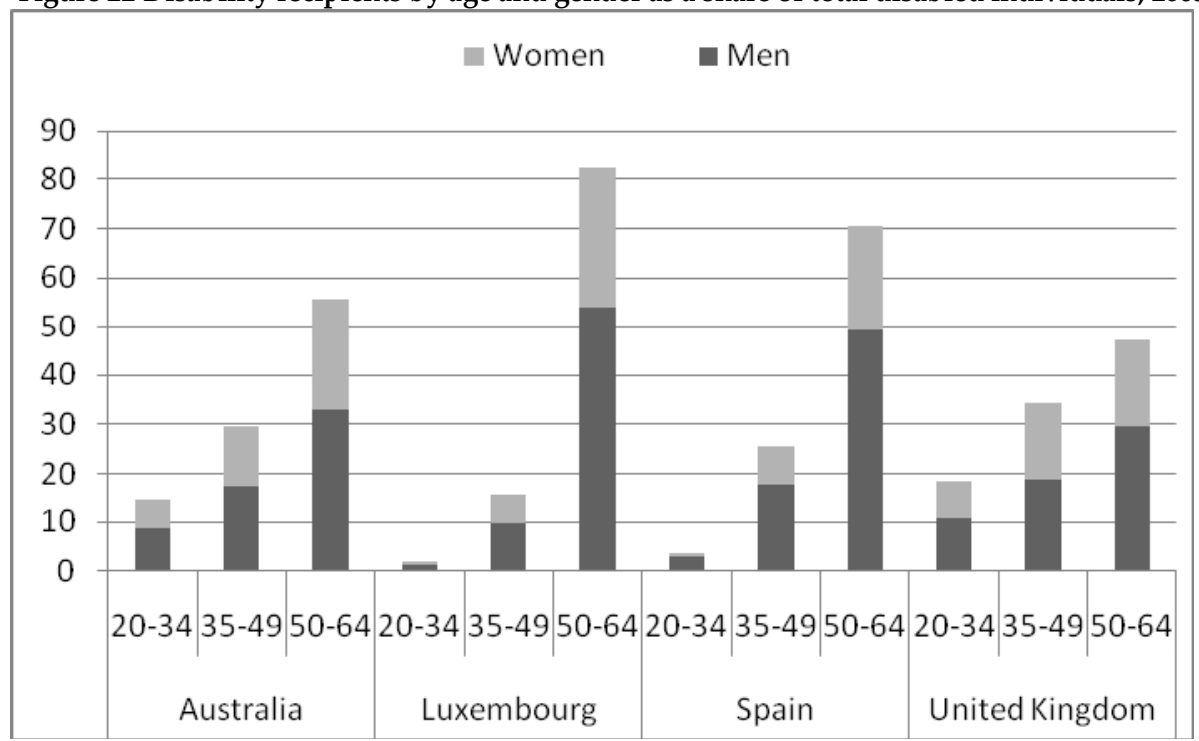

Source: OECD 2007a; National authorities: DEWR Australia; IGSS Luxembourg; MTAS Spain; DWP United Kingdom.

66 
Figure 23 Employment rates of disabled individuals

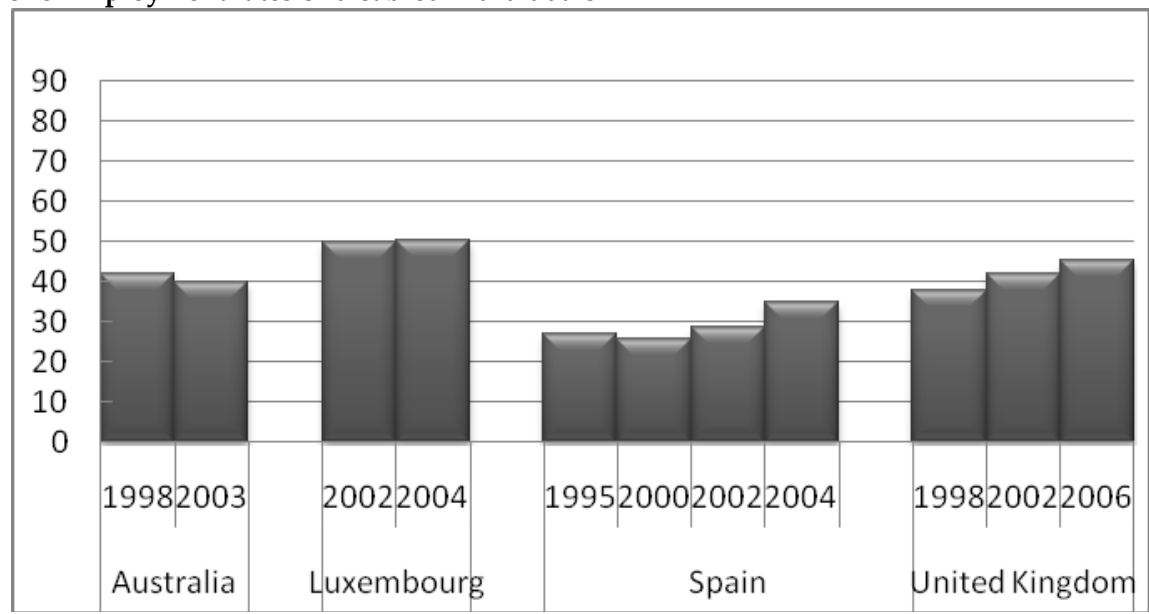

Source: OECD 2007a.

Furthermore, spending on disability benefits has been quite high in Spain and it stood at 1,2\% of GDP in 2005. This is an important quantity as, for example, unemployment-related expenditures reached 2,5\% of GDP in 2005. However, unemployment policies have traditionally raised much more attention among researchers and policy makers than disability policies.

Having revised the evolution of the main characteristics of disability policies and after highlighting the main challenges regarding the labour market integration of disabled individuals in Spain, the aim of this chapter is to understand the way in which a particular change in employer's incentives (an increase in the deductions of employer's social security contributions for hiring disabled women) affects employment rates of disabled women ${ }^{31}$.

In order to do that, we first explore the characteristics and evolution of the group of individuals that is the focus of our research, i.e. individuals receiving a permanent disability pension, in order to get some insights on the evolution of their labour market participation from 1996 until 2007. In doing that, we realize the possibility of having differential trends between men and women in our sample before the implementation of the policy in 2004. If this is so, the basic assumption of traditional difference-and-difference models would not be fulfilled. Therefore, when we proceed to the econometric analysis of the effectiveness of the policy measure in increasing employment of disabled women, we condition on any preexisting trends. When describing the characteristics of our sample, we also

\footnotetext{
31 There are also other employment promotion measures in place for disabled individuals such as a $2 \%$ quota for firms of more than 50 employees and a subsidy for firm's that hire a disabled worker. However, the $2 \%$ quota threshold is not implemented by Spanish firms and the authorities do not enforce the fulfillment of this quota system.
} 
realize that disabled women suffer from a double discrimination in the labour market as they have a much lower probability of working than disabled men. This observation reinforces the need to introduce policy initiatives that aim at counterbalancing this discrimination.

At the same time, another important issue to take into consideration is the crucial role that will be played by the different degrees of disability benefits available in the Spanish system that entail different working restrictions as well as pension amounts. For this reason, we choose a bivariate probit model as our estimation strategy to be able to model the employment situation and the type of pension received in a simultaneous way. The final goal of the research is to draw some conclusions on the type of policy initiatives that could be more effective in promoting employment among disabled individuals.

The present work contributes to the literature in two dimensions. First, it estimates the employment effects of a policy change that has never been analyzed before as an employment promotion tool for disabled individuals. Although there have been studies that have focused on the estimation of anti-discrimination legislation and quotas with respect to disabled workers, we are not aware of any studies that analyze the effects of deductions on the social security contributions for employers on the employment prospects of disabled individuals.

Second, we try to fill in the information gap existing in Spain with regards to the labour market behavior of disabled individuals and its evolution over time. There are only three cross-sectional surveys focusing on disabled individuals and only one of them pays special attention to the relation between disability and work (EDAD 1999 and 2008 and EPA 2002). Therefore, there is a lack of information on the evolution of employment rates of disabled individuals over time. To our knowledge, we are the first ones to use a longitudinal database on disability benefits to shed some light on the composition and labour market situation of permanent disability pensioners in the Spanish economy.

The chapter proceeds as follows: section 2 explains the disability system in Spain and the compatibility of the benefits with paid work. Section 3 reviews the main literature focusing on the combination of disability benefits and a job and on the type of policies that can be introduced to foster employment of disabled individuals. Section 4 presents the data used while section 5 includes some descriptive statistics which allow us to draw a number of conclusions of the evolution of the population receiving disability benefits in Spain. Section 6 explains the econometric approach used in the analysis and presents the main results and section 7 introduces some robustness checks. Finally, the main conclusions and policy recommendations are derived in the last part of the chapter, section 8 . 


\subsection{Types of disability benefits \& compatibility with a job}

In Spain, permanent contributive ${ }^{32}$ disability benefits are defined as the economic benefits that aim at compensating the individual for losing a certain amount of wage or professional earnings when the person is affected by a reduction or a complete loss of his/her working ability in a way that is assumed to be permanent due to the effects of a pathologic or traumatic process derived from an illness or an accident ${ }^{33}$.

In order to capture the different situations in which a person can be after suffering from a disabling condition, the Spanish Social Security administration differentiates between four degrees of disability that depend on the amount of working capacity that has been lost:

Permanent Limited disability for the usual job: is the kind of disability that, without reaching the level of partial disability, causes a decrease to the individual of at least $33 \%$ of the standard performance for his/her usual job but the individual is still able to develop the fundamental tasks of his/her usual job or professional activity.

Permanent Partial disability for the usual job (PD): is the kind of impairment that disables the individual to develop all or the fundamental tasks of his/her usual job or professional activity but the individual is still capable of developing a different job or professional activity.

Permanent Total disability for all jobs (TD): is the kind of impairment that disables the individual for the development of any kind of job or professional activity.

Severe disability: is the situation for which, as a result of anatomic or functional loses, the individual needs the assistance of a third person to develop the most essential acts of live such as eating, moving, etc...

Therefore, the degree of disability in which the individual is classified is set in relation to the working capacity lost as the goal of the benefits is to compensate for the reduction on wages or professional earnings caused by the disabling

\footnotetext{
32 Please note that, for the purpose of this paper, we only focus on contributive benefits, that is, economic benefits that require having contributed to the Social Security before becoming disabled (employed or receiving unemployment benefits). The reasons are; data availability problems for noncontributory pensioners and the idea that disabled individuals that have worked before are probably in a better position to find a new job.

33 Own translation of the definition of permanent disability given by the Spanish Social Security administration at www.seg-social.es.
} 
condition. The amount of pension received varies according to the disability degree in which the individual is classified. For example, individuals in the partial disability scheme receive, in general, $55 \%$ of the regulatory base (which is an average of the last salaries) because they are assumed to get some income from work that would allow them to reach a similar amount of money than before becoming disabled ${ }^{34}$. On the contrary, total disability benefits provide a $100 \%$ of the regulatory base as the individual is considered to have lost all his/her ability to work and, thus, is (in principle) unable to get any extra income from work.

However, when defining the compatibilities of each of these kinds of benefits, the Social Security administration states that the receipt of a total disability pension will not impede the development of those activities (both paid and unpaid) that are compatible with the disability status of the individual and that do not represent a change in his working ability.

Therefore, it can be concluded from this revision of the legislation that both partial and total disability pensioners are entitled to take up a job if the characteristics of it are in accordance with the definition of the type of disability that has been described above. At the same time and in line with the definitions, it seems clear that total disability holders will have a lower capacity to work than partial disability pensioners.

However, as it will be shown in the descriptive statistics of the next section, even if disability pensioners in Spain are "legally" given the option to combine the disability pension with a job, the data analysis reveals that most of the disabled individuals in Spain are, in fact, not working.

As our interest lies on the effectiveness of a policy initiative in increasing employment of disabled individuals, we restrict our analysis to disabled individuals in the partial and total disability schemes. We have included total disability holders because, even if these individuals have more restrictions to work, we observe in the data that some of them do work and we considered that it was important to include them. We don't include Limited disability holders because they are allowed to continue in their previous job and the benefit given is paid only in one installment so that there are really no incentives/disincentives to work to analyze.

\footnotetext{
${ }^{34}$ For individuals in the partial disability scheme, this $55 \%$ increases to a $75 \%$ at the age of 55 years old if the individual is found to be unlikely to find a job. This disincentive to work is studied in the following chapter. See Table 18 below for a summary on the way in which the pension amount is calculated. 


\subsection{Disability and work: A survey}

The literature that assesses the effects of policy initiatives that try to promote employment rates of disabled individuals has mainly focused on antidiscrimination legislation and has been concentrated both on the Americans with Disabilities Act (ADA), which was introduced in 1990 in the United States of America, and on the Disability Discrimination Act of 1995 in the UK.

Taking advantage of the different timing on the implementation of the ADA in numerous states, two groups of authors find opposing results of the effects of the introduction of this policy. On the one hand, DeLeire (2000), Acemoglu and Angrist (2001) and Beegle and Stock (2003) conclude that ADA has not increased employment for disabled individuals whereas, on the other hand, Kruse and Schur (2003) argue that these findings result from the imprecise information on disability status used by the authors and warn that the results must be interpreted with care and are not conclusive. Jolls and Prescott (2004) and Jolls (2004) find that the main effect of ADA was the increase in the returns on education which, in turn, raised education participation of disabled individuals as well as their employment prospects.

The results obtained by the first set of authors about the introduction of ADA in the USA coincide with the findings of Bell and Heitmueller (2005) for the UK Disability Discrimination Act in the sense that the authors are not able to find any significant impact on employment prospects for disabled individuals after the introduction of this new anti-discrimination legislation.

Another two studies focus on the evaluation of an alternative policy initiative to promote employment for disabled individuals; the introduction of disabled vs. non-disabled quotas for employees. First, Wagner et al. (2001) analyze the impact of employment quotas on job dynamics in 400 small firms in Germany and they find no effect of the quota threshold. In a more recent paper, Lalive et al. (2009) analyze increases in the demand for disabled workers of an employment quota introduced in Austria in 1969 that required firms to hire at least one disabled individual per 25 non-disabled employees. If firms failed to comply with this obligation they were subject to the payment of a tax for each unfilled quota slot. The authors exploit the discontinuous change in financial incentives for firms below and above the quantities of the quota threshold $(25,50,75 \ldots)$ with a regression discontinuity approach model and find that the elasticity of substitution between disabled and non-disabled workers is around 2.4 for the first threshold (and 0.7 for higher thresholds). However, they also note that this change does not 
occur in the short-term as firms need some time to comply with employment quota rules.

They also find different effects for different firms and sectors of the economy; firms paying higher wages seem to have a lower response to the quota requirements as the monetary non-compliance fine is defined per-head. Firms in the manufactures sector show the strongest effect to the quota requirements while services and construction firms lie below the average effect. The authors attribute these differences between sectors of the economy to the role of technology in facilitating the accommodation of disabled workers.

Even if the evaluation of policy initiatives to increase employment of disabled workers has captured some attention among USA and European researchers, in Spain the majority of studies that include an analysis of the disability system are centered on the evaluation of the use of the disability scheme as an alternative exit route from the labour force, particularly for older workers approaching retirement (see, for example, Blanco (2000), Jimenez et al. (2006 \& 2009).

Yet these kinds of studies are exclusively focused on entries into disability, disregarding the labour market trajectory of these individuals once they are accepted in the scheme. We are aware of only one paper by Malo et al. (2007) that uses Spanish data and focuses on the possibilities for disabled individuals to combine the receipt of the benefits with the development of a job once the individual starts receiving a disability pension. Using a cross-sectional sample for 2006, they estimate logistic regressions in order to analyze the variables that affect the probability of combining a disability pension with a job. However, their paper is mainly a descriptive study which does not include any analysis of employment promotion policies.

Therefore, there are no previous studies analyzing the effect of employment promotion measures for disabled individuals in Spain, which is partly due to the lack of data availability as well as to the lack of compliance of the $2 \%$ employment quota required for Spanish firms with more than 50 employees.

\subsection{Database and sample selection}

The study will use the Continuous Sample of Working Lives ("Muestra Continua de Vidas Laborales", MCVL) which is a microeconomic data set of the Spanish Social Security Administration. It contains a random sample of $4 \%$ of all the individuals who, at some point during 2007, had contributed towards the social security system. 
There is information available on the entire employment and pension history of the workers and several variables that describe the characteristics of the job or the unemployment/disability benefits. The macroeconomic variables used to capture the economic business cycle are from the Spanish "Instituto Nacional de Estadistica".

We select in our sample all individuals who are receiving a partial or total disability pension in 1996-2007. The pooled sample contains 49.989 individuals, of which 34.357 are men and 15.632 women. As new individuals become disabled and start receiving disability benefits each year, the sample is growing from an initial size of 19.961 individuals in 1996 up to 31.737 individuals in 200735. We include individuals from 17 to 64 years old. We don't include ages above 64 years old as all disabled individuals are automatically transferred to old-age benefits when they reach age 65 . Therefore, individuals leave the sample mainly because they reach age 64 and also, few individuals leave because they stop receiving the disability pension (only $0,15 \%$ of the sample).

\subsection{Descriptive statistics}

From Table 11 below we can derive the main characteristics of the sample. It is composed by a majority of men, as only $28.8 \%$ of the observations are from women, and by low educated individuals, as half of the observations come from individuals who dropped out of education before finishing high school, $23 \%$ of the individuals hold a high school diploma (or equivalent) and only $9 \%$ of the sample is composed by people with a bachelor's degree and other higher education ${ }^{36}$. Our data confirms some of the observations highlighted in the OECD report such as the fact that disabled individuals in Spain are relatively old, as the average age of disabled individuals in our sample is 53.4 years old. They also appear to be a relatively poor group, as our data shows that the average monthly pension is 624 euro. However, this quantity varies substantially among individuals, as $55 \%$ of them receive a pension below 500 euro/month, 40\% get between 500 and 1500 euro/month and $4.6 \%$ receive a pension above 1500 euro/month.

\footnotetext{
${ }^{35}$ See Table 17 in the appendix to see the number of individuals each year in the sample.

36 These percentages are very close to the ones found in the EDAD-1999 and EDAD-2008 surveys of disabled individuals in Spain, which are based on a broader sample of the disabled population than our sample (as our sample only includes permanent \& contributory disability pensioners).
} 
Table 11 Summary statistics selected variables.

\begin{tabular}{r|rrrrr} 
Variable & Obs & Mean & Std. Dev. & Min & Max \\
\hline Female & 294366 & .2881345 & .4528948 & 0 & 1 \\
Educ. level1 & 294366 & .5139962 & .4998049 & 0 & 1 \\
Educ. level2 & 294366 & .2366748 & .4250417 & 0 & 1 \\
Educ. level3 & 294366 & .0931018 & .2905755 & 0 & 1 \\
Age & 294366 & 53.45321 & 8.801795 & 17 & 64 \\
Pension & 294366 & 624.0395 & 451.7436 & 0 & 17227.91 \\
P. 0-500 & 294366 & .5564365 & .4968056 & 0 & 1 \\
P. 500-1500 & 294366 & .3967951 & .4892337 & 0 & 1 \\
P.Above 1500 & 294366 & .0467683 & .2111426 & 0 & 1 \\
Age Disabil. & 294366 & 46.12592 & 10.11334 & 10 & 64
\end{tabular}

Therefore, if these individuals do not have any other source of income, such as a job, we can expect to have high poverty rates among disabled individuals, as more than half of the sample earn a monthly pension well below the Spanish minimum wage, which was set at 624 euro for $2009^{37}$.

At the same time, according to our data, the financial resources available to disabled individuals that work are, on average, $46 \%$ higher than those of disabled without a job. Therefore, a policy that is effective in increasing the labour market prospects of disabled individuals and that helps them in finding a job, not only increases their social integration, but it also prevents them from falling into poverty.

Table 12 presents the summary statistics according to working/not working observations. It can be observed that disabled individuals that work are mainly men, a bit more educated, young and with a slightly lower pension amount, who become disabled at a younger age. Thus, both the current age as well as the age at which he/she becomes disabled, appear to be important factors in determining their chances to find a job.

\footnotetext{
${ }^{37}$ The minimum wage in Spain was 390,18 euro in 1996; 424,8 in 2000 and 490,80 in 2004.
} 
Table 12 Summary statistics selected variables by working status

\begin{tabular}{|c|c|c|c|c|c|}
\hline Variable & Obs & Mean & std. Dev. & Min & $\operatorname{Max}$ \\
\hline Female & 268930 & .3043245 & .4601216 & 0 & 1 \\
\hline Educ. levell & 268930 & .5277507 & .4992302 & 0 & 1 \\
\hline Educ. level2 & 268930 & .2247165 & .4173962 & 0 & 1 \\
\hline Educ. level3 & 268930 & .0910572 & .2876909 & 0 & 1 \\
\hline Age & 268930 & 54.05436 & 8.509114 & 17 & 64 \\
\hline Pension & 268930 & 635.1704 & 458.4892 & 0 & 17227.91 \\
\hline P. $0-500$ & 268930 & .5464507 & .4978386 & 0 & 1 \\
\hline P. $500-1500$ & 268930 & .4038114 & .4906614 & 0 & 1 \\
\hline P.Above 1500 & 268930 & .0497378 & .2174032 & 0 & 1 \\
\hline Age Disabil. & 268930 & 46.90183 & 9.790287 & 10 & 64 \\
\hline \multicolumn{6}{|l|}{ WORKING : } \\
\hline Variable & Obs & Mean & std. Dev. & Min & Max \\
\hline Female & 25436 & .1169602 & .3213792 & 0 & 1 \\
\hline Educ. levell & 25436 & .3685721 & .482427 & 0 & 1 \\
\hline Educ. level2 & 25436 & .3631074 & .4809049 & 0 & 1 \\
\hline Educ. level3 & 25436 & .1147193 & .3186891 & 0 & 1 \\
\hline Age & 25436 & 47.09734 & 9.317987 & 18 & 64 \\
\hline Pension & 25436 & 506.3546 & 352.1352 & 0 & 10275.09 \\
\hline P. $0-500$ & 25436 & .6620145 & .4730329 & 0 & 1 \\
\hline P. $500-1500$ & 25436 & .3226136 & .4674855 & 0 & 1 \\
\hline P.Above 1500 & 25436 & .0153719 & .1230293 & 0 & 1 \\
\hline Age Disabil. & 25436 & 37.92239 & 9.82861 & 15 & 64 \\
\hline
\end{tabular}

If we make use of the time series dimension of the data, we can see that the number of disabled individuals (both men and women) has increased over time since 1996 (see Table 17) but the percentage of disabled men/women has remained quite stable. Similarly, the proportion of individuals with a partial/total disability pension in the sample has also remained constant during these years (see Figure 24). This stability in the composition of the sample reinforces the idea that no major changes have occurred in the evolution of the characteristics of the sample during this period. 
Figure 24 Evolution of the percentages of women and total disability pensioners in the sample.

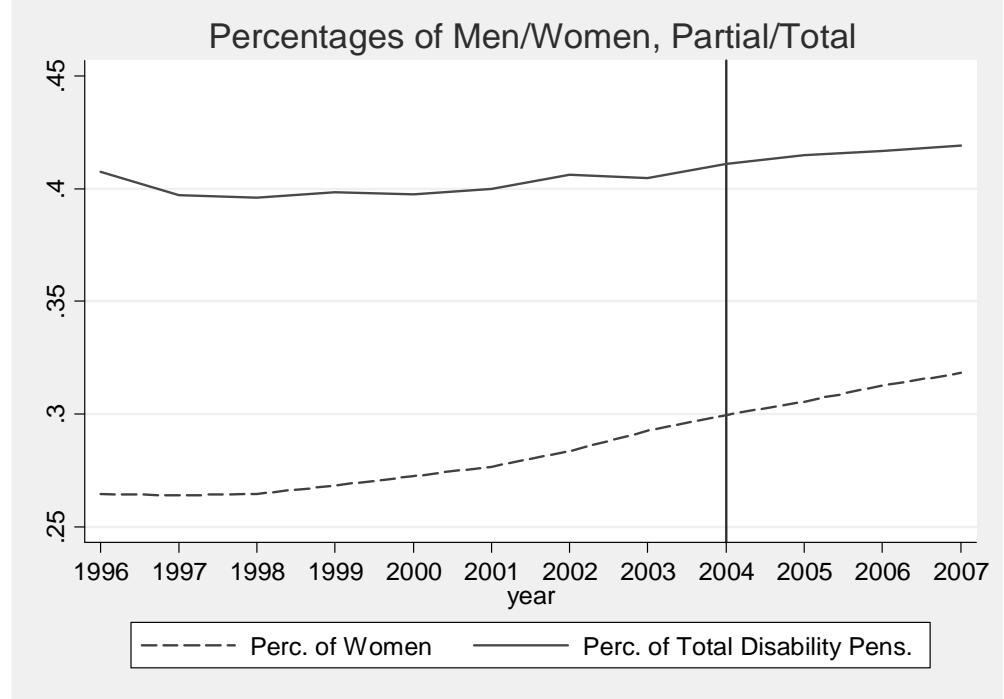

The probability of working for disabled individuals has also increased over the sample period, both for men and women. This probability has been calculated performing a series of cross-sectional probit estimations and predicting the probability of working for each year and for each sub-group of the population studied ${ }^{38}$.

Even if it is increasing, the probability of working for disabled individuals is quite low and it reaches its maximum value, which is only 12\%, in 2007 (see Figure 25). Disabled women have a much lower probability of working than disabled men (approximately half), which can be compared in Figure 26 and Figure 27. This observation reinforces the idea of the need to introduce policy initiatives that are particularly targeted to disabled women and that are designed to increase their labour market prospects in order to reverse this discrimination problem that they suffer in the Spanish labour market.

\footnotetext{
${ }^{38}$ Please note that no covariates are included in this model so that there are no controls for the several different sources of heterogeneity, which will be introduced in the econometric section below. 
Figure 25 Evolution of the probability of working for disabled individuals in our sample

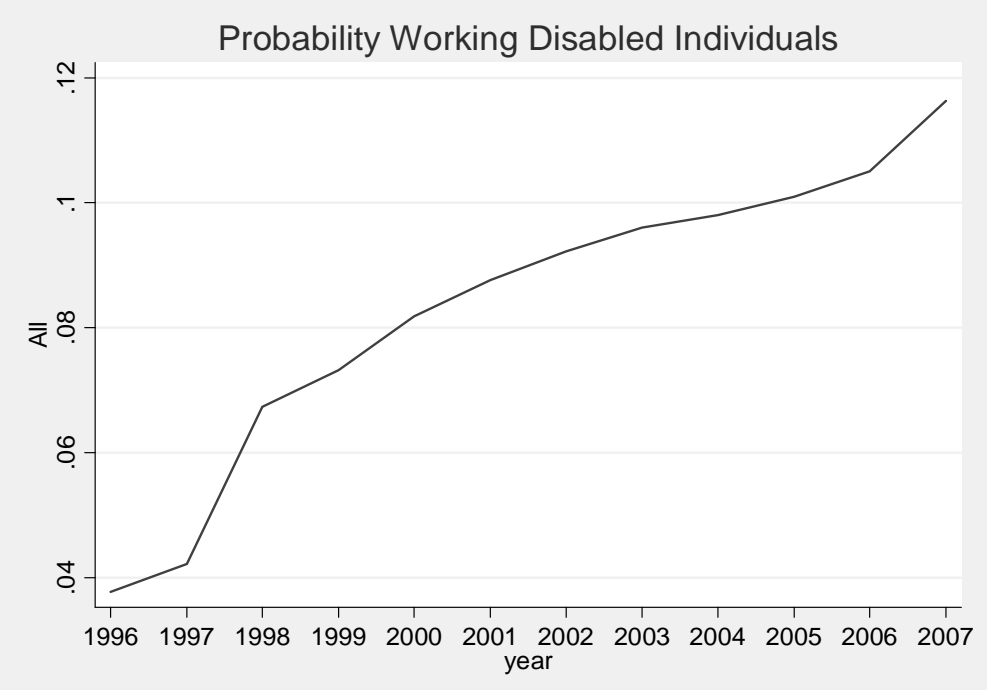

Figure 26 Evolution of the probability of working for disabled women in our sample

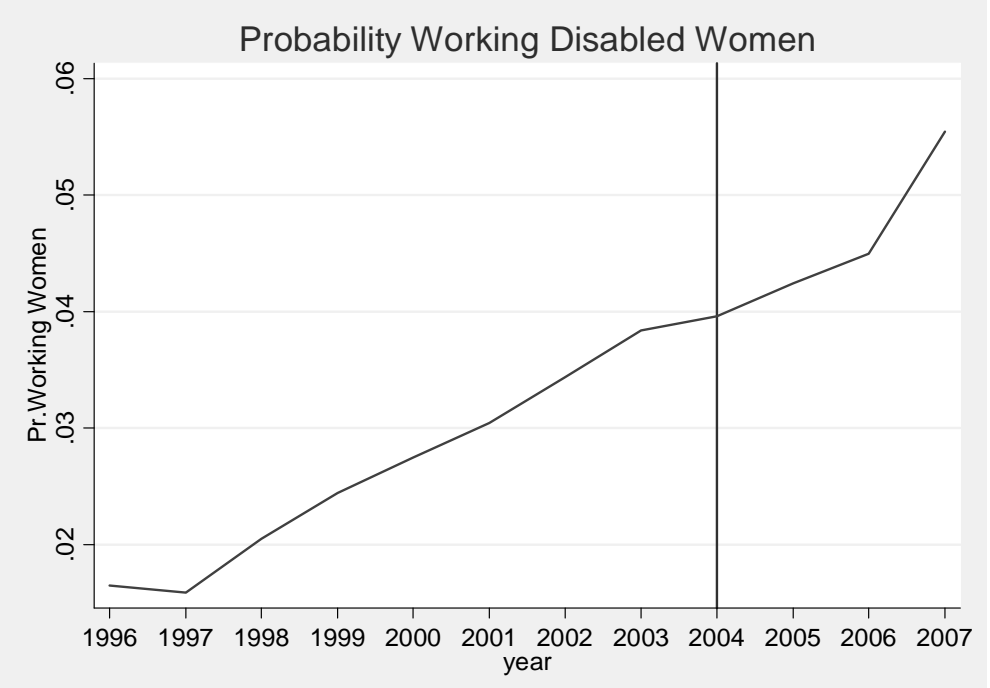


Figure 27 Evolution of the probability of working for disabled men in our sample

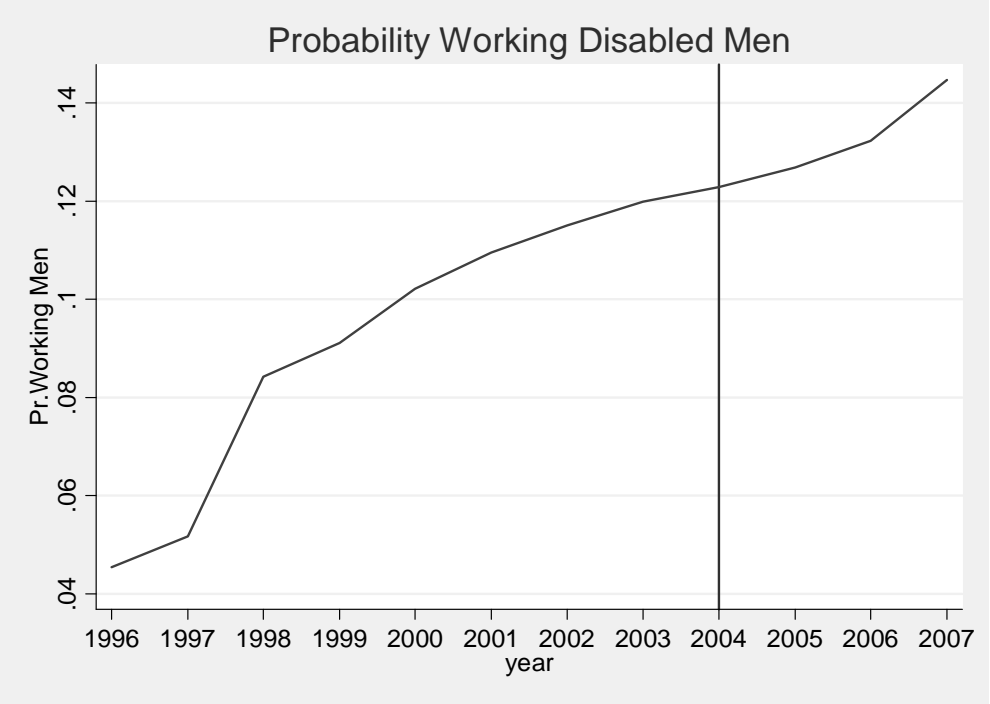

\subsection{Econometric analysis}

\subsubsection{The baseline model}

Given that, as explained above, individuals can receive two different types of benefits which are defined according to the remaining capacity to work kept by the disabled individual and, in order to take into account in the estimation the number of individuals in each of these two types of benefits, we have chosen to use a bivariate probit model as the estimation method. This model allows us to estimate movements in the labour market and between types of pension simultaneously and to incorporate the correlation in residuals of the two equations due to unobserved characteristics (such as the effective remaining "capacity to work").

In order to introduce the policy variables, we have constructed a table (Table 13) which contains a summary of the major reforms implemented by the Spanish central government in order to provide incentives for firms to hire disabled individuals. The majority of these incentives were first established in 1983 following what was ruled in 1982 by the (very important) law "Ley de Integracion Social de los Minusvalidos" (Social Integration of the Disabled). The LISMI, as it was later called, set up the basic pillars of public policies towards disabled individuals in terms of anti-discrimination and employment promotion measures which were later converted into concrete measures in 1983 in the form of a 78 
statutory order. In terms of employment protection, the 1983 statutory order introduced the requirement for firms with more than 50 employees to have at least $2 \%$ of disabled workers among their employees ${ }^{39}$. On the other hand, as employment promotion measures, it established a subsidy of 500.000 pessetas (3.012 euros) for each disabled worker that the firm hired, as well as a $70 \%$ deduction of the social security contributions for each disabled worker younger than 45 years old that was hired or a $90 \%$ deduction if the individual was older than 45 years old.

After the LISMI was implemented, only some minor changes were introduced up until 2004, when a differential treatment for disabled women was introduced in the measures directed towards promoting the labour market integration of disabled workers. Therefore, deductions to the Social Security contributions to hire disabled women were increased from 70 to $90 \%$ for women below 45 years old and from 90 to 100\% for women aged 45 and over. Apart from this reform in 2004, there was a substantial reorganization of the packet of firms' incentives in 2006 when deductions were changed from a percentage to a fixed amount of the monthly contribution that the employer has to pay to the administration for each disabled individual. However, this reform in 2006 did not involve any increase in the deductions previously given and, instead, it only changed the way in which these deductions were computed from a percentage to a fixed amount. Therefore, we are confident that this reform did not entail changes in the hiring behavior of employers and will not interfere in our identification strategy of the policy effects of the increase in the deductions for disabled women in 2004.

Figure 26 and Figure 27 above plot the probability for individuals in the sample to have a job for each calendar year from 1996 until 2007. These figures seem to suggest an acceleration of the increase in the probability for disabled women to have a job from 2004 onwards while the probability for disabled men to have a job seems to grow at a relatively constant rate for the entire period.

\footnotetext{
${ }^{39}$ However, it is well known in Spain that this employment quota is not implemented by employers and that there are no monitoring or punishment mechanisms in place.
} 
Table 13 Legislative reforms in firm's incentives in Spain.

\begin{tabular}{|c|c|c|c|c|c|}
\hline Years & $\begin{array}{l}\text { Type of } \\
\text { Incentive }\end{array}$ & $\begin{array}{l}\text { Permanent \& Full- } \\
\text { time contract }\end{array}$ & $\begin{array}{l}\text { Temporary } \\
\text { contract } \\
\text { (part or full- } \\
\text { time) }\end{array}$ & $\begin{array}{l}\text { Permanent \& Part- } \\
\text { time contract }\end{array}$ & Self-employed \\
\hline \multirow{2}{*}{$\begin{array}{l}\text { Status } \\
\text { Quo: } \\
1983\end{array}$} & $\begin{array}{l}\text { Subsidy1 } \\
\text { Subsidy2 }\end{array}$ & $\begin{array}{l}500.000 \text { ptas/contract } \\
\text { Avoid accidents }\end{array}$ & & & \\
\hline & $\begin{array}{l}\text { Deductions SS } \\
\text { contributions }\end{array}$ & $\begin{array}{l}70 \% \text { if }<45 \\
90 \% \text { if }>=45\end{array}$ & & & \\
\hline \multirow[b]{2}{*}{$\begin{array}{l}1999 \\
\text { (Jan) }\end{array}$} & Subsidy1 & 650.000 ptas/contract & & Proportional to $\mathrm{h}$ & \\
\hline & $\begin{array}{l}\text { Deductions SS } \\
\text { contributions }\end{array}$ & & & $\begin{array}{l}70 \% \text { if }<45 \\
90 \% \text { if }>=45\end{array}$ & \\
\hline \multirow[t]{2}{*}{$\begin{array}{l}2002 \\
(\mathrm{Dec})\end{array}$} & $\begin{array}{l}\text { Deductions in } \\
\text { firm's taxes }\end{array}$ & $\begin{array}{l}6.000 \text { euro for each } \\
\text { person/year of } \\
\text { increase over the } \\
\text { mean of disabled } \\
\text { workers wrt mean of } \\
\text { non-disabled }\end{array}$ & & $\begin{array}{l}6.000 \text { for each } \\
\text { person/year of } \\
\text { increase over the } \\
\text { mean of disabled } \\
\text { workers wrt mean } \\
\text { of non-disabled } \\
\end{array}$ & \\
\hline & $\begin{array}{l}\text { Deductions SS } \\
\text { contributions }\end{array}$ & & & & $50 \%$ for 3 years \\
\hline \multirow{3}{*}{$\begin{array}{l}2004 \\
\text { (Jan) }\end{array}$} & $\begin{array}{l}\text { Deductions SS } \\
\text { contributions }\end{array}$ & $\begin{array}{l}90 \% \text { if }<45 \& \text { women } \\
100 \% \text { if }>=45 \& \\
\text { women }\end{array}$ & & $\begin{array}{l}90 \% \text { if }<45 \& \\
\text { women } \\
100 \% \text { if }>=45 \& \\
\text { women }\end{array}$ & \\
\hline & Subsidy1 & $\begin{array}{l}3.907 \text { eur/contract } \\
\text { (no change) }\end{array}$ & & Proportional to $\mathrm{h}^{40}$ & \\
\hline & Subsidy2 & $\begin{array}{l}\text { Avoid accidents \& } \\
\text { adjust working } \\
\text { space } \\
\text { (max.901,52eur) }\end{array}$ & $\begin{array}{l}\text { Avoid } \\
\text { accidents \& } \\
\text { adjust working } \\
\text { space }\end{array}$ & & \\
\hline $\begin{array}{l}2006 \\
(\mathrm{Dec})\end{array}$ & $\begin{array}{l}\text { Deductions SS } \\
\text { contributions }\end{array}$ & $\begin{array}{l}375 \text { euro/month } \\
425 \text { if severe } \\
\text { disability } \\
+100 \text { if }>=45 \text { years } \\
+70,83 \text { if women }\end{array}$ & $\begin{array}{l}291,66 \text { euro/ } \\
\text { month } \\
341,66 \text { if severe } \\
\text { disability } \\
+50 \text { if }>=45 \\
+50 \text { if women } \\
\end{array}$ & $\begin{array}{l}{ }^{42} 100 \% \text { of full-time } \\
\text { if } \mathrm{h}=3 / 4 \\
75 \% \text { if } 1 / 2>\mathrm{h}<3 / 4 \\
50 \% \text { if } 1 / 4>\mathrm{h}<1 / 2 \\
25 \% \text { if } \mathrm{h}<1 / 4\end{array}$ & $50 \%$ for 5 years \\
\hline \multirow[t]{2}{*}{$\begin{array}{c}2007 \\
\text { (June) }\end{array}$} & Subsidy3 & & & & $\begin{array}{l}\text { Establish; max } \\
10.000 \text { euro } \\
\text { External } \\
\text { Services; } 75 \% \\
\text { of cost, max } \\
2.000 \text { euro } \\
\text { Education; } \\
75 \% \text { of cost, } \\
\text { max } 3.000 \text { euro }\end{array}$ \\
\hline & $\begin{array}{l}\text { Interest rate } \\
\text { reduction }\end{array}$ & & & & $\begin{array}{l}4 \text { points : loans } \\
\text { for investment }\end{array}$ \\
\hline
\end{tabular}

\footnotetext{
${ }^{40}$ Number of working hours
}

${ }^{41}$ I will not be able to identify individuals with a severe disability, as I don't have information on the specific disability of each individual.

${ }^{42}$ Also for temporary and part-time contracts. 
Therefore, in order to identify whether the policy introduced in 2004 induced a differential change in employment for disabled women relative to disabled men, we estimate a series of difference-in-differences models. The key identifying assumption in traditional difference-in-differences models is that the change in the outcome variable of interest, $\mathrm{Y}$, in recent years would have been the same for women as it was for men in the absence of the 2004 policy change. If this assumption is correct, then the parameters $\beta$ 's capture the policy-induced change in the outcome variable $Y$. However, to the extent that differential trends in $Y$ between the group of men and women are present even prior to the policy change, this would suggest that the identifying assumptions are questioned. Therefore, and following the methodology in Autor \& Duggan (2008), we estimate a model that evaluates the existence of any shift in the trend of the outcome variable in the women relative to men sample following the policy change and conditional on any preexisting trends.

The baseline model is given by the following two equations:

$$
\begin{aligned}
& y_{j t}^{1}=\alpha^{1}+\sum_{t=1997}^{2007}\left(a_{t}^{1} \times J_{t}^{1}\right)+\gamma^{1} F_{j}^{1}+\sum_{t=1997}^{2007}\left(\beta_{0}^{1} \times F_{j}^{1} \times(t-1996)\right)+ \\
& +\sum_{t=2005}^{t=2007}\left(\beta_{1}^{1} \times F_{j}^{1} \times(t-2004)\right)+\sum_{t=1997}^{2007}\left(\eta_{t}^{1} \times Y O B \times J_{t}\right)+\varepsilon_{j t}^{1}
\end{aligned}
$$

(Equation 13) 
The first dependent variable, $y_{j t}^{1}$, captures the type of pension that the individual $\mathrm{j}$ is receiving at time $t$ and equals 0 if he/she receives a partial disability pension and 1 when it is a total disability pension. The second dependent variable, $y_{j t}^{2}$, is 0 if the individual $\mathrm{j}$ is not working at time $\mathrm{t}$ and 1 when he/she has a job.

$F_{j}$ is an indicator variable that equals 1 if individual $j$ is a female and 0 otherwise, while $\mathrm{J}_{\mathrm{t}}$ is a vector of twelve indicator variables for each of the years included in our sample. We also include interactions of these year dummies with the person's year of birth (YOB) in order to account for the different effect of the macroeconomic environment on labour force participation of disabled individuals of different cohorts (or years of birth). The $\varepsilon$ 's characterize the corresponding BVN error terms.

The parameters of interest are captured by the $\beta^{\prime} s ; \beta_{0}$ represents the preexisting trend in the women relative to the men group just before the policy change and $\beta_{1}$ captures any change in the women relative to the men trend following the policy change ${ }^{43}$. Furthermore and to the extent that the policy introduced different deductions of the SS contributions for women above and below 45, we could expect to detect a differential effect of the policy for these two age groups. We will examine this possibility by estimating separate models of the bivariate probit for two separate groups of disabled individuals ( $<$ or $=>$ age 45$)$.

In a next step, we introduce a number of covariates to the previous model to control for some personal observable characteristics that could affect both the labour market situation of disabled individuals as well as the type of pension that they receive. These covariates are the level of education, age, age at which they became disabled, immigrant from other regions of Spain, the level of the disability benefit, 3 dummies for special professional schemes (agriculture, self-employed and working accident), regional fixed effects for each of the 17 Autonomous Communities in Spain and a dummy that is 1 if the individual lives in a town of less than 40.000 citizens $^{44}$. Apart from these variables that are included in both equations of the model, we also include in the first equation two more variables that are only related to the type of pension received and act as exclusion restrictions in order to improve the identification of the parameters of the model. These variables are the percentage of Disability Evaluation Offices (DEO), which is obtained by dividing the number of disability evaluation offices in each of the 52 provinces by the population in that province, and the percentage of disability benefits granted in each Autonomous Community (AC), which is obtained by

\footnotetext{
${ }^{43}$ We take 2005 to be the first year after the policy but the results don't change that much if we use year 2004 as the first year after the policy.

${ }^{44}$ These variables are explained in more detail in the appendix section.
} 
dividing the number of benefits granted each year in each AC (17) by the population in each autonomous community. This last variable is introduced with the aim of capturing the way (rigorous/flexible) in which the health conditions are evaluated in each region ${ }^{45}$.

This choice of exclusion restrictions is based on two things; first, it seems reasonable for us to accept the assumption that these two variables will have an effect on the probability for disabled individuals of being classified as partial/totally disabled while not affecting their employment probabilities. Second, we've run simple probit models for both equations separately and have checked that these variables are, in effect, not significant when included in the employment equation.

\subsubsection{Results from the baseline model}

Table 14 presents the results of the models without the variables that capture personal characteristics. The first column provides results from the bivariate probit model for all the sample of individuals aged 17 to 64. As the results show, employment was significantly lower for women than for men at the start of the sample period in 1996. This labour market disadvantage widened between the two genders in the years prior to the policy change although the coefficient is not statistically significant $\left(\beta_{0}\right)$. After the policy was launched, this trend reversed considerably with a positive and significant coefficient for $\beta_{1}$ suggesting the fact that the policy introduced the necessary incentives for employers to hire disabled women vis-à-vis disabled men.

At the same time, results show that the policy had also an impact on the probability of receiving a total disability pension for women. At the beginning of the period, women were receiving less total disability benefits than men. However, the positive and significant $\beta_{0}$ coefficient suggests that this disparity was reduced during the years before the introduction of the policy with women receiving more total disability benefits than men. Nevertheless, once the policy was initiated, this trend reversed and women received less total disability benefits vis-à-vis men.

\footnotetext{
${ }^{45}$ We have also test to estimate the models with only one of the two exclusion restrictions and results remain the same.
} 
Table 14 Estimation bivariate probit model, all years all ages.

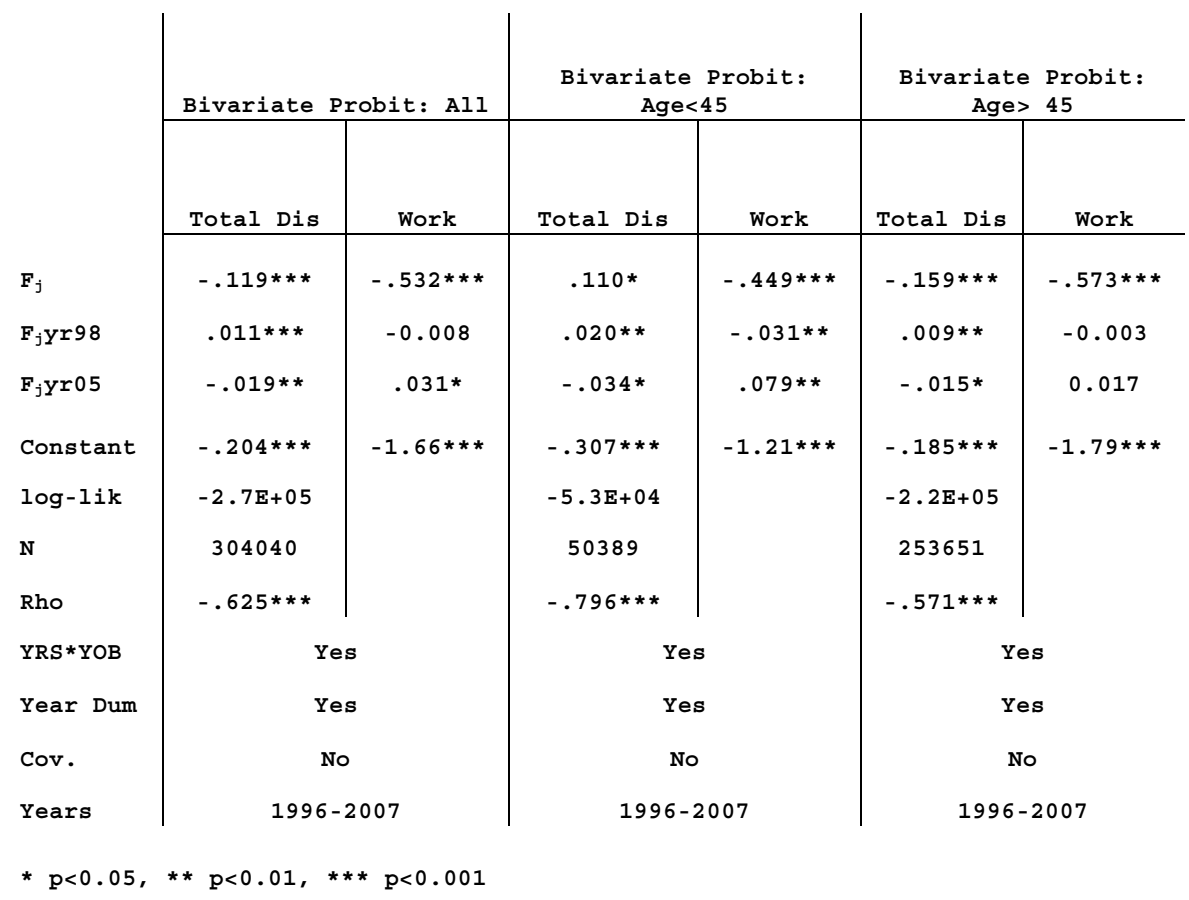

The estimated correlation coefficient between the two equations is negative and very significant which suggests the existence of unobserved factors that are relevant and that affect the probability of finding a job and the probability of receiving a total disability pension in opposite directions.

The second and third columns of Table 14 show results for the bivariate probit specification for two separate samples of individuals; younger than 45 years old, and individuals who are 45 or older. The effect of the policy in reversing a negative employment trend and increasing the labour market opportunities for disabled women are much stronger and very significant for the age group of individuals below age 45 . On the other hand, the impact of the policy seems to be insignificant for individuals who are 45 years or more. 
Table 15 Estimation bivariate probit model with covariates and exclusion restrictions, all years all ages.

\begin{tabular}{|c|c|c|c|c|c|c|}
\hline & \multicolumn{2}{|c|}{$\begin{array}{c}\text { Bivariate Probit: } \\
\text { All }\end{array}$} & \multicolumn{2}{|c|}{$\begin{array}{c}\text { Bivariate Probit; } \\
\text { Age }<45\end{array}$} & \multicolumn{2}{|c|}{$\begin{array}{c}\text { Bivariate Probit; } \\
\text { Age }>45\end{array}$} \\
\hline & Total Dis & Work & $\begin{array}{l}\text { Total } \\
\text { Dis }\end{array}$ & Work & $\begin{array}{l}\text { Total } \\
\text { Dis }\end{array}$ & Work \\
\hline$F_{j}$ & -0.017 & $-.568 * * *$ & -0.006 & $-.447 * * *$ & -0.034 & $-.622 * * *$ \\
\hline$F_{j} y r 98$ & $.015 * * *$ & -0.008 & $.035 * * *$ & -.024 * & $.013 * * *$ & -0.004 \\
\hline$F_{j} Y r 05$ & -0.006 & 0.026 & -0.019 & $.060 *$ & -0.006 & 0.016 \\
\hline Percentr & $.144 *$ & & 0.042 & & $.155 *$ & \\
\hline Percpen & $-.036 * *$ & & -0.068 & & $-.036 * *$ & \\
\hline Constant & $1.68 * * *$ & $-.687 * * *$ & $1.48 * * *$ & $-.449 * * *$ & $1.81 * * *$ & $-.747 * * *$ \\
\hline $\log -1 i k$ & $-2.3 E+05$ & & $-4.4 \mathrm{E}+04$ & & $-1.9 \mathrm{E}+05$ & \\
\hline $\mathbf{N}$ & 304040 & & 50389 & & 253651 & \\
\hline Rho & $-.601 * * *$ & & $-.769 * * *$ & & $-.547 * * *$ & \\
\hline YRS *YOB & & & & & & \\
\hline Year Dum & & & & & & \\
\hline Cov. & & & & & & \\
\hline Years & 1996 & 007 & 1996 & 2007 & 1996 & 2007 \\
\hline
\end{tabular}

* $p<0.05, * * p<0.01, * * * p<0.001$

Note: Covariates include the level of education, age, age at which they became disabled, immigrant from other regions of Spain, the level of the disability benefit, 3 dummies for special professional schemes (agriculture, self-employed and working accident), regional fixed effects for each of the 17 Autonomous Communities in Spain, a dummy if the individual lives in a town and the two exclusion restrictions: the percentage of Disability Evaluation Offices (DEO) in each of the 52 provinces and the percentage of disability benefits granted in each Autonomous Community $(\mathrm{AC})$.

Table 15 includes results of the specifications with the variables that capture personal characteristics in the model $^{46}$. In general, the results are very similar than the models without personal characteristics. However, for the bivariate probit model, the $\beta_{1}$ coefficients for the effect of the policy on the probability of finding a job for disabled women vis-à-vis disabled men are no longer significant when we include these new covariates. As there are two variables that act as exclusion restrictions (which are only included in the type of

\footnotetext{
${ }^{46}$ Covariates include the level of education, age, age at which they became disabled, immigrants from another region in Spain, the level of disability benefit, 3 dummies for special professional schemes (agriculture, self-employed and working accident), regional fixed effects, dummy for a city/town and the two exclusion restrictions: percentage of Disability Evaluation Offices in each province and the percentage of disability benefits granted in each Autonomous Community.
} 
pension equation), the results of the bivariate probit model are better identified than in Table 14.

Columns 2 and 3 of Table 15 report the results of the estimations for the sample of individuals younger than 45 years old and for the sample of individuals of 45 years or more. Again, results are pretty similar than the ones obtained in Table 14 when no personal characteristics were introduced. The main results is that $\beta_{1}$ is still positive and significant for the sample of disabled individuals below 45 years old, implying that the deteriorating trend in employment prospects that existed for disabled women before the implementation of the policy was reversed by the introduction of the policy and employment increased for women with respect to men from the year 2004 onwards for this younger group of workers.

\subsection{Robustness checks}

\subsubsection{The definition of disability}

As we have explained above, our definition of disability includes only disabled individuals who are receiving a permanent contributory disability pension, as this administrative dataset is the only source of data available for disabled individuals in Spain which is presented as a panel. However, the disadvantage of this kind of data relies on the fact that it does not cover all the population with a disabling condition (like surveys do), as it only includes disabled individuals who have worked (and contributed) at some point in their life and who have qualified to receive a disability pension.

On the other hand, administrative data has the advantage of reducing the problems involved in self-reported measures of disability, which are commonly found in surveys.

If we compare our results with the ones obtained in EDAD (survey on disabilities, deficiencies and health status), which was conducted in Spain in 1999 and 2008, we can see that employment rates ${ }^{47}$ of self-reported disabled individuals are calculated to be $24 \%$ (16\% for women and 32\% for men) in 1999 and $27 \%$ (22\% for women and $32 \%$ for men) in 2008. Both figures are higher than the ones we find in this chapter. This is quite reasonable if we take into account that there are many individuals that report having a disability in EDAD which will not qualify for receiving disability benefits (and will not be included in our sample) for two main reasons:

\footnotetext{
${ }^{47}$ This is calculated for the population aged 16-64. 
1. Their disability level does not reach the medical threshold to become a pensioner.

2. They have not worked the required time to be eligible for the pension $^{48}$.

Therefore, we think that our results have to be taken with care and interpreted as only being representative of the population receiving a permanent disability pension and not representative of the whole population with some kind of disabling condition.

\subsubsection{Alternative policy measures}

The EDAD survey conducted in 2008 also allows us to explore a bit more the utilization of other policy measures that have been introduced to promote employment of disabled individuals in Spain. The survey is answered by 22.795 disabled individuals (only 9055 below age 65), from which only 2669 are receiving a disability pension (29.5\% of disabled persons below age 65$)$.

Table 16 shows that only $0.8 \%$ of respondents say that they have benefited from an employment quota for disabled individuals in the public sector and $0.68 \%$ in the private one.

\footnotetext{
${ }^{48}$ The amount of contributory time required in order to be eligible for this type of benefits depends on the source of the disabling condition. If it is originated by an ordinary illness, eligibility to the pension requires having contributed $1 / 3$ of the time between turning 20 and the appearance of the disabling condition, with a minimum of 5 years of contribution. There is no contributive requirement if the disability is caused by an accident (whether or not work-related or by a professional illness), but you need to have contributed.
} 
Table 16 Selected results from EDAD survey

Percentage Working if ages 16-65

Are you currently working or did you work in your last job in a Special Centre for Disabled workers?

Are you working or did you work in your last job in a non-for-profit institution related to the disability sector?

Have you ever benefited from an employment quota for disabled individuals in a public sector?

Have you ever benefited from an employment quota for disabled individuals in the private sector?

Have you benefited from an employment contract specific for disabled persons?

Have you benefited from an incentive for employment or deductions to the Social Security contributions for disabled workers?

Have you benefited from any other mechanism or intervention targeted to promote access to employment for disabled people?

How did you find your current job (or the last job you had)?

Are you looking for a job? Only if age $<65$

Why do you think you are not finding a job if you are looking for one? Only if age $<65$

Why you are NOT looking for a job if age $<65$ ? (5157)

Have you felt discriminated because of your disability in your job in the last 12 months?

Have you felt discriminated to find a job because of your disability in the last 12 months?

\begin{tabular}{|ccc} 
Total & Men & Women \\
\hline $27 \%$ & $32 \%$ & $22 \%$ \\
$(2317)$ & $(1287)$ & $(1030)$ \\
$1.7 \%$ & $1.97 \%$ & $1.44 \%$ \\
$(265)$ & $(148)$ & $(117)$ \\
$2.18 \%$ & $2.36 \%$ & $2.02 \%$ \\
$(341)$ & $(177)$ & $(164)$ \\
$0.80 \%$ & $0.85 \%$ & $0.75 \%$ \\
$(125)$ & $(64)$ & $(61)$ \\
$0.68 \%$ & $0.89 \%$ & $0.48 \%$ \\
$(106)$ & $(67)$ & $(39)$ \\
$2.20 \%$ & $2.81 \%$ & $1.64 \%$ \\
$(344)$ & $(211)$ & $(133)$ \\
& & \\
$0.84 \%$ & $0.92 \%$ & $0.77 \%$ \\
$(132)$ & $(69)$ & $(63)$ \\
& & \\
$1.07 \%$ & $1.15 \%$ & $1.01 \%$ \\
$(168)$ & $(86)$ & $(82)$
\end{tabular}

$41.4 \%$ friend or family

$18.7 \%$ directly to the firm

$4.3 \%$ firm contacted him

$2.62 \%$ public employment service

$1.15 \%$ association people w/ disability

$10.16 \%(610)$

$43.65 \%$ (of these $10 \%$ ) because disability

$23.85 \%$ thinks it will be difficult to find a job as a disabled

$50 \%$ cannot work

$9.42 \%$ (out of 2462 )

$20.8 \%$ (out of 2462 ) 
At the same time, only $2.20 \%$ of respondents say that they have benefited from an employment contract for disabled individuals, $0.84 \%$ report having benefited from a deduction to the Social Security contributions for disabled workers and $1.07 \%$ from another mechanism targeted to promote employment among disabled individuals ${ }^{49}$.

Therefore, the incidence of these policy initiatives is rather small and, even if they are available, they seem to play a secondary role in determining employment probabilities for the disabled.

\subsection{Conclusions and policy recommendations}

The analysis above has filled in an important information gap as it has presented the first evaluation of an employment promotion policy for disabled individuals in Spain. We make use of the availability of a 12 year bracket in our dataset in order to investigate the employment effects for disabled women of the introduction of a policy reform in 2004 which increased the deductions to the Social Security contributions for employers who hired a disabled woman.

In order to do so, we have first drawn a picture of a number of personal characteristics and of the labour market situation of disability pensioners in Spain and its evolution from 1996 to 2007.

Our findings suggest that this type of reforms provide the right incentives to employers as they increase the probability of finding a job for disabled women in Spain. This kind of political incentive proves to go in the right direction for reversing the negative double discrimination problem that disabled women suffered in the Spanish labour market before the implementation of the policy in 2004.

The result that the policy increased employment for disabled women with respect to men appears to be pretty stable across the different estimation techniques that we have implemented in this chapter and this effect is particularly strong and significant for the younger group of individuals below age 45 . The question still remains with regards to finding the best policy mechanism to obtain similar positive employment results for older groups of disabled individuals as results are not significant for individuals of more than 45 years old. We find that the policy is unable to increase employment prospects for older women, which constitute the majority group on the disability rolls. This result suggests that

\footnotetext{
${ }^{49}$ Of course, these numbers are probably higher in reality as some of the respondents may not be aware (or may have forgotten) that the employer made use of one of these policies.
} 
discrimination against older disabled women is a very persistent characteristic in the Spanish labour market as employers prove not to be willing to hire older disabled women even if there are incentives in place to do that. An alternative interpretation would suggest that the incentives in place are not enough to motivate employers to hire this older group of disabled women and that more incentives need to be introduced for the policy to be effective.

Furthermore, the introduction of these measures should also be complemented by other labour market initiatives. The improvements provided by isolated policy measures are prone to be rather limited in size if they are not accompanied by a more comprehensive and far-reaching packet of measures. This is particularly important in countries like Spain, which exhibit very low employment rates of disabled workers. At the same time, utilization of all the available policy measures targeted to increase employment for disabled workers seems to be rather small and a biggest effort should be made from the administration to advertise and promote their use, as results from the EDAD survey show that there is room to improve employment prospects of disabled workers in Spain: $23.85 \%$ of the disabled do not look for a job because they think that it will be difficult for them to find one as a disabled worker and $43.65 \%$ of the disabled who are looking for a job think that they cannot find one because of the disability (see Table 16).

Special employment centers that would support and guide the job search process of disabled workers could also bring good results as $41.4 \%$ of the disabled report having found their current or last job through a friend or family while $18.7 \%$ dealt directly with the firm and only $2.62 \%$ used a public employment service.

As more updated databases become available, it will be interesting to assess the effects of more recent reforms as well as to evaluate the extent to which employment rates of disabled individuals have been affected by the economic crisis of 2008-2010. 


\subsection{Appendix: Tables and figures}

Covariates included:

1) Characteristics of the individual and the pension:

- Level of education: The education variable has 3 levels: The first one captures individuals who cannot read or write or who dropped out of education before finishing high school. The second one includes individuals holding a high school diploma (or equivalent) whereas the third one is for people with a bachelor's degree and other higher education.

- Age

- Age at which he/she became disabled: even if we only have information on the characteristics of the pension from 1996, we do have an extra variable which captures the year in which the pension was granted. This is a very important piece of information as the age at which the individual became disabled proves to be a strong determinant of the labour market behavior of the individual during his/her disability spell.

- Internal Immigrant: A dummy variable that is 1 if the province in which the individual lives is different from the province in which he/she was born. Therefore, we are only considering internal migration.

- Amount of disability pension: There are 3 dummy variables capturing the amount of pension received by the individual in the last period (lagged values). Pension low is for values between 0500 euros/month, pension high for individuals receiving between 500 and 1500 euro/month and pension top for amounts above 1500 euro/month.

- Regime of the pension: Dummy variables that identify the group of workers in which the individual has been included during his/her professional live: self-employed, agriculture (includes fishing and mining) and individuals that become disabled due to a work accident or professional sickness. The reference category excluded from the regressions is the general regime.

- Regional fixed effects: dummies for each of the 17 CCAA $^{50}$.

50 There are 19 Autonomous Communities (CCAA) in Spain. However, we include both Ceuta and Melilla inside Andalucia because these are two small cities in the north of Africa that do not have 
- Town: is a dummy variable which is 1 if the town in which the individual lives (independently of the province or autonomous community) is smaller than 40.000 habitants. This variable captures spatial constraints affecting disabled individuals from small towns which make it more difficult for them to reach the Disability Evaluation Office, which are usually placed in the biggest cities of the province, or to find a job.

2) Variables only affecting the type of pension:

- Percentage of Disability Evaluation Offices: this variable is obtained by dividing the number of disability evaluation offices in each of the 52 provinces by the population in that province. We introduce this variable in order to capture differences between provinces in the service provided to disability claimants and to explore how these differences affect the probability of receiving a total or a partial type of pension. This variable will also be used as exclusion restriction as it has a clear effect on the type of pension diagnosed but it does not have an effect on the probability of disabled individuals to find a job.

- Percentage of Disability Benefits granted: this variable is the result of dividing the number of benefits granted each year in each autonomous communities (17) divided by the population in each autonomous community. It describes the way (rigorous/flexible) in which the health conditions are evaluated in each region. As the previous one, this variable affects the type of pension that the individual receives but is not going to affect the probability of working for disabled individuals either. 
Table 17: Probabilities of working and number of individuals in the sample

\begin{tabular}{|c|c|c|c|c|c|c|c|c|c|}
\hline Year & $\begin{array}{l}\text { Prob. } \\
\text { Working }\end{array}$ & $\begin{array}{l}\text { Number of } \\
\text { Individuals }\end{array}$ & $\begin{array}{l}\text { PrWork } \\
\text { Women }\end{array}$ & $\begin{array}{l}\text { Number } \\
\text { Ind. } \\
\text { Women }\end{array}$ & $\begin{array}{l}\text { PrWork } \\
\text { Men }\end{array}$ & $\begin{array}{l}\text { Number } \\
\text { Ind. Men }\end{array}$ & $\begin{array}{l}\text { PrWork } \\
\text { Partial } \\
\text { Disab. }\end{array}$ & $\begin{array}{l}\text { Ind. Partial } \\
\text { Disab. } \\
\text { Benefits }\end{array}$ & $\begin{array}{l}\text { PrWork } \\
\text { Total Dis. } \\
\text { Pens }\end{array}$ \\
\hline 1996 & 0.0377 & 19961 & 0.0164 & 5279 & 0.0453 & 14682 & 0.0558 & 11825 & 0.0113 \\
\hline 1997 & 0.0422 & 20259 & 0.0158 & 5348 & 0.0516 & 14911 & 0.0632 & 12216 & 0.0101 \\
\hline 1998 & 0.0673 & 20803 & 0.0205 & 5505 & 0.0842 & 15298 & 0.1021 & 12565 & 0.0143 \\
\hline 1999 & 0.0732 & 21530 & 0.0244 & 5776 & 0.0911 & 15754 & 0.1118 & 12954 & 0.0149 \\
\hline 2000 & 0.0818 & 22293 & 0.0274 & 6075 & 0.1021 & 16218 & 0.1253 & 13428 & 0.0159 \\
\hline 2001 & 0.0876 & 23140 & 0.0304 & 6402 & 0.1095 & 16738 & 0.1365 & 13886 & 0.0148 \\
\hline 2002 & 0.0922 & 24121 & 0.0343 & 6839 & 0.1151 & 17282 & 0.1434 & 14324 & 0.0173 \\
\hline 2003 & 0.096 & 25443 & 0.0383 & 7448 & 0.1198 & 17995 & 0.1488 & 15147 & 0.0182 \\
\hline 2004 & 0.098 & 26978 & 0.0395 & 8082 & 0.1229 & 18896 & 0.1540 & 15892 & 0.0176 \\
\hline 2005 & 0.101 & 28064 & 0.0424 & 8576 & 0.1268 & 19488 & 0.1606 & 16418 & 0.0171 \\
\hline 2006 & 0.105 & 30037 & 0.0449 & 9388 & 0.1323 & 20649 & 0.1683 & 17520 & 0.0164 \\
\hline 2007 & 0.1163 & 31737 & 0.0554 & 10099 & 0.1447 & 21638 & 0.1859 & 18438 & 0.0198 \\
\hline
\end{tabular}

Table 18 Rules for the determination of the pension amount

\begin{tabular}{|c|c|c|}
\hline & PDP & TDP \\
\hline \multirow[b]{2}{*}{ Regulatory Base } & \multicolumn{2}{|c|}{ Depends on the contributions in the last job (salary in the last job) } \\
\hline & \multicolumn{2}{|c|}{$\begin{array}{l}\text { Depends on the source of the disability: common illness, non-work } \\
\text { accident or working accident (or professional illness) }{ }^{51} \text {. }\end{array}$} \\
\hline \multirow{2}{*}{$\begin{array}{l}\text { Percentage applied to } \\
\text { Regulatory Base }\end{array}$} & $\begin{array}{l}\text { Depends on age of the individual: } \\
55 \% \text { if }<55 \text { years old } \\
75 \% \text { if }>55 \text { years old \& no job }\end{array}$ & $100 \%$ \\
\hline & \multicolumn{2}{|c|}{$\begin{array}{l}\text { Depends on the source of the disability: if working accident (or } \\
\text { professional illness), } 30 \%-50 \% \text { more if employer broke safety regulations } \\
\text { for the job }{ }^{52} \text {. }\end{array}$} \\
\hline Income Taxes & $\begin{array}{l}\text { Pay normal income taxes } \\
\text { Exempted if Basc }{ }^{53} \text { country \& no job }\end{array}$ & Exempted from income taxes \\
\hline $\begin{array}{l}\text { Reduction in } \\
\text { employment income } \\
\text { used to calculate the } \\
\text { income tax }\end{array}$ & $\begin{array}{l}2.800 \text { euros/year (if disability level } \\
\text { between } 33 \% \text { and } 65 \% \text { ) if working } \\
6.200 \text { euros (if disability more than } 65 \% \\
\text { or below that but disabled with reduced } \\
\text { mobility) if working }\end{array}$ & \\
\hline
\end{tabular}

\footnotetext{
${ }^{51}$ In our database we don't observe the source of the disability, we only observe the regulatory base.

52 Please note that in the case of a TDP, the final percentage applied could be more than $100 \%$ of the regulatory base if the employer is found guilty of not preserving the required safety conditions for the job and has to pay between a $30 \%-50 \%$ increase in the percentage of the regulatory base (over the $100 \%$ already established for TDP benefits).

53 Disabled individuals in the provinces of Vizcaya, Alava and Guipuzcoa, which constitute the Basc country, are exempted of paying income taxes on Total Disability Benefits if they don't work.
} 

4. The Employment Effect of

Increasing Disability

Benefits: A Regression

Discontinuity Approach 


\subsection{Introduction}

Disabled individuals have incomes which are on average almost 15 percent lower than the rest of the population in developed Western economies and only 70 percent of the mean in the United States (OECD 2009). This is despite a very substantial documented increase in disability insurance (DI) availability and generosity in recent decades (Autor and Duggan, 2006; OECD, 2003). The cost of expanding this protection program has so far been outweighed by the sustained economic growth of the past twenty years ${ }^{54}$. With the fallouts of the financial crisis on government spending limitations, the burden of DI on the public purse will certainly come under renewed criticism. The recurring principal argument for reform of the disability benefit system has however not been its cost but rather its potential perverse incentive on the labour market participation (LMP) of certain groups of individuals.

The relationship between DI availability and generosity and LMP is an intrinsically difficult question to answer. The main criterion for eligibility is broadly always defined as having a physical or mental impairment that prevents a person from engaging in substantial gainful activity. This shows how the selection process into DI is strongly based on an individual having low LMP probability, making the claim and work decisions highly endogenous. Any evaluation of a disability benefit program must therefore carefully deal with this endogeneity issue in order not to over-estimate its impact on the labour market behaviour of recipients. There is now an influential literature exploring this relationship using various methodological approaches to the problem and we review it in the next section of this chapter. The almost universal consensus is that DI has a very negative effect on the attachment to the labour market of eligible claimants. The remaining debate seems to be mostly about the size of this effect.

Autor and Duggan $\left(2007,2008^{55}\right)$ are among the few that have recently focused on better understanding the mechanisms behind the behavioral response of DI claimants. Their main argument is that it could be due not only to the usually put forward distortionary substitution effect on incentives but also to a nondistortionary income effect. The latter interpretation would imply that the observed reduction in labour supply is not a deadweight loss and it is providing

\footnotetext{
${ }^{54}$ Despite increases in the number of claimants and of the average generosity of these benefits, the good economic performance of the economy has meant that the cost of DI has remained stable since the early 1990s in OECD countries at around 1.3 percent of GDP over this period

${ }^{55}$ We would like to thank these authors for making their 2008 unpublished report to the Social Security Administration available to us.

96
} 
the right amount of transfer income in order for disabled individuals not to have to work above their substantial gainful activity level. These authors have attempted to empirically measure the importance of the income effect channel on LMP by using one of the few such DI programs in the USA which is not provided elusively on a work-contingent basis (Agent Orange). Their findings suggest a large income effect on near elderly males but are only tentative because of data limitations. We propose here to investigate this issue by exploiting certain unique features of the DI system in Spain.

The Spanish insurance system for disabled individuals is first characterized by a low and relatively stable recipiency rate by international standards ${ }^{56}$. Those who are eligible then receive monthly transfers which are fixed at a certain proportion of their wage level prior to the disability (i.e. it is a contributory insurance scheme ${ }^{57}$ ) and is secure until moving to retirement pension at age 65 . This proportion is 55 percent for partial disability and 100 percent for total disability. Crucially the benefit amount is not contingent on not having employment income and has even built in taxation mechanisms to make LMP advantageous while on DI. Another interesting feature of the Spanish system is that certain claimants of partial disability benefits are eligible to a 36 percent increase when they turn 55 years old (the proportion increases from 55 to $75 \%$ ). This is granted to DI recipients with lower skill level and exposed to local labour market conditions which are deemed to make it difficult for them to find employment. The 75 percent replacement rate is granted to just under two thirds of partial disability claimants over the age threshold and close to none before that. This particularity enables us to investigate the impact of this large increase in DI generosity on employment of near elderly individuals using a regression discontinuity approach.

We use a large representative sample of the Spanish population receiving disability benefits for which we have monthly administrative data on work and benefit history between 1996 and 2007. We focus our attention on partial disability recipients who are aged between 51 and 58 and are able to identify the individuals who are treated with the DI increase. Because of selection on low employment probability, naïve OLS estimates of the treatment effect logically generate huge policy impacts (-17 percent) even after controlling for observable characteristics. Augmenting the model with the inclusion of individual fixed effects yields a policy impact almost three times smaller. Our regression discontinuity (RD) approach

\footnotetext{
${ }^{56}$ Only 4 percent of the population aged 20 to 64 receives disability benefits in Spain compared to an OECD average of 6 percent, which is the same number than in the United States.

57 There is also a non-contributory disability benefits system but it is comparatively smaller in size (205.319 people received non-contributory disability benefits in Spain in 2007 as opposed to 868.026 that receive contributory disability benefits). We do not include the group of non-contributory pensioners in our analysis.
} 
first considers different age windows around the 55 years threshold. These results suggest that the increase in DI generosity is at least responsible for a 3 percentage points decrease in employment. However, when we run some tests about the linearity of covariates around the eligibility age threshold, we can see that age at which individuals start claiming DI is not continuous. This result can be interpreted as evidence that the benefit increase accelerates the entry rate into the disability rolls of individuals aged 55 or over. Therefore, we proceed by estimating a new RD model but with a sample restricted to individuals who start receiving DI benefits before reaching age 55 . Now results suggest that the policy prompts a 1 percentage point decrease in employment probability, which is translated into an 8 percent reduction in employment probability (as the average employment rate for this sample is 12.5 percent).

We believe that these results are very much in line with the findings from previous research on this subject (specially results from Gruber, 2000) and claim that, considering the features of the Spanish system in terms of the benefit not being contingent on working status, the observed impacts of DI on employment may be mainly due to an income effect, in line with was is argued in Autor and Duggan (2007, 2008).

The rest of the chapter is structured as follows. Section 2 gives an overview of the related literature on the impact of DI on employment. Section 3 discusses the disability benefit system in Spain and the increase in DI generosity program. Section 4 describes the data and gives some descriptive statistics. Section 5 presents the methodology. Section 6 reports and discusses the results and the final section concludes.

\subsection{Related Literature}

Much of the literature on work disincentives of permanent disability benefits is based on the analysis of the Social Security Disability Insurance (SSDI) program in the USA.

Labour force participation rates for older males in the USA have been falling during the last three decades and an extensive body of research has emerged that tries to link this evolution with the growth of the disability insurance program. The argument is based on the high implicit marginal tax rate on earnings above a threshold (\$940/month in 2008) that is part of the eligibility criteria in order to be accepted to the disability program ${ }^{58}$. It is widely accepted that the current design of

58 Applicants to the disability insurance system in the USA need to demonstrate that they did not work during the five months prior to the application and once they start receiving the benefits they cannot gain more than the threshold defined by the substantial gainful activity (SGA which was $\$ 940$ per month in 2008). However, since 1960 disability recipients have access to a Trial Work Period in which, 98 
the program creates disincentives to work for disabled individuals but there is still disagreement on the magnitude of these effects and their contribution to the decrease in labour force participation of older Americans.

The main problem encountered when trying to estimate the size of the disincentives to work resulting from the disability insurance system is the endogeneity of the receipt of disability benefits in a labour force participation equation. Therefore, in order to get unbiased results, researchers have tried to use an exogenous variation in the level of benefits or to rely on econometric techniques that can account for this endogeneity.

In this line of research, Bound (1989) compares a sample of rejected and accepted DI beneficiaries and estimates that the counterfactual labour force participation rate of disability recipients would have been 30 percentage points higher if they wouldn't have received the benefits. The validity of his estimates relies on the assumption that both groups are relatively similar in observed and unobserved characteristics although he recognizes that rejected applicants are usually somewhat healthier than accepted applicants so that he defends that his estimates represent an "upper bound" of the potential labour force participation of DI receivers.

Using a similar approach, a more recent study by Chen and Van Der Klaauw (2008) focuses on the impact of the receipt of disability benefits for marginal applicants for which access to the disability system is only decided in a second stage of the eligibility process and on the basis of vocational and age factors. Individuals that reach this second stage have been found to fulfill the medical impairment required in the first stage of the eligibility process and case workers use a grid of individual characteristics of the disabled worker such as age, education and past work experience in order to determine "the individual's residual functional capacity to perform work-related physical and mental activities". For age, the cutoff points are set at 45, 50 and 55 years old and the authors use the discontinuity in DI award rates at these points to estimate the effect of benefit receipt on labour supply. Their findings suggest that the receipt of disability benefits reduce labour force participation by 6-12 percentage points and labour supply by 16-20 hours per month. However, the question remains to whether this result can be extrapolated to the whole population of disability benefit recipients as calculations are only done with individuals that reach the second stage of the benefits adjudication process who are also probably the ones with a relatively better health among the pool of disability recipients.

for 5 years, they can accumulate up to nine months of work above the SGA. If they earn more than the SGA for more than nine months, benefits are terminated (Maestas and Yin, 2008). 
Maestas and Yin (2008) take a difference approach and exploit the fact that, once disabled individuals reach the Full Retirement Age (FRA), disability benefits are automatically converted to old-age pension. Since the year 2000, this change abolishes the working restriction embedded in the US disability system so that the tax on earnings disappears while the benefit amount remains the same. They calculate changes in labour force participation as DI beneficiaries move to old-age benefits and using a difference-in-difference approach get an estimate of 10.4 percentage points rise in labour force participation at full retirement age among former DI beneficiaries relative to non-DI participants. However, this number is calculated using a sub-population and it cannot be generalized to the whole population in the disability rolls as labour force participation naturally decreases with age. For that reason, the authors conclude that this number represents a "lower bound" estimate on the potential work capacity of individuals in the disability system (Maestas and Yin, 2008).

Apart from evidence for the United States, there are two more important studies that focus on Canadian data. The study by Gruber (2000) makes use of an increase of $36 \%$ in the level of disability benefits in all Canadian regions except Quebec introduced in 1987 in order to estimate an elasticity of labour force nonparticipation of $0.28-0.36$ with respect to disability insurance benefits. Or course, his identification strategy relies on the exogenous variation in benefit amounts between the two regions, which assumes no correlation between the change in benefits and other differential labour market trends in the two regions. Another study by Hyatt (1996) focuses on Canadian data (Ontario) and uses a Heckman selection model to estimate the effect of permanent disability benefits on postinjury wages accounting for the self-selection of individuals into the employment option. Hyatt proves that the generosity of worker's permanent disability benefits is negatively associated with post-injury employment.

In an attempt to summarize the results and to raise the attention of both governments and the general public opinion about the distortions introduced by the relatively generous disability systems, the OECD calculated the disincentive effects to work using the "disability benefits net replacement rates ${ }^{59}$ " for average earners which were estimated to be $39 \%$ in Australia, between $43-60 \%$ in the UK, $74 \%$ in Luxembourg and $64 \%-84 \%$ in the case of partial disability holders in Spain (121\% in the case of full disability). Additionally, in a companion report published in 2003 also by the OECD, a "benefit generosity indicator" was constructed and proved to have a positive correlation with both beneficiary rates and disability benefit inflows (OECD, 2003). Therefore, the literature in the European context has, for some time, accepted that disability systems in Europe are not only used for

\footnotetext{
59 Net replacement rates compare the income situation when moving from paid work to receiving disability benefits without working (OECD, 2007a). 
persons with health incapacities but also as an alternative pathway into early retirement or as uncovered unemployment, particularly for the case of older individuals. As a result, countries have focused on the introduction of reforms to activate disabled individuals and to substitute the disincentives by incentives to take up a job for disability benefit recipients. Consequently, most of the latest literature relative to the European disability systems consists of policy evaluations of these reforms ${ }^{60}$.

For the particular case of Spain, a number of papers have tried to identify the extent to which disability benefits have been used as an alternative exit from the labour market for disabled individuals: Blanco (2000) uses a competing risk model to identify the characteristics that affect older individuals when leaving employment to enter early retirement or disability benefits while in chapter 2 of this book we focus on the effects of the business cycle on older workers going into disability benefits, unemployment or inactivity. Malo (2007) and chapter 3 of this book focus on the factors that influence the low employment rates of disabled individuals and the later chapter also finds positive but small effects of an employment promotion policy introduced in 2004 to foster the integration of disabled women in the labour market (an increase in the deductions to the Social Security contributions offered to employers that hire a disabled women). However, none of the literature in Spain has tried to estimate the disincentives to work provided by the level of disability benefits awarded.

\subsection{The Disability Insurance System in Spain}

\subsubsection{Types of disability benefits}

In Spain, permanent contributive disability insurance is defined as the economic benefits that aim at compensating the individual for losing a certain amount of wage or professional earnings when the person is affected by a reduction or a complete loss of his/her working ability in a way that is assumed to be permanent due to the effects of a pathologic or traumatic process derived from an illness or an accident ${ }^{61}$.

\footnotetext{
${ }^{60}$ Examples of these evaluations are Humer et al. (2007) and Lalive et al. (2009) for Austria, Duell et al. (2009) for Norway, Stafford et al. (2006) and Corden et al. (2001) for the U.K., reports from the Department of Employment and Workplace Relations (2005) and from the Department of Family and Community Services (2003) for Australia, Van Ours (2006) for The Netherlands or Hartmann (2006) for Luxembourg, among others.

${ }^{61}$ Own translation of the definition of permanent disability given by the Spanish Social Security administration at www.seg-social.es.
} 
In order to capture the different situations in which a person can be after suffering from a disabling condition, the Spanish Social Security administration differentiates between three main degrees of disability ${ }^{62}$ that depend on the amount of working capacity that has been lost:

(i) Partial Disability: Individuals suffering from the kind of impairment that disables the individual to develop all or the fundamental tasks of his/her usual job or professional activity but the individual is still capable of developing a different job or professional activity.

(ii) Total Disability: Individuals suffering from the kind of impairment that disables the individual for the development of any kind of job or professional activity.

(ii) Severe Disability: Individuals who are in a situation in which, as a result of anatomic or functional loses, the individual needs the assistance of a third person to develop the most essential acts of live such as eating, moving, etc...

Therefore, the degree of disability in which the individual is classified is set in relation to the working capacity lost as the goal of the benefits is to compensate for the reduction on wages or professional earnings caused by the disabling condition. The procedure of applying for permanent disability benefits can be initiated by the provincial office of the National Institute of Social Security (NISS), by the institutions that collaborate in the process (such as hospitals), or by the individual himself (in which case, more documentation is required). The evaluation is done by the Disabilities Evaluation Team which analyses the medical report prepared by doctors in the provincial office of the NISS and the report explaining the professional background of the person. The Disabilities Evaluation Team writes a report that will be evaluated by the directors of the provincial office of the NISS in order to take a decision on the type of disability pension granted (if any), the benefit level and the date of the next planned revision to check whether there has been an improvement or an aggravation of the condition. Similarly, any revision of the disability degree or pension amount is done by the provincial office of the NISS. A graphical description of the process is provided in Figure 34 of the appendix.

\subsubsection{Elegibility and Pension Amount}

As we are dealing with contributory benefits, there are a number of rules in terms of eligibility requirements that the individual has to fulfill in order to qualify for the pension. These requirements as well as the pension amount vary depending

\footnotetext{
62 These three levels of disability represented 99.6 percent of permanent contributory DI claimants in 2007. A remaining 0.4 percent of claimants received a lump sum payment for every minor disability. 
on the source of the disability, which can be an ordinary illness, a work-unrelated accident or a work-related accident or professional illness. In the case of an ordinary illness, eligibility to the pension requires having contributed $1 / 3$ of the time between turning 20 years old and the appearance of the disabling condition, with a minimum of 5 years of contributions ${ }^{63}$. There is no contributive requirement when the disability is caused by an accident, whether or not work-related, or a professional illness.

The total amount of the pension is obtained from multiplying a percentage, which varies depending on the type of pension, to the regulatory base, which depends on the source of the disability and on previous salaries. The regulatory base of the pension in the case of an ordinary illness is computed as the average wage of the last 8 years of work. For a work-unrelated accident, is the average annual wage over a period of 24 consecutive months chosen by the person within the last 7 years of work. For work-related accident or professional illness, it is the average wage in the last year of work.

The percentage applied to the regulatory base is $55 \%$ under the Partial Disability regime, $100 \%$ under the Total Disability scheme and $100 \%$ plus another $50 \%$ to cover for the person that is taking care of the disabled in the case of Severe Disability. However, for partial disability pensioners, this $55 \%$ can be increased by $36 \%$ for individuals who are older than 55 years old and "as a result of their lack of education/preparation and the social and labour market conditions of the region where they live, it is assumed that it will be difficult for them to find a job". Therefore, individuals in the Partial Disability scheme that comply with these requirements can receive a $75 \%$ of the regulatory base instead of a $55 \%$. All permanent disability benefits are automatically converted to old-age benefits once the individual turns 65 years old.

In terms of income taxes, Partial Disability benefits are taxable under the general income tax rules and Total disability benefits are always exempted from income taxes. Furthermore, if the individual works while receiving the pension, there is a reduction in the employment income used to calculate the income tax of 2.800 euros/year if their degree of disability is low (between $33 \%$ and $65 \%$ ) or 6.200 if the disability level is higher (more than 65\%) or if the disabled has reduced mobility. All this legislation can be translated in the following equations for recipients of Partial Disability benefits:

\footnotetext{
${ }^{63}$ If the individual is younger than 31 when becoming disabled, the requirement is to have contributed for $1 / 3$ of the time between turning 16 years old and the appearance of the disabling condition with no minimum of years required.
} 
Partial Disability without a job:

$$
y_{i}(p, a,)= \begin{cases}0,55 p_{i}-r \times\left(0,55 p_{i}\right) & \text { if } a<55 \mid a \geq 55 \& t=0 \\ 0,75 p_{i}-r \times\left(0,75 p_{i}\right) & \text { if } a \geq 55 \& t=1\end{cases}
$$

(Equation 14)

Where $p_{i}$ is the regulatory base of the pension amount that depends on the contributions in the last job (salary) and on the source of the disability ${ }^{64}, \mathrm{t}$ is an indicator function for treatment and $a$ is age.

Partial Disability with a job:

$$
y_{i}(d, w, p)=\alpha p_{i}-c \times d_{i}+w_{i}-r \times\left[\alpha p_{i}+\left(w_{i}-k\left(d_{i}\right)\right]\right.
$$

(Equation 15)

With

$$
\mathrm{k}\left(\mathrm{d}_{\mathrm{i}}\right)=\left\{\begin{array} { l } 
{ 2 . 8 0 0 \text { if } 3 3 \leq d _ { i } \leq 6 5 } \\
{ 6 . 2 0 0 \text { if } d _ { i } > 6 5 }
\end{array} \quad \left\{\begin{array}{l}
\alpha=0.55 \text { if } a<55 \mid a \geq 55 \& \mathrm{t}=0 \\
\alpha=0.75 \text { if } a \geq 55 \& \mathrm{t}=1
\end{array}\right.\right.
$$

(Equation 16)

Where $d_{i}$ is the degree of disability, $\mathrm{k}\left(\mathrm{d}_{\mathrm{i}}\right)$ is the reduction to the income considered for tax purposes, $\mathrm{r}$ is the income tax rate applied and $c \times d_{i}$ is the cost of working (in monetary terms) for a disabled individual which is a linear function of his/her degree of disability.

For this chapter, our interest lies on the evaluation of the disincentives to work caused by the increase in the pension amount at age 55. For this reason, we are restricting our analysis to disabled individuals in the Partial Disability scheme where the law applies.

\subsection{Data and Descriptive Statistics}

\subsubsection{The Data}

The study will use the Continuous Sample of Working Lives ("Muestra Continua de Vidas Laborales", MCVL) which is a microeconomic data set based on administrative records provided by the Spanish Social Security Administration. It

\footnotetext{
${ }^{64}$ We take it as a value; we don't calculate it as everybody in the sample receives always a pension and it would be very difficult to calculate because we don't know the source of the disability. 
contains a random sample of $4 \%$ of all the individuals who, at some point during 2007, had contributed towards the social security system (either by working or being in an unemployment scheme) or had received a contributory DI (disability insurance). The random sample selected contains over one million individuals.

It contains information on the entire monthly employment and benefit history of the workers, including the exact duration of employment, unemployment and disability benefit spells, and for each spell, several variables that describe the characteristics of the job or the unemployment/disability benefits. There is also some information on personal characteristics such as age, gender, nationality and level of education. We also capture the economic business cycle by compiling quarterly unemployment rates at the province level (there are 52 provinces in Spain).

We select in our sample all individuals who are aged 51-58 and are receiving a Partial disability pension at some point between 1996 and 2007. The final sample for our analysis contains 623,228 monthly observations for 14,692 individuals.

\subsubsection{Descriptive Statistics}

About a third of the claimants in our sample are women $(4,708)$ which is relatively large but follows the recent trends in the increase in the female to mail ratio among disability benefit recipients. The education level of these DI (disability insurance) claimants is low with only about 30 percent having completed at least secondary education. This is not surprising since we are focusing on older workers which have on average less schooling but also because disability is likely to be correlated to education, as it is likely to generate differences in health investment. Almost 18 percent of the individuals in our sample $(2,592)$ have worked at some point while they were claiming Partial Disability benefits. This is relatively high considering that this is only about half the employment rate of non disabled workers of the same age group in Spain over this period.

Our methodological approach (described below) relies on the discontinuity in the 36 percent increase of DI (DII; disability insurance increase) at age 55 which is a criterion for selection into the program. We show in Figure 28 that the proportion of individuals treated does dramatically jump after individuals reach this age threshold. There also appears to be a very small number of individuals who receive the DII before being 55 which may reflect some level of administrative error or cheating by disability case workers. Still the difference in treatment is very large, about 60 percent, and does warrant evaluation using a fuzzy regression discontinuity design. 
Figure 28 Proportion of disability recipients receiving the increase in disability benefits by age.

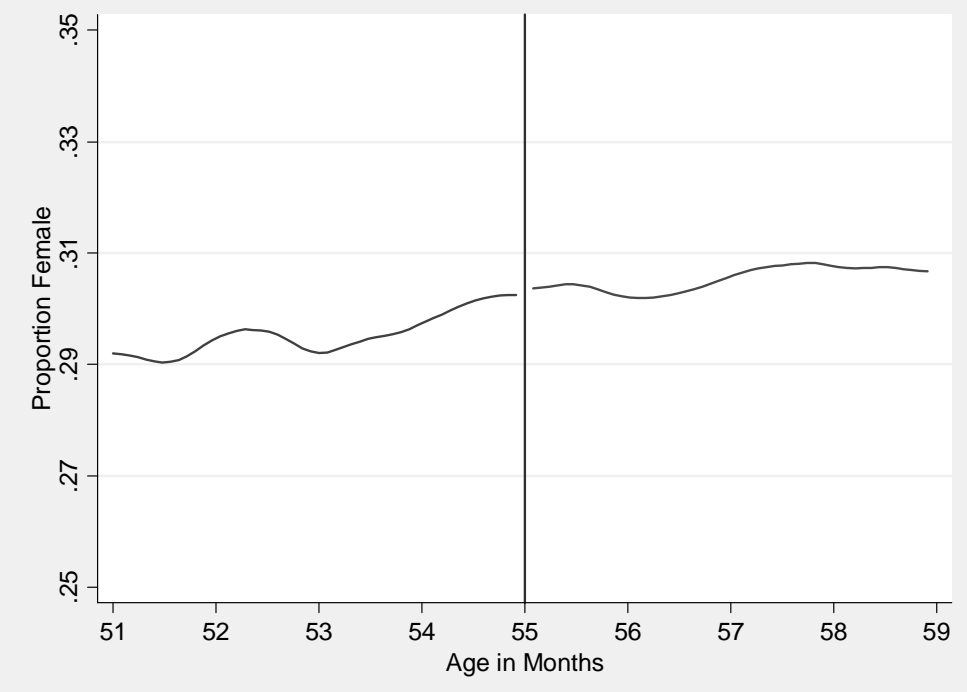

Figure 29 Proportion of disabled individuals who are female in the sample by age.

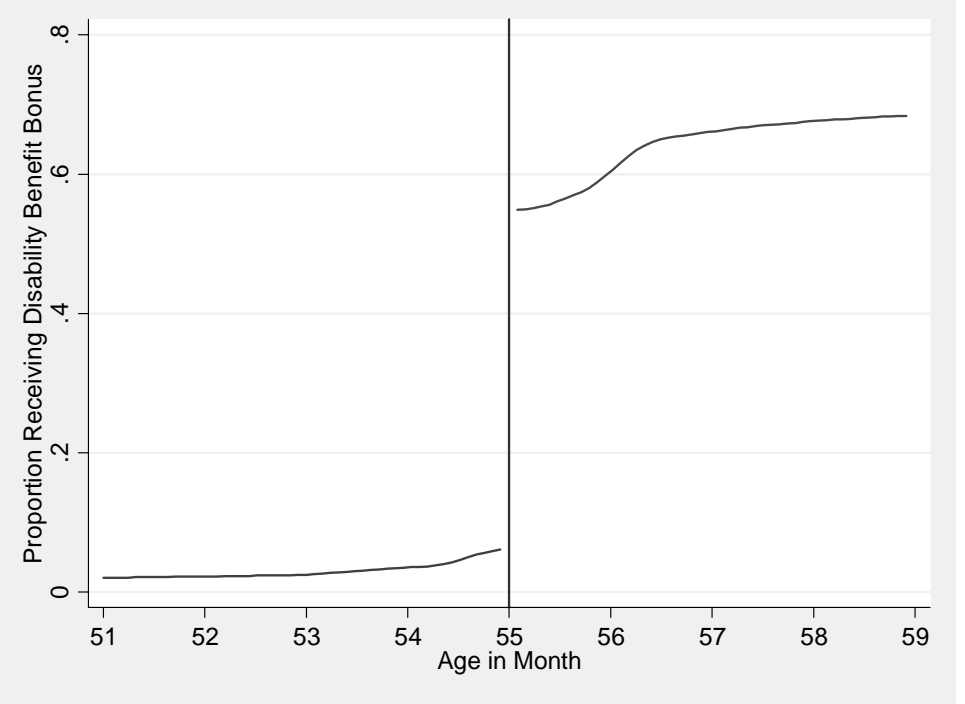

Source: Own calculations from the sample of the MCVL database. 
Figure 30 Proportion of disabled individuals with secondary education or above.

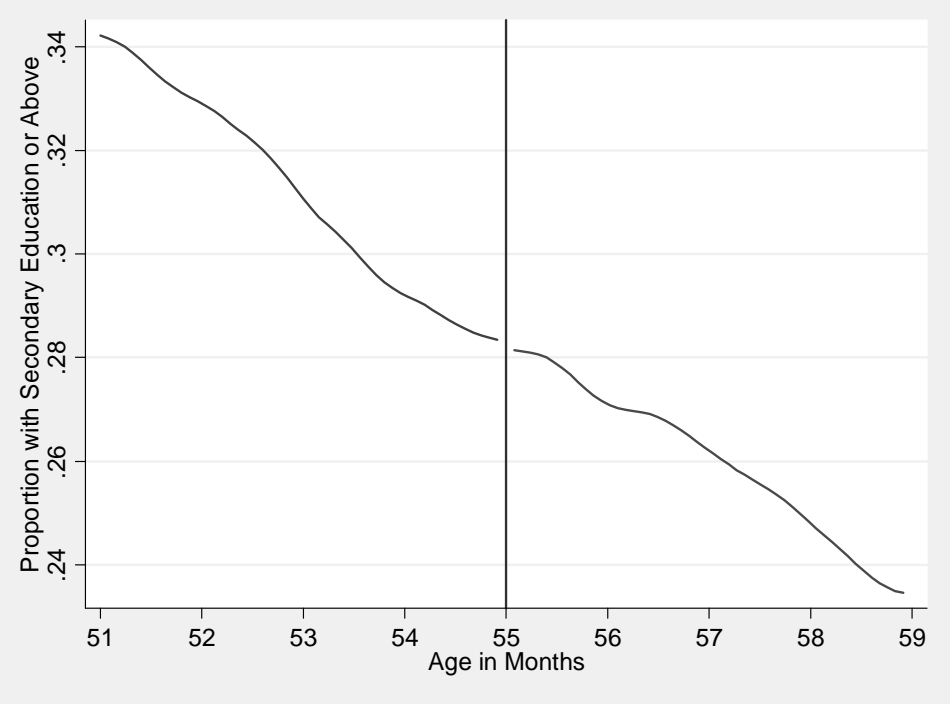

We check that the treatment discontinuity is not a result of differences in covariates around the age threshold graphically. Figure 29 shows that women constantly represent approximately one third of our sample of claimants throughout. In Figure 30 we must first note that older individuals are on average less educated. But the graph is reassuring and shows that this criterion for eligibility to the benefit increase appears to be very smooth around the age threshold. The pattern for age started claiming DI in Figure 31 has an increasing shape, with older benefit recipients having on average entered DI older. The distribution of average age started claiming DI still appears to be relatively smooth around the eligibility threshold but we will check whether the small jump at age 55 is significant or not in a more systematic way in our statistical analysis.

Finally we plot the changes in our outcome of interest, employment status, by age in Figure 32. Again we see that the detachment from employment increases from age 52 onwards as our sampled individuals become older ${ }^{65}$. We also note what appears to be a small discontinuity around the threshold which could be resulting from the change in treatment probability. The significance of this gap is however difficult to judge graphically and will be confirmed or otherwise in our statistical model estimates.

\footnotetext{
65 The marked drop in EMP at age 52 onward is still relatively puzzling to us since there are no disability insurance entitlement changes at this age. It could be due to the 'natural' effect of age on EMP as claimants become older and we therefore carefully control for this phenomenon in our statistical analysis.
} 
Figure 31 Age started claiming DI by age

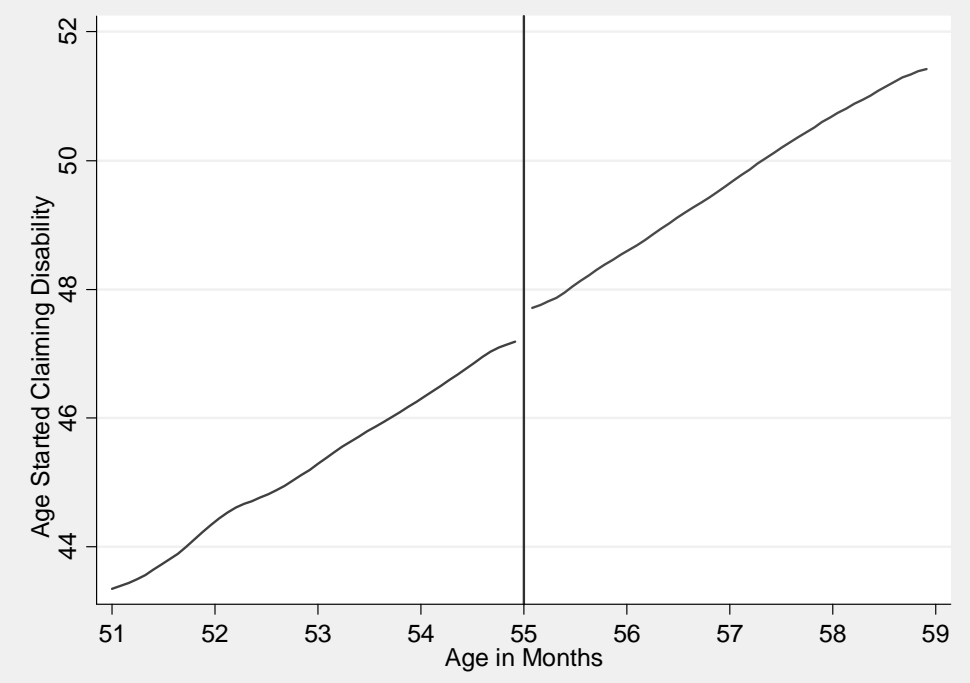

Figure 32 EMP of disability recipients by age.

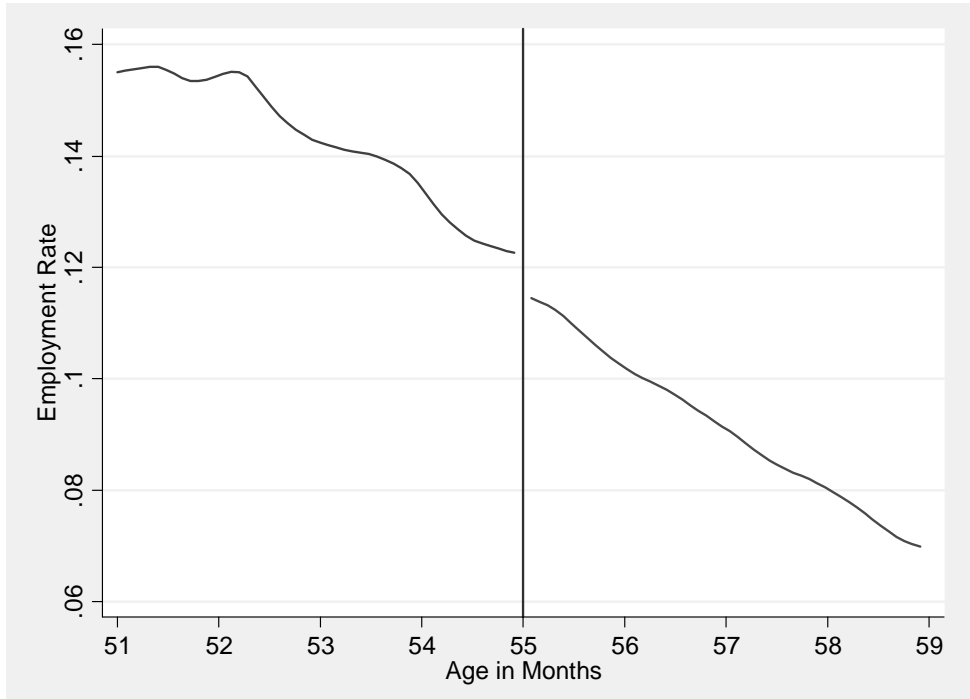

Source: Own calculations from the sample of the MCVL database. 


\subsection{Methodology}

\subsubsection{OLS and Fixed Effect Models}

For individual $i$ in month $t$, a simple statistical model relating EMP (employment, our outcome of interest) to DII participation (the policy treatment) can be written as:

$$
E M P_{i t}=\alpha+\beta D I I_{i t}+\delta(\text { Age })+u_{i t}
$$

(Equation 17)

where $\alpha$ is an intercept, EMP is a dummy variable for working or not, DII a dummy variable for receiving the disability benefit increase and $u$ is an error term. We control for the age in months of the claimants in quadratic form, $\delta(A g e)$, since we have observed in Figure 32 that is negatively correlated to EMP. If assignment to DII treatment was random, then $\beta$ would be an unbiased estimator of the impact of DII on EMP.

However, the definition of having a low EMP probability for DII selection makes it non-random and so a regression estimate from (Equation 17) will be biased - overestimating the decreases in employment rates due to the program. One possible means to deal with this is to augment (Equation 17) by adding observable characteristics of claimants to amend the equation as:

$$
E M P_{i t}=\alpha+\beta D I I_{i t}+\delta(A g e)+\gamma_{k} X_{k i}+U R{ }_{i t}+u_{i t}
$$

\section{(Equation 18)}

Where $k$ individual characteristic are included in the vector of control variables, $X$, and UR is the unemployment rate the claimant is exposed to in the area where he resides in month $t$. The Ordinary Least Squares (OLS) estimate of $\beta$ is then the relationship between EMP and DII holding constant the $X^{\prime}$ 's and controlling for labour market conditions ${ }^{66}$.

Since we have panel data information on the treatment and employment status of disability benefit claimants we can include individual fixed effects, $\alpha_{\mathrm{i}}$, as follows:

\footnotetext{
${ }^{66}$ We use the unemployment rate to control for labour market characteristics rather than month and year dummies since these would be highly correlated with the age (in months) control that we include in the model.
} 


$$
E M P_{i t}=\alpha_{i}+\beta D I I_{i t}+\delta(\text { Age })+U R_{i t}+u_{i t}
$$

(Equation 19)

The individual characteristics, $X s$, from (Equation 18) are now dropped since they do not vary over time. Our interpretation of the estimated $\beta$ is that it should now be free of observed and unobserved claimant characteristics. Still, if selection into DII and EMP is dependent on factors not included in equation (Equation 19) the selection problem remains. Since the rule for DII selection is that claimants must be over 55 years old, we consider another methodology which should be better in addressing the discussed selection problem: Regression Discontinuity.

\subsubsection{Regression Discontinuity Models}

Regression Discontinuity (RD) design has had a long history in statistics, but has recently gained prominence among economists for its potential for dealing with the problem of unobservable characteristics alongside its conceptual simplicity ${ }^{67}$. This method can only be applied when there exists a cut-off point of an assignment variable $Z$ above and below which there is a strong difference in treatment probability. As we clearly illustrated in Figure 28, this is the case for DII treatment depending on age of the claimant $(Z)$ due to the 55 years minimum selection rule.

A widely researched and very intuitive example of RD occurs for the 50 percent cut-off rule for winning or losing an election. The argument is that different units (areas, firms) which have had very close votes around the cut-off are likely to be very similar in observed and unobserved characteristics. Still they will have opposite outcomes whether they were above or below the assignment cut-off, making it very simple to compare the difference in impact of selection or not. In this case, an unbiased treatment effect on outcome, here EMP, with subscripts + and - indicating proximity to either side of the threshold can be written as:

$$
\beta=E M P^{+}-E M P
$$

(Equation 20)

It is extremely simple to estimate $\beta$ here since being above the cut-off guarantees treatment and we only have to compare the means of the outcome around that point. This is called a sharp RD as the probability of treatment, or inclusion into a program, jumps from 0 to 1 on either side of the cut-off.

\footnotetext{
${ }^{67}$ For a clear and detailed discussion on the RD methodology, see for example Imbens and Lemieux (2008). 
In the case of DII treatment, as in many other programs, the change in the probability of treatment around the assignment variable threshold is not so sharp but does greatly increase. This type of set up is called a fuzzy RD and it is still possible to exploit the discontinuity to identify a treatment effect ${ }^{68}$. In this case however the difference in outcomes around the cut-off will be a function of the difference in the jump in the proportion treated around this point. Mathematically, using average EMP, the mean proportion of claimants receiving DII, and the subscript + and - as before, we can write $E M P^{+}-E M P^{-}=\beta\left(D I I^{+}-D I I^{-}\right)$.

This can be re-written as the RD estimator:

$$
\beta=\frac{E M P^{+}-E M P^{-}}{D I I^{+}-D I I^{-}}
$$

(Equation 21)

If it is the case that claimants just below and just above the age cut-off do have similar characteristics (observable and unobservable) then the estimator in (Equation 21) can legitimately be used to estimate the causal impact of DII on EMP. This is because it simply compares the difference in employment rates of individuals which have been randomly assigned around an assignment threshold and which should consequently have similar characteristics. Of course since not all claimants over 55 receive the benefit increase, this must be scaled by the difference in the jump in the proportion of individuals that are treated around this point.

We can estimate $\beta$ using different + and - windows in terms of age on each side of the threshold. As the age difference of individuals around the threshold becomes smaller we expect the RD estimate of DII treatment to decrease since claimants on either side will be ever more similar in observed (and unobserved) characteristics. A more robust test of this similarity is to include individual characteristics of our claimants as controls when obtaining RD estimates of DII on EMP in the smallest age window available. If these characteristics are randomly distributed around the age threshold, we expect that including controls will not significantly change the RD estimates. But if they become significantly different with the inclusion of certain individual trait of DI claimants, it will suggest that we must consider how this affects the validity of our RD estimates.

\footnotetext{
${ }^{68}$ In our case we are actually facing what has been referred to as a 'partially fuzzy' by Battistin and Rettore (2008) or a 'simple special case' by Blundell and Costa Dias (2009) version of the RD methodology. This is because treatment is only available but not mandatory on one side of the threshold. Both of these papers highlight the advantage of this approach relative to the standard fuzzy RDD.
} 


\subsection{Results}

The results from the OLS, columns (1) to (3), and fixed effect estimates, columns (4) and (5), of DII on EMP are reported in Table 19. The simple OLS estimate including a quadratic term in age is very large and only slightly smaller when controlling for individual characteristics (gender, education, age started claiming disability). Also taking into account changes in labour market conditions by including provincial unemployment rates does not change the estimated impact of 17 percent of the policy on employment participation. This large effect was to be expected considering that selection for DII is contingent on having a low EMP probability. The fixed effect estimates are much smaller and suggest that the program only reduces the probability of working by 6 percent. We believe this to be a superior estimate of the DII impact to the OLS one since it measures the average effect of switching from non-treatment to treatment in terms of changes in EMP for the same individuals. As we explained above we may still be concerned that individual fixed effects and labour market conditions cannot account for the endogenous nature of selection for treatment of a claimant and her behavioral response. For this we turn to the RD analysis.

Table 20 reports RD estimates for four different age windows (from $+/-4$ years to $+/-1$ year) around the 55 year threshold. The discontinuity in DII is clearly important and represents a jump of between 50 and 60 in the proportion of treated claimants. The difference in EMP is significant and between 5.1 and 1.6 percentage points lower after the age cut-off. The RD coefficients are the ratios of these differences and they are all statistically significant ${ }^{69}$. However it is clear that the impact of DII on EMP becomes much smaller as the age window around the threshold is reduced as the individuals in our sample become ever more similar. A straightforward RD methodology therefore suggests that an increase in DI generosity reduces work probability by, at least, 3 percentage points.

\footnotetext{
${ }^{69}$ As the estimate is similar to a local IV estimate of DII on EMP instrumented by a claimant being older than the cut-off age, we are able to obtain standard errors as recommended by Hahn et al. (2001)
} 
Table 19 OLS and fixed effects results

\begin{tabular}{|c|c|c|c|c|c|}
\hline & \multicolumn{5}{|c|}{$\begin{array}{l}\text { Dependent Variable: } \\
\text { Employment Status }\end{array}$} \\
\hline & \multicolumn{4}{|c|}{ OLS } & \multirow{2}{*}{$\begin{array}{l}\text { FE } \\
\text { (5) }\end{array}$} \\
\hline & (1) & (2) & (3) & (4) & \\
\hline $\begin{array}{l}\text { Disability Benefit Bonus } \\
\text { (DBB) }\end{array}$ & $\begin{array}{l}-.187 \\
(.001)\end{array}$ & $\begin{array}{l}-.170 \\
(.001)\end{array}$ & $\begin{array}{l}-.170 \\
(.001)\end{array}$ & $\begin{array}{l}-.060 \\
(.001)\end{array}$ & $\begin{array}{l}-.060 \\
(.001)\end{array}$ \\
\hline Age/Age $^{2} /$ Age $^{3}$ & Yes & Yes & Yes & Yes & Yes \\
\hline Individual Controls & No & Yes & Yes & No & No \\
\hline Unemployment Rate & No & No & Yes & No & Yes \\
\hline Individual Fixed Effects & No & No & No & Yes & Yes \\
\hline Number of Observations & 623,228 & 623,228 & 623,288 & 623,288 & 623,288 \\
\hline Number of Individuals & 14,692 & 14,692 & 14,692 & 14,692 & 14,692 \\
\hline
\end{tabular}

Note: Age is in month; $\mathrm{Age}^{2}$ and $\mathrm{Age}^{3}$ are respectively the square and cube of the difference from the mean Age. The Individual Controls are: gender; secondary school completion; and age start claiming disability benefits. The Unemployment Rate is quarterly for the 51 Spanish administrative regions.

Table 20 RD results for different age windows around the eligibility age threshold.

\begin{tabular}{|c|c|c|c|c|}
\hline & \multicolumn{4}{|c|}{$\begin{array}{l}\text { Estimation on Individuals } \\
\text { Aged } 55 \text { and }+/-4,3,2 \text { and 1Year }\end{array}$} \\
\hline & $\begin{array}{c}\text { All } \\
\text { Ages }\end{array}$ & $\begin{array}{l}+/-3 \\
\text { Years }\end{array}$ & $\begin{array}{l}+/-2 \\
\text { Years }\end{array}$ & $\begin{array}{l}+/-1 \\
\text { Years }\end{array}$ \\
\hline $\begin{array}{l}\text { Discontinuity of DII Treatment Around Threshold } \\
\left(D I I^{+}-D I I^{-}\right)\end{array}$ & $\begin{array}{c}.612 \\
(.001)\end{array}$ & $\begin{array}{c}.595 \\
(.001)\end{array}$ & $\begin{array}{l}.567 \\
(.001)\end{array}$ & $\begin{array}{l}.517 \\
(.002)\end{array}$ \\
\hline $\begin{array}{l}\text { Difference in EMP Around } \\
\text { Threshold }\left(E M P^{+}-E M P^{-}\right)\end{array}$ & $\begin{array}{l}-.051 \\
(.001)\end{array}$ & $\begin{array}{l}-.041 \\
(.001)\end{array}$ & $\begin{array}{l}-.030 \\
(.001)\end{array}$ & $\begin{array}{l}-.016 \\
(.002)\end{array}$ \\
\hline $\begin{array}{l}\text { Estimated Effect of DII on EMP } \\
\begin{array}{ll}\text { Participation } & \left(E M P^{+}-E M P-\right) /\left(D I I^{+}-D I I^{-}\right)\end{array}\end{array}$ & $\begin{array}{l}-.084 \\
(.001)\end{array}$ & $\begin{array}{l}-.070 \\
(.002)\end{array}$ & $\begin{array}{l}-.052 \\
(.002)\end{array}$ & $\begin{array}{l}-.031 \\
(.003)\end{array}$ \\
\hline Number of Observations & 632,228 & 463,438 & 306,460 & 151,904 \\
\hline Number of Individuals & 14,692 & 12,424 & 10,314 & 8,313 \\
\hline
\end{tabular}


In Table 21 we report RD estimates which include DI claimant individual characteristics for the 55 years old $+/-1$ year sample. The second and third columns of results show that the inclusion of gender and secondary education completion dummies does not significantly change the estimated impact of the DI increase on EMP which remains roughly -.03. However, the inclusion of the age at which individuals started claiming disability benefits generates an RD estimate three times smaller. This suggests that this covariate is not linearly distributed around the eligibility age threshold although this was not graphically obvious from Figure 31. We may, for example, worry that the benefit generosity increase incites a number of individuals to start claiming DI after turning 55 and have low EMP probabilities (i.e. the new higher replacement rate is enough for them to use DI as a form of early retirement).

Table 21 RD results +/-1 year around eligibility age threshold with individual controls.

\begin{tabular}{|c|c|c|c|c|}
\hline \multirow[b]{2}{*}{$\begin{array}{l}\text { Discontinuity of DII Treatment Around Threshold } \\
\left(D I^{+}-D I I^{-}\right)\end{array}$} & \multicolumn{4}{|c|}{$\begin{array}{l}\text { Estimation on Individuals } \\
\text { Aged } 55 \text { and }+/-1 \text { Year }\end{array}$} \\
\hline & $\begin{array}{l}.517 \\
(.002)\end{array}$ & $\begin{array}{l}.517 \\
(.002)\end{array}$ & $\begin{array}{c}.517 \\
(.002)\end{array}$ & $\begin{array}{c}.508 \\
(.002)\end{array}$ \\
\hline $\begin{array}{l}\text { Difference in EMP Around } \\
\text { Threshold }\left(E M P^{+}-E M P^{-}\right)\end{array}$ & $\begin{array}{l}-.016 \\
(.002)\end{array}$ & $\begin{array}{l}-.016 \\
(.002)\end{array}$ & $\begin{array}{l}-.015 \\
(.001)\end{array}$ & $\begin{array}{l}-.006 \\
(.002)\end{array}$ \\
\hline $\begin{array}{l}\text { Estimated Effect of DII on EMP } \\
\text { Participation }\left(E M P^{+}-E M P^{-}\right) /\left(D I I^{+}-D I I^{-}\right)\end{array}$ & $\begin{array}{l}-.031 \\
(.003)\end{array}$ & $\begin{array}{l}-.030 \\
(.003)\end{array}$ & $\begin{array}{l}-.029 \\
(.002)\end{array}$ & $\begin{array}{l}-.011 \\
(.003)\end{array}$ \\
\hline Proportion Female & No & Yes & Yes & Yes \\
\hline Proportion with Secondary Education & No & No & Yes & Yes \\
\hline Age Started Claiming Disability & No & No & No & Yes \\
\hline Number of Observations & 151,904 & 151,904 & 151,904 & 151,904 \\
\hline Number of Individuals & 8,313 & 8,313 & 8,313 & 8,313 \\
\hline
\end{tabular}

Figure 33 plots the proportion of claimants who entered DI at different ages in our sample. We do find here that there appears to be a substantial acceleration in the proportion of new entries of individuals aged 55 or older into DI. This cannot be entirely explained by the natural increase of probability to claim DI with age. The jump in entry rates between ages 54 to 55 is substantial and we must therefore conclude to an important entry effect into DI of increasing the generosity of benefits available. To obtain an impact of DII on EMP net of entry effects, we restrict our sample to individuals who started claiming disability benefits before 
age 55. We report our RD estimates for the $+/-1$ year window including individual characteristic controls for this sample in Table 22. We first note that our RD estimates are robust to the inclusion of claimant individual characteristics suggesting that observed (and unobserved) characteristics of claimants around the threshold are linearly distributed for this sample. We therefore conclude that the net impact of DII is to reduce by 8 percent employment probability ${ }^{7071}$.

Figure 33 Distribution of age started claiming DI.

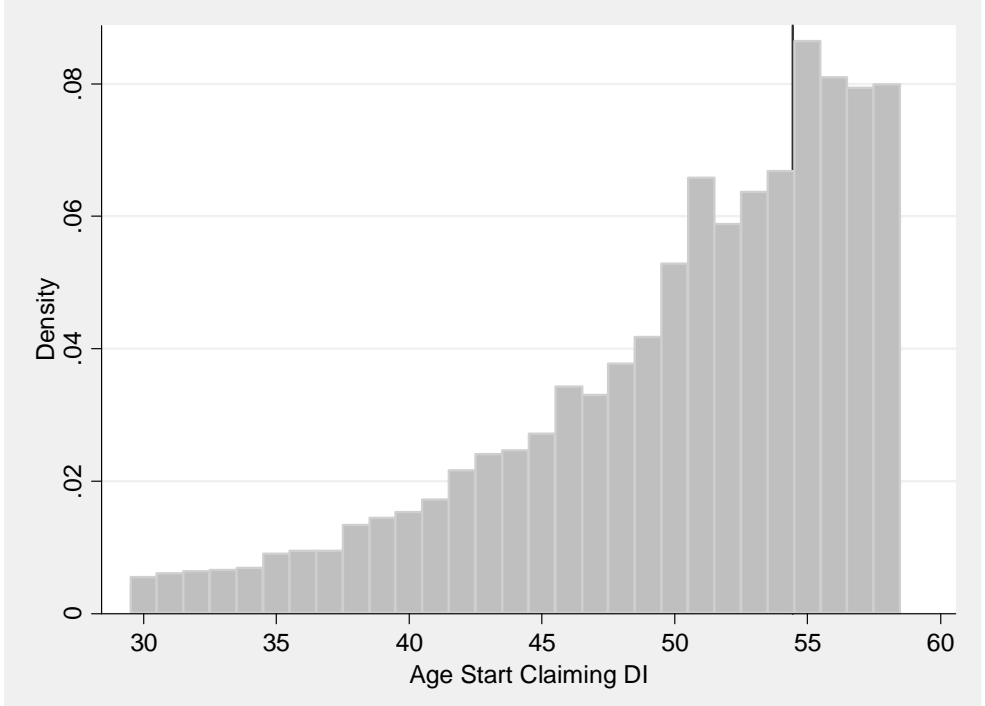

${ }^{70}$ The average EMP for this sample is of 12.5 percent and thus a 1 percentage point decrease corresponds to an 8 percent drop in employment probability.

${ }^{71}$ We recognize the fact that the effects of DI on employment could potentially be different for heterogeneous groups of individuals and we leave the analysis of these differential effects for future work. In this chapter, our interest lied on the estimation of the average effects of increasing DI benefits on employment prospects of the entire group of disabled individuals. 
Table 22 RD results +/-1 year around eligibility age threshold with individual controls for individuals who started claiming before age 55 .

Estimation on Individuals

Aged 55 and +/- 1Year

\begin{tabular}{lcccc} 
Discontinuity of DII Treatment Around Threshold & .500 & .500 & .500 & .498 \\
$\left(D^{+}-I^{+}-I^{-}\right)$ & $(.002)$ & $(.002)$ & $(.002)$ & $(.002)$ \\
Difference in EMP Around & -.007 & -.007 & -.007 & -.005 \\
Threshold $\left(E M P^{+}-E M P^{-}\right)$ & $(.002)$ & $(.002)$ & $(.002)$ & $(.002)$ \\
& -.014 & -.015 & -.013 & -.010 \\
Estimated Effect of DII on EMP & $(.003)$ & $(.003)$ & $(.002)$ & $(.003)$ \\
Participation $\left(E M P^{+}-E M P^{-}\right) /\left(I^{+}-D^{-}\right)$ & No & Yes & Yes & Yes \\
Proportion Female & No & No & Yes & Yes \\
Proportion with Secondary Education & No & No & No & Yes \\
Age Started Claiming Disability & 138,121 & 138,121 & 138,121 & 138,121 \\
Number of Observations & 6,879 & 6,879 & 6,879 & 6,879 \\
\hline Number of Individuals & & & &
\end{tabular}

\subsection{Conclusions}

In this chapter we analyze the employment effects of a 36 percent increase in the amount of disability benefits (DII) that is granted to almost 60 percent of the individuals aged 55 or above who are receiving a partial disability pension in Spain. The DI system in Spain allows partially disabled claimants to combine the receipt of benefits with income from employment without any implicit tax on labour supply being levied (and even providing for tax incentives to work).

We exploit this discontinuity of DII provision from age 55 onwards and first use a straightforward fuzzy regression discontinuity approach to estimate the effect of treatment on EMP (which are likely to be endogenously determined). We generate RD estimates using different age windows, from $+/-4$ to 1 year before and after the cut-off age, which suggests that the increase in DI generosity reduces the probability of working by, at least, 3 percentage points.

However, once we model more carefully for the impact of other individual characteristics we discover an acceleration of entry into DI of claimants aged 55 and older which we believe is partly due to the increased generosity of available benefits. Once we take this phenomenon into account, and estimate the RD model only with individuals that entered the disability rolls before turning 55 years old, our results suggest that the employment of DI recipients would have been 8 116 
percent higher had they not received the benefit increase. Since the replacement rate is in practice increased by 36 percent, this translates into an elasticity of DI generosity to EMP of approximately 22 .

These results are very much in line with the literature on the employment effect of DI almost unanimously concluding to a negative causal relationship. Our results nevertheless are an important contribution for two distinct reasons. Firstly, they are among the first, together with Gruber (2000), to focus on the impact of benefit generosity rather than entitlement. Secondly, the features of the DI institutional system we study make it possible to rule out that this impact stems from a substitution effect. As benefit receipt is not work contingent, it suggests that there is an important income effect at play in the work decision of older workers as observed by Autor and Duggan $(2007,2008)$.

This latter point is important in terms of the efficiency of policy reforms since an income effect does not imply any deadweight loss. We believe this should be seriously considered in future reforms which may use the disincentive substitution argument to cut the benefits of a group in an already relatively weak income position. This is especially true considering the findings by Bound et al. (2004) that workers on average value increased benefits somewhat above the average cost of providing them. 


\section{Appendix; Tables and figures}

Figure 34 Description of the claiming process to access permanent disability benefits

What is the permanent disability pension?

It is a pension that is recognized to workers who, after having followed the prescribed treatment, they still present severe anatomic or functional reductions that diminish or abolish his/her working capacity in a permanent way.

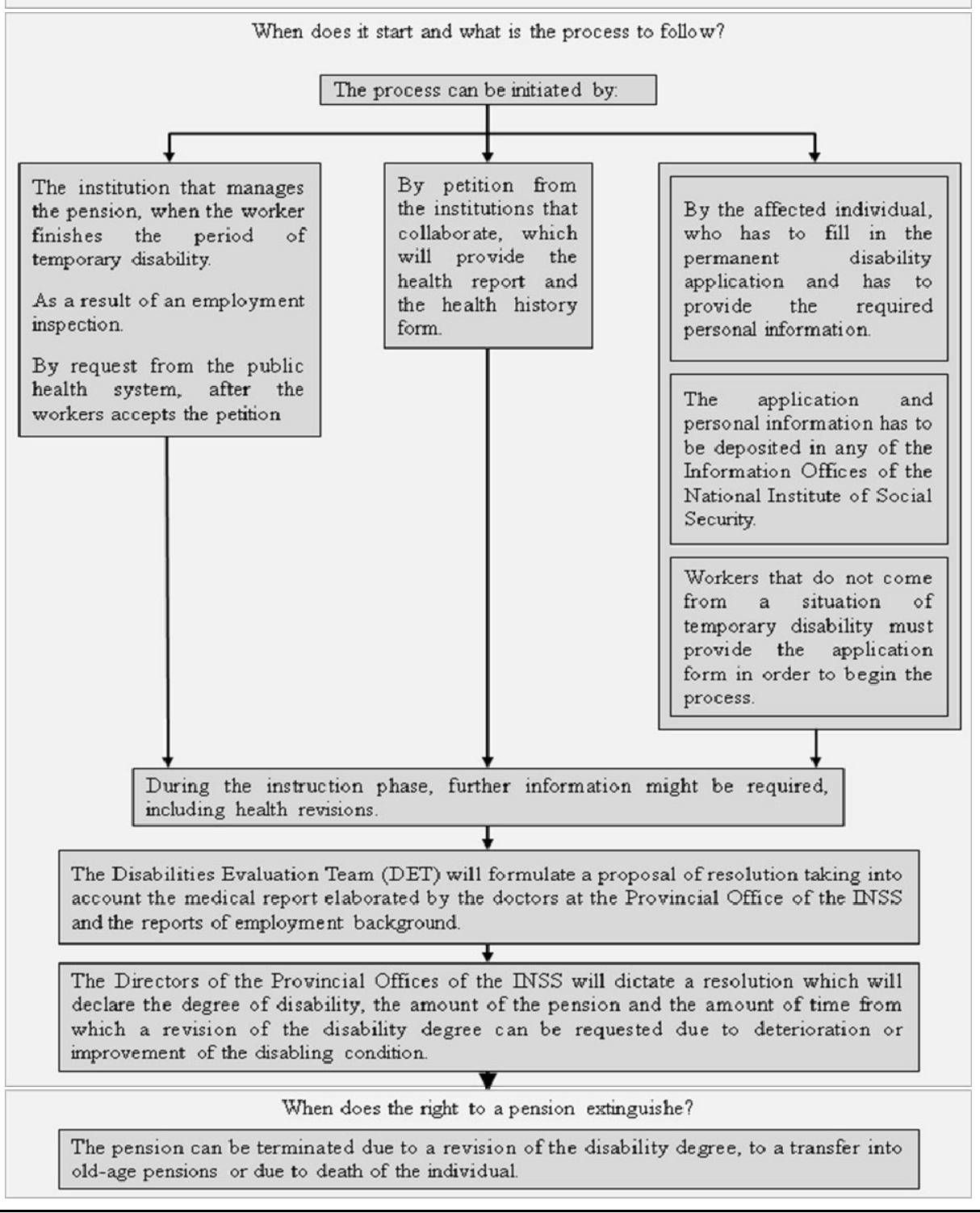

Source: Own translation from the legislation available at the webpage of the Spanish Social Security Administration. 
5. Conclusion 
This dissertation studies two broad aspects of the disability system in Spain, the inflow into the disability system and the labour market situation of individuals once they are on the disability rolls. Chapter 2 focuses on the first of these two aspects and analyzes the effects of the business cycle on transitions from employment to unemployment, inactivity and disability benefits for older individuals approaching retirement age. Chapter 3 gives an overall overview of the main characteristics of disabled individuals and their relation to the labour market and evaluates the effects of a policy introduced to raise the employment prospects of disabled women. Chapter 4 captures the disincentives to work provided by an increase in the amount of disability benefits for individuals who are older than 55 and are deemed to have lower chances of finding a job.

In this final chapter, we revise each of the previous chapters and highlight their main conclusions and policy implications.

\subsection{Business Cycle Effects on Labour Force Transitions for Older People in Spain}

Even if the inflow into disability benefits has not experienced a dramatic increase in Spain during the last years (as it has in other countries like The Netherlands or the USA), it is still important to understand which variables have an influence on this inflow rate and to what extent there is a situation of complementarity or substitution between the exits out of the labour market into unemployment, inactivity and disability benefits.

In Chapter 2 we have applied two duration models in order to identify the effect of business cycle conditions on transitions out of the labour force for older individuals aged 45-59 in the Spanish economy. In the first part, we fit a logistic regression model for single exit transitions from employment to all the other nonemployment situations whereas in the second part we distinguish between exits from employment to either unemployment, inactivity or disability benefits with a competing risk duration model. This exercise allows us to understand the kind of transitions that are happening in the Spanish labour market for individuals approaching retirement age (but not yet entitled to neither retirement nor early retirement benefits) and to assess the contribution of business cycle conditions to these transitions.

At the same time, we also include in the model dummy variables at ages 52, 55 and 58 because of the existence of certain special schemes in the legislation that have the potential to facilitate the transitions at these ages. The aim is to test 
whether the existence of these schemes induce people to behave accordingly and to do the transitions at exactly these ages.

We highlight three main results that can be derived from our analysis. Firstly, business cycle conditions are found to be an important determinant in explaining transitions from employment to both unemployment and disability benefits. Our estimations suggest that individuals are more likely to enter into the disability rolls and receive disability benefits when the unemployment rate of the region in which they live increases as well as when the GDP growth of the country decreases. Therefore, business cycle conditions at both the local and the national level are important determinants for transitions out of the labour force for older individuals in Spain and, more specifically, they are strong determinants of the inflow into disability benefits. In terms of policy implications, this means that disability benefits are, to a certain extent, being used as an alternative tool to leave the labour force for individuals who do not have access to other benefits (such as unemployment) and are also being strategically used by firms to renew their labour force and substitute older workers by younger ones.

Secondly, our results also show that the effect of the economic environment of the sector of activity is stronger in affecting transitions from employment to disability benefits than the effect of the economic environment in the region where the individual lives.

Finally, we find that the special schemes available at ages 52,55 and 58 induce a strategic behavior from individuals and firms to leave the labour force at exactly these ages, particularly so for exits to unemployment benefits.

Therefore, the authorities should be very careful when designing the rules to access disability benefits as, in many occasions, they induce individuals and firms to act strategically to maximize their opportunities and chances to get accepted into the system. Similarly, the use of the disability system as an alternative stabilization tool in times of economic downturns should also be revised by the government as this is not the objective of such a system and there are already other systems in place, such as unemployment and social assistance benefits, to serve this objective (although, from the point of view of the worker, they don't offer a life-time income).

\subsection{Promoting Employment of Disabled Women in Spain: Evaluating a Policy}

There are several legislation measures in place in Spain that try to protect and promote the labour market opportunities of disabled individuals. However, these measures have never been properly analyzed before due to serious problems 
in finding the right data for the evaluations. Therefore, we make use of a recently released administrative database from the Social Security Administration in Spain that contains information on both permanent disability benefits and employment and unemployment profiles of the individuals included in the sample to develop, in Chapter 3, the first analysis of the effectiveness of an employment promotion policy targeted towards disabled individuals. For this reason, after a process of reviewing all the legislation in place and the changes occurred since the 1980's in Spain in terms of permanent disability benefits, we focus on evaluating the employment effects of a law that was introduced in 2004 which increased the deductions to the Social Security contributions paid by the employer that hired a disabled woman. The aim of this legislative change was to promote the labour market integration of disabled women as it was argued that this group of individuals was suffering from a double discrimination in the Spanish labour market.

We proceed in our analysis in two steps. Firstly, we empirically investigate the evolution of the labour market situation of disabled individuals in Spain in the last 12 years and explore some of the characteristics of the composition of this sample of individuals. In doing so, we realize that there exists the possibility of having differential trends in the evolution of employment between men and women before the introduction of the policy change. For that reason, we estimate a model that evaluates the existence of any shift in the trend of employment in the women relative to the men sample following the policy change but introducing controls to condition on any preexisting trends (following Autor and Duggan, 2008).

Furthermore, in order to take into account the availability of both partial and total disability benefits in Spain and the interactions that this could have with employment prospects, we estimate a bivariate probit model with one equation capturing the labour market situation and the other one capturing the type of pension received.

Our findings are pretty stable across the several specifications that we have estimated and suggest that the policy change boosts employment of disabled women vis-à-vis disabled men. However, this positive effect is only significant for the younger group of individuals in the sample, individuals below the age of 45 . The policy turns out not to be significant for the older group of disabled women.

Therefore, the question still remains to find the best policy to promote the labour market integration of older disabled individuals (in particular women) who seem to be less responsive to the financial incentives to employers.

Moreover, our results suggest that further incentive measures and mediation mechanisms between disabled workers and employers need to be introduced in 
order to maximize the potential positive results in terms of employment prospects of disabled individuals as the current measures are not fully used and many disabled workers claim to receive no help or guidance from the public administration services to find a job (EDAD survey 2008).

\subsection{The Employment Effect of Increasing Disability Benefits: A Regression Discontinuity Approach}

Even if in Spain individuals with a partial disability are given the change to receive $55 \%$ of the benefits while being completely allowed to work as much as they want, the data reveals that, in reality, only a few of them do actually work. Having such a dual system in which disabled individuals are divided between partial and total disability according to their degree of disability and their remaining capacity to work is what other countries, such as the USA, have been claiming for.

Most of the criticisms to disability policies in the literature have focused on the potential disincentives to work embedded in the system. As the OECD suggests, maybe one of the reasons why so few partially disabled individuals in Spain are effectively working is found on the disincentives to work derived from within the system.

Again, this is a topic that has never been properly analyzed for the case of Spain and is the central aim of Chapter 4 . In this chapter we focus on a law that allows for a $36 \%$ increase in the amount of disability benefits (from 55 to $75 \%$ of the regulatory base) received by partially disabled individuals who are 55 (or older) and who are, as a result of their lack of skills and of the labour market conditions they face, deemed unlikely to find a job. As the selection process for being treated (receiving the increase) is conditional on having a low probability of employment, traditional diff-diff strategies will give biased results.

Therefore, our approach is to explode the fact that selection for treatment is clearly defined by age in order to apply regression discontinuity (RD) models. We use two alternative RD specifications; a traditional fuzzy RD and a second one in which we restrict the sample to individuals who joined the disability rolls before turning 55. We introduce this new specification as we corroborate the existence of non-linearities of this covariate (age at which they start receiving disability benefits) around the eligibility age threshold. We interpret this as evidence that the benefit increase accelerates the entry rate into DI of individuals aged 55 and over. We include 4 different samples of individuals $+/-4(+/-3,2$ and 1) years around the age threshold and apply the estimation methods mentioned above. 
Our results suggest that traditional OLS and fixed effects models with a dummy variable capturing the treatment effect significantly overestimate the effect of the policy in reducing employment (EMP) of disabled individuals. Our traditional RD results report a statistically significant reduction of the probability of working by 3 percentage points as a result of the increase in the generosity of benefits. However, once we restrict the sample to individuals who joined DI before age 55, the new estimates suggest that the policy decreases employment probability by 1 percentage points (as the average employment rate for this sample is 12.5 percent, a 1 percentage point decrease corresponds to an 8 percent drop in employment probability).

Therefore, in this chapter we quantify the effect of increasing disability benefits on employment of disabled individuals in a system in which benefit receipt is not work contingent. We interpret this result as evidence of the existence of an income effect instead of a substitution effect, in line with the argumentation in Autor and Duggan (2008). Furthermore, our results are very similar to what has been previously obtained in the literature, particularly in the case of Gruber (2000) which estimates an elasticity of benefits with respect to employment of $0.28-0.36$ for an increase of $36 \%$ in disability benefits in Canada. Our estimates translate into an elasticity of 0.22 also for an increase of $36 \%$ in the benefits.

\subsection{Main Policy Implications and Further Work}

As we have summarized in this concluding chapter, each of the topics analyzed throughout this book has resulted in a number of policy implications. Adopting an overall look, the main conclusions that can be extracted from this book point to the need to reform the disability system in Spain in order to introduce real incentives for disabled individuals to find a job as well as to abolish a number of legislative measures which provide, from the one hand a clear incentive to join the disability rolls at certain ages and from the other hand, disincentives for partially disabled individuals to search for a job at other ages.

As the inflow into the disability rolls has not experienced a dramatic increase in Spain during the past years, the government has not been pressured to introduce any important reform in the system and it has not made any serious attempt to foster the integration in the labour market of partially disabled individuals which would, in turn, improve and facilitate their integration in the society as a whole.

When designing and implementing this needed reform of the disability system, a particularly important emphasis should be placed in the case of older disabled individuals and disabled women, as they have proved to be two of the most difficult targets in terms of employment integration policies. 
Therefore, the Spanish authorities should basically focus their reform efforts on four main points:

1. Abolishing the incentive effects of joining the disability rolls at certain ages, which have been documented in chapter 2 of this book.

2. Abolishing the disincentives to work provided by the system at age 55, which have been documented in chapter 4 of this book.

3. Introducing new incentives (or monitoring the current unfulfilled obligations) of employers to hire disabled workers. As chapter 3 of this book has documented, the current ones prove to have limited effects.

4. Introducing new mechanisms and institutions to help disabled individuals in the job search process in order to decrease the search effort needed and to improve the match between the characteristics of the disabled employee and the needs of the firm.

As for future work, the idea is to extend the analysis done in chapter 2 to an European context in order to study whether the effects of the business cycle at the level of the regions and the economic sectors that are found for the Spanish case, can also be generalized to the European context.

For the Spanish context, further work needs to be done to study the incidence of temporary disability and sickness benefits as a stabilization tool in response to fluctuations of the business cycle and its interactions with the permanent disability scheme. Particular attention needs to be placed to identify how the labour market transitions documented in this book have been affected by the current economic crisis. 



\section{References}

Aarts, L.J.M. \& P.R.De Jong. (1996). European Experiences with Disability Policy. In Mashaw, J.L., V.Reno, R.V.Burkhauser \& M.Berkowitz (Eds.), Disability, Work and Cash Benefits. W.E. Upjohn Institute for Employment Research. Kalamazoo, Michigan.

Acemoglu, D. \& J.Angrist. (2001). Consequences of Employment Protection? The Case of the Americans with Disabilities Act. Journal of Political Economy, 109(5), 915-957.

Alba-Ramirez, A. (1997). Labour Force Participation and Transitions of Older Workers in Spain. Working paper 97-39 U. Carlos III Madrid.

Alba, A. \& F.Moreno. (2004). Discapacidad y Mercado de Trabajo. Obra Social Caja Madrid. Gente Interactiva. S.L. Madrid.

Allison, P.D. (1982). Discrete-Time Methods for the Analysis of Event Histories. In Leinhardt, S. (Ed.), Sociological Methodology. San Francisco, CA: Jossey-Bass Publishers.

Argimon, I., C.I.Gonzalez, \& R.Vegas. (2007). Retirement Behaviour and Retirement Incentives in Spain. Banco de España.

Autor, D.H. \& M.G.Duggan. (2003). The Rise in the Disability Rolls and the Decline in Unemployment. Quarterly Journal of Economics, 118, 157-205.

Autor, D.H. \& M.G.Duggan. (2006). The Growth in the Social Security Disability Role: A Fiscal Crisis Unfolding. Journal of Economic Perspectives, 20(3), 71-96.

Autor, D.H. \& M.G.Duggan. (2007). Distinguishin Income from Substitution Effect in Disability Insurance. American Economic Review Papers and Proceedings, 97(2), 119-124.

Autor, D.H. \& M.G.Duggan. (2008). The Effect of Transfer Income on Labour Force Participation and Enrollment in Federal Benefits Programs: Evidence from the Veterans Disability Compensation Program. A Report to the Social Security Administration.

Balleer, A., R.Gómez-Salvador \& J.Turunen. (2009). Labour Force Participation in the Euro Area; A Cohort Based Analysis. Working Paper Series No. 1049 European Central Bank, Frankfurt am Main. 
Beegle, K. \& W.Stock. (2003). The Labour Market Effects of Disability Discrimination Laws. Journal of Human Resources, 38(4), 806.

Bell, D. \& A.Heitmueller. (2005). The Disability Discrimination Act in the UK: Helping or Hindering Employment Amongst the Disabled?. IZA Discussion Papers 1476, Institute for the Study of Labour (IZA).

Benítez-Silva, H., M.Buchinsky, H.Chan, S.Cheidvasser \& J.Rust. (1999). An Empirical Analysis of the Social Security Disability Application, Appeal and Award Process. Labour Economics, 6, 147-178.

Benítez-Silva, H., M.Buchinsky, H.Chan, S.Cheidvasser \& J.Rust. (2004). How Large is the Bias in Self-Reported Disability?. Journal of Applied Econometrics, 19-6, 649-670.

Benítez-Silva, H., M.Buchinsky \& J.Rust. (2006). How Large are the Classification Errors in the Social Security Disability Award Process?. NBER Working Paper 10219.

Benítez-Silva, H. \& F.Heiland. (2007). The Social Security Earnings Test and Work Incentives. Journal of Policy Analysis and Management, 26-3, 527-555.

Benítez-Silva, H., M.Buchinsky \& J.Rust. (2008). Using a Life Cycle Model to Predict Induced Entry Effects of a $\$ 1$ for $\$ 2$ Benefit Offset in the SSDI Program. Forthcoming in the Journal of Policy Analysis and Management.

Benítez-Silva, H. \& F.Heiland. (2008). Early claiming of Social Security Benefits and Labour Supply Behavior of Older Americans. Applied Economics, 40-23, 2969-2985.

Benitez-Silva, H., J.I.Garcia-Perez \& S.Jimenez-Martin. (2008). A Cross Country Comparison of the Effects of Social Security Policies and Employment Uncertainty on the Labour Supply and Claiming Behaviour of Older Workers. MIMEO.

Berg, G.J.V.D. \& B.V.D.Klaauw. (2000). Combining Micro and Macro Unemployment Duration Data. IZA Discussion Paper No. 109.

Blanco, A. (2000). The Decision of Early Retirement in Spain. FEDEA EEE 76.

Blanco, J.M. (2002). Las Incapacidades Laborales. Un punto de vista práctico. $2^{\underline{a}}$ edition, Editorial Lex Nova, Valladolid.

Blau, D.M. (1994). Labour Force Dynamics of Older Men. Econometrica, 62, 117-156.

Blondal, S. \& S.Scarpetta. (1998). Falling Participation Rates among Older Workers in OECD Countries: The Role of Social Security Systems. OECD Economic Department Working Paper. 
Boldrin, M., S.Jimenez-Martin \& F.Peracchi. (1999). Social Security and Retirement in Spain. In Gruber, J. \& D.Wise (Ed.), Social Security Programs and Retirement around the World, Chicago University Press for the NBER.

- (2004). Micro-Modelling of Retirement Behaviour in Spain. In Gruber, J. \& D. Wise (Ed.), Social Security and Retirement around the World: Micro-Estimation, Chicago University Press for the NBER.

Börsch-Supan, A. (1998). Incentive Effects of Social Security on Labour Force Participation: Evidence in Germany and across Europe. National Bureau of Economic Research, NBER Working Paper No.6780, Cambridge MA.

Bound, J. (1989). The Health and Earnings of Rejected Disability Insurance Applicants. American Economic Review, 79(3), 482-503.

Bound, J., M.Schoenmbaum, T.R.Stinebrickner \& T.Waidman. (1999). The Dynamic Effects of Health on the Labour Force Transitions of Older Workers. Labour Economics, 6, 179-202.

Bound, J. \& R.Burkhauser. (1999). Economic Analysis of Transfer Programs Targeted on People with Disabilities. In Ashenfelter, O. \& D.Card (Eds.), Handbook of Labor Economics, 3C. Elsevier Science, North Holland. Amsterdam, The Netherlands.

Bound, J., J.B.Cullen, A.Nichols \& L.Schmidt. (2004). The Welfare Implications of Increasing Disability Insurance Benefit Generosity. Journal of Public Economics, 88(12) 2487-2514.

Bover, O., M.Arellano \& S.Bentolila. (2002). Unemployment Duration, Benefit Duration and the Business Cycle. Economic Journal, 112, 223-265.

Bover, O. \& R.Gomez. (2004). Another Look at Unemployment Duration: Exit to a Permanent Vs. A Temporary Job. Investigaciones Economicas, XXVIII, 285314.

Burkhauser, R.V., A.J.Houtenville \& D.C.Wittenburg. (2003). A User's Guide to Current Statistics on the Employment of People with Disabilities. In Stapleton, D.C. \& R.V. Burkhauser (Eds.), The Decline of People with Disabilities: A Policy Puzzle. W.E. Upjohn Institute for Employment Research. Kalamazoo, Michigan.

Burkhauser, R.V., M.C.Daly \& P.R.De Jong. (2008). Curing the Dutch Disease: Lessons for United States Disability Policy. Michigan Retirement Research Center Working Paper 2008-188.

Cairo, I. (2007). An Empirical Analysis of Retirement Behaviour in Spain: Partial Vs. Full Retirement. Unpublished. 
Chen, S. \& W.Van Der Klaauw. (2008). The Work Disincentive Effects of the Disability Insurance Program in the 1990s. Journal of Econometrics, 142, 757784.

Corden, A. \& R.Sainsbury. (2001). Incapacity Benefits and Work Incentives. Research Report No.141, Department for Work and Benefits, London.

Darby, J., R.A.Hart \& M.Vecchi. (2001). Labour Force Participation and the Business Cycle: A Comparative Analysis of France, Japan, Sweden and the United States. Japan and the World Economy, 13, 113-133.

DeLeire, T. (2000). The Wage and Employment Effects of the Americans with Disabilities Act. Journal of Human Resources, 35(4), 693-715.

DEWR-Department of Employment and Workplace Relations. (2005). Job Network Disability Support Pension Pilot Progress Report. Canberra.

Duell, N., S.Singh \& P.Tergeist. (2009). Activation Policies in Norway. OECD Social Employment and Migration Working Papers No.78, OECD Publishing.

Euwals, R., M.Knoef \& D.Van Vuuren. (2007). The Trend in Female Labour Force Participation: What can be Expected for the Future?. IZA Discussion Paper 3225, Bonn.

FaCS-Department of Family and Community Services. (2003). Improving Employment Opportunities for People with a Disability: Report of the Review of the Employer Incentives Strategy. Canberra.

Fischer, J.A.V. \& A.Sousa-Poza. (2006). The Institutional Determinants of Early Retirement in Europe. Universitat St.Gallen Discussion Paper No.2006-08.

Garcia-Perez, I. \& N.Ahn. (2002). Unemployment Duration and Workers' Wage Aspirations in Spain. Investigaciones Económicas.

Garcia-Perez, I. \& Y.Rebollo. (2005). Wage Changes Through Job Mobility in Europe: A Multinomial Endogenous Switching Approach. Labour Economics.

Garcia-Perez, I. (2006). Non-stationary job search when jobs do not last forever: a structural estimation to evaluate alternative unemployment insurance systems. Journal of Applied Econometrics, 21(2), 245-272.

Garcia-Perez, I. \& Y.Rebollo. (2007). The Use of Permanent and Temporary Jobs Across Spanish Regions: Do Unit Labour Cost Differentials Offer an Explanation?. Moneda y Crédito.

Garcia-Perez, I. (2008). La Muestra Continua de Vidas Laborales: Una Guia de Uso para el Análisis de Transiciones. Revista de Economía Aplicada, E-1, XVI. 
Garcia-Perez, I. \& A.Sanchez-Martin. (2008). Social Security and the Search Behavior of Workers Approaching Retirement. Working Paper Universidad Pablo de Olavide Sevilla.

Garcia-Perez, I., S.Jimenez-Martin \& A.R.Sanchez-Martin. (2008). Incentivos Implicitos en el Sistema de Proteccion Social en Espana y sus efectos sobre las pautas de retiro. Informe Proyecto FIPROS 2007/17.

Garcia-Perez, I. \& Y.Rebollo. (2009). The Use of Permanent Contracts Across Spanish Regions: Do Regional Wage Subsidies Work?. Investigaciones Económicas.

Gielen, A.C. (2007). Working Hours Flexibility and Older Workers' Labour Supply. IZA Discussion Paper No. 2946.

Greene, W.H. (2008). Econometric Analysis. Sixth Edition, Prentice Hall, New Jersey.

Gruber, J. \& D.A.Wise. (1999). Social Security and Retirement around the World. Chicago University Press for the NBER.

Gruber, J. (2000). Disability Insurance Benefits and Labour Supply. Journal of Political Economy 108(6), 1162-1183.

Gruber, J. \& D.A.Wise. (2004). Social Security and Retirement around the World: Micro Estimation. Chicago University Press for the NBER.

Gruber, J. \& D.A.Wise. (2007). Social Security and Retirement around the World: Fiscal Implications. Chicago University Press for the NBER.

Gutierrez-Domenech, M. (2006). The Employment of Older Workers. La Caixa Working Paper Series No.04/2006.

Haardt, D. (2006). Transitions out of and Back to Employment among Older Men and Women in the UK. ISER Working Paper. 2006-20. Colchester: University of Essex.

Hahn, J., P.Todd \& W.Van Der Klaauw. (2001). Identification and Estimation of Treatment Effects with a Regression-Discontinuity Design. Econometrica, 69(1), 201-209.

Harding, A., Q.N.Vu \& R.Percival. (2005). The Distributional Impact of the Welfare-to-Work Reforms Upon Australians with Disabilities. NATSEM Working Paper, Canberra.

Hartmann-Hirsch, C. (2006). L'incapacité de travail. Une mesure de maintien à l'emploi aux effets pervers?. Population et Emploi 19, CEPS/INSTEAD, Luxembourg. 
Hassink, W.H.J., J.C.Van Ours \& G.Ridder. (1997). Dismissal Through Disability. De Economist, 145, 24-46.

Haveman, R.H. \& B.Wolfe. (2000). The Economics of Disability and Disability Policy. In Culyer, A.J. \& J.P. Newhouse (Eds.), Handbook of Health Economics, 1. Elsevier Science, North Holland. Amsterdam, The Netherlands.

Hoynes, H.W. \& R.Moffitt. (1996). The Effectiveness of Financial Work Incentives in Social Security Disability Insurance and Supplemental Security Income: Lessons from Other Transfer Programs. In Mashaw, J.L., V.Reno, R.V.Burkhauser \& M.Berkowitz (Eds.), Disability, Work and Cash Benefits. W.E. Upjohn Institute for Employment Research. Kalamazoo, Michigan.

Humer, B., J.P.Wuellrich \& J.Zweimüller. (2007). Integrating Severely Disabled Individuals into the Labour Market: The Austrian Case. IZA Working Paper No. 2649.

Hyatt, D. (1996). Work Disincentives of Workers' Compensation Permanent Partial Disability Benefits: Evidence for Canada. The Canadian Journal of Economics, 29(2), 289-308.

Jenkins, S. (2004). Survival Analysis. Colchester: Institute for Social and Economic Research, University of Essex.

Jenkins, S.P. \& C.Garcia-Serrano. (2004). The Relationship between Unemployment Benefits and Re-Employment Probabilities: Evidence from Spain. Oxford Bulletin of Economics and Statistics, 66, 305-329.

Jimenez-Martin, A. \& S.Sanchez-Martin. (2004). Social Security Rules, Monetary Incentives and Retirement Behaviour in Spain. Hacienda Publica Española, 2004.

Jimemez-Martin, S., J.M. Labeaga \& C.Vilaplana.Prieto. (2006a). A sequential model for older workers' labour transitions after a health shock. Health Economics, 15(9), 1033-1059.

Jiménez-Martín, S., J.M.Labeaga \& C.Vilaplana-Prieto. (2006b). Award Errors and Permanent Disability Benefits in Spain. Universitat Pompeu Fabra WP-966.

Jimenez-Martin, A. \& S.Sanchez-Martin. (2007). An evaluation of the life-cycle effects of minimum benefits on retirement behavior. Journal of Applied Econometrics, 22(5), 923-950, 2007.

Jiménez-Martín, S. (2008). Aspectos Económicos de la Dependencia y el Cuidado Informal en España. Universitat Pompeu Fabra, Fedea y Fundación AstrZeneca. 
Jiménez-Martín, S. \& J.Vall-Castello. (2009). Business Cycle Effects on Labour Force Transitions for Older People in Spain. FEDEA Working Paper 2009-25.

Jolls, C. (2004). Identifying the Effects of the Americans with Disabilities Act Using State-Law Variation: Preliminary Evidence on Educational Participation Effects. The American Economic Review, 94(2), 447-453.

Jolls, C. \& J.Prescott. (2004). Disaggregating Employment Protection: The Case of Disability Discrimination. Working Paper 10740, National Bureau of Economic Research.

Juhn, C. (1992). Decline of Male Labour Market Participation: The Role of Declining Market Opportunities. Quarterly Journal of Economics, 107, 79-121.

Koning, P. \& D.Van Vuuren. (2007). Hidden Unemployment in Disability Insurance. Labour, 21, 611-636.

Koning, P. \& D.Van Vuuren. (2009). Disability Insurance and Unemployment Insurance as Substitute Pathways, forthcoming in Applied Economics.

Kruse, D. \& L.Schur. (2003). Employment of People with Disabilities Following the ADA. Industrial Relations, 42(1), 31-66.

Lalive, R., J.P.Wuellrich \& J.Zweimüller. (2009). Do Financial Incentives for Firms Promote Employment of Disabled Workers? A Regression Discontinuity Approach. CEPR Discussion Paper No.7373.

Lemieux, T. \& K.Millingan. (2008). Incentive Effects of Social Assistance: A Regression Discontinuity Approach. Journal of Econometrics, 142(2), 807-828.

Machin, S. \& O.Marie. (2009). Crime and Police Resources: The Street Crime Initiative. Journal of the European Economic Association, 8(4).

Maestas, N. \& N.Yin. (2008). The Labour Supply Effects of Disability Insurance Work Disincentives: Evidence from the Automatic Conversion to Retirement Benefits at Full Retirement Age. University of Michigan Retirement Research Center Working Paper 2008-194.

Magnac, T. \& D.Thesmar. (2002). Identifying Dynamic Discrete Decision Processes. Econometrica, 70-2, 801-816.

Malo, M.A. (2004). Cómo Afectan las Discapacidades a la Probabilidad de ser Activo en España? Un Análisis Empírico con Datos de la Encuesta sobre Discapacidades, Deficiencias y Estado de Salud de 1999. Cuadernos de Economía, 27, 75-108.

Malo, M.A. \& F.Muñoz-Bullón. (2006). Employment Promotion Measures and the Quality of the Job Match for Persons with Disabilities. Hacienda Pública Española, 179, 79-111. 
Malo, M.A., B.Cueto \& V.Rodríguez. (2007). Compatibilidad entre Pensiones Contributivas por Incapacidad y Empleo: El Caso Español. Presented at the Economic Well-Being and Social Protection in Southern Europe: Changing Policies and Trends, Instituto de Estudios Fiscales, Madrid.

Marie, O. \& S.Machin (forthcoming). Crime and Police Resources: The Street Crime Initiative. Journal of the European Economic Association.

Meghir, C. \& E.Whitehouse. (1997). Labour Market Transitions and Retirement of Men in the UK. Journal of Econometrics, 79, 327-354.

Narendranathan, W. \& M.Stewart. (1993). Modelling the Probability of Leaving Unemployment: Competing Risk Models with Flexible Base-Line Hazards. Applied Statistics, 42, 63-83.

OECD. (2003). Transforming Disability into Ability: Policies to Promote Work and Income Security for Disabled People. OECD, Paris.

OECD. (2007a). Sickness, Disability and Work: Breaking the Barriers. 2: Australia, Luxembourg, Spain and the United Kingdom. OECD, Paris.

OECD. (2007b). New Ways of Addressing Partial Work Capacity. OECD, Paris.

OECD. (2008). Sickness, Disability and Work: Breaking the Barriers: Vol. 3: Denmark, Finland, Ireland and The Netherlands. OECD, Paris.

OECD. (2009). Sickness, Disability and Work: Keeping on Track in the Economic Downturn: Background Paper. OECD, Paris.

Prieto-Rodriguez, J. \& C.Rodriguez-Gutierrez. (2000). The Added Worker Effect in the Spanish Case. Applied Economics, 32, 1917-1925.

Stafford, B., et al. (2006). New Deal for Disabled People: Second Synthesis ReportInterim Findings from the Evaluation. Research Report No.377, Department for Work and Benefits, London.

Stephens, M. (2002). Worker Displacement and the Added Worker Effect. Journal of Labor Economics, 20, 504-537.

Vall-Castello, J. (2010). Promoting Employment of Disabled Women in Spain: Evaluating a Policy. FEDEA Working Paper 2010-10.

Van Ours, J.C. (2006). Leaving "Hotel California" How Incentives Affect Flows of Benefit Recipients in The Netherlands. CentER Discussion Paper No.2006116.

Vendrik, M. \& Cörvers, F. (2009). Male and Female Labour Force Participation: The Role of Dynamic Adjustments to changes in Labour Demand, Government 
Policies and Autonomous Trends. ROA-RM-2009/13, Maastricht University. Also available as IZA paper No.4397.

Wagner, J., C.Schnabel \& A.Kölling. (2001). Threshold Values in German Labour Law and Job Dynamics in Small Firms: The Case of the Disability Law. IZA Discussion Papers 386, Institute for the Study of Labour (IZA).

Yin, N. (2008). Partial Benefits in the Social Security Disability Insurance: A Policy Alternative to Foster Work among the Disabled. Manuscript, SUNY-Stony Brook and Baruch College. 


\section{Nederlandse Samenvatting}

Arbeidsongeschiktheidsbeleid heeft recentelijk veel aandacht gekregen in OECD landen, aangezien arbeidsongeschiktheidsverzekeringssystemen één van de belangrijkste obstakels zijn in een poging om arbeidsmarkt participatie in ontwikkelde landen te laten stijgen (of dalingen in arbeidsmarkt participatie tegen te gaan.. Veel hervormingen zijn ingevoerd in de OECD landen om werkelozen aan het werk te krijgen en vervroegde pensioen schema's af te schaffen. Deze hervormingen hebben, samengaand met economische groei, geleid tot dalingen in de werkeloosheidscijfers. Echter, deze positieve ontwikkelingen hebben zich vertaald in een hogere arbeidsongeschiktheid onder bevolkingsgroepen, specifiek onder oudere werknemers. Tevens staat vast dat werkgelegenheids percentages van arbeidsongeschikten zeer laag zijn gebleven, ondanks stijgingen in de Bruto Nationale Inkomens.

Daarom hebben zowel nationale als ook internationale autoriteiten de noodzaak ingezien om actie te ondernemen: ten eerste door een controle op / beperking van de instroom van mensen in de arbeidsongeschiktheids regelingen en ten tweede, door invoering van reintegratiebeleid voor arbeidsongeschikten op de arbeidsmarkt, voor die groep die de capaciteiten heeft om (deels) aan het werk te blijven.

Dit onderzoek richt zich op deze twee beleidsdoelstellingen en is gedeeld in drie delen. In het eerste hoofdstuk richten we ons op de effecten van de conjunctuurcyclus en de (wetgeving gedreven) leeftijdseffecten op de transitie van werkend naar werkeloos, inactief of arbeidsongeschikt. Het doel van het onderzoek is het bepalen van de mate waarin de conjuntuurcyclus zowel op lokaal als op national niveau een effect heeft op de overgang van werkend naar arbeidsongeschikt, voor individuen die de pensioensgerechtigde leeftijd bereiken.

Het tweede en derde hoofdstuk richt zich op individuen die een permanente arbeidsongeschiktheids uitkering hebben ontvangen tussen 1996 en 2007 maar voorheen werkend waren. In beide hoofdstukken proberen we de effecten van een aantal wetten en hervormingen op de kans dat arbeidsongeschikten een baan vinden te schatten.

Gedurende de periode 1996-2007 werd erkend dat arbeidsongeschikte vrouwen zich in een zeer kwetsbare positie bevonden op de arbeidsmarkt, in 
vergelijking met hun mannelijke counterparts. In 2004 werd een hervorming geintroduceerd die de integratie van invalide vrouwen op de arbeidsmarkt moest bevorderen. In het tweede hoofdstuk evalueren we de werkgelegenheids effecten van deze hervorming, die zich uit in de vorm van een stijging van de kortingen in sociale zekerheidsbijdragen van werkgevers die arbeidsongeschikte vrouwen in dienst namen .

In het derde en laatste hoofdstuk bekijken we het gebruik of misbruik van een wet die is geintroduceerd in de 1980's om een extra zekerheid te bieden aan gedeeltelijk arbeidsongeschikten, die in economische achtergestelde regio's in Spanje woonden en lager opgeleid waren. De wet biedt de mogelijkheid tot stijgingen van $36 \%$ in het pensioen van arbeidsongeschikte individuen, van 55 jaar of ouder die aan de bovengenoemde criteria voldoen, als erkenning voor de moeilijkheden die zij ondervinden bij het vinden van een baan in economisch minder goede tijden.

De data die we gebruiken voor de drie hoofdstukken zijn die van de doorlopende steekproef onder werkenden (Muestra Continua de Vidas Laborales, MCVL), een microeconomische dataset gebasseerd op administratieve data met meer dan een miljoen mensen. De referentie groep betreft individuen die werkten, werkeloos waren of een pensioen ontvingen (arbeidsongeschiktheid, ouderdom of wezen) in 2007, van wie de gehele werkgeschiedenis van 1980 tot 2007 is opgevraagd bij de Spaanse sociale zekerheidsadministratie. Voor elk van de hoofdstukken selecteerden we steekproefsgewijs een verschillende groep individuen uit deze dataset, afhankelijk van het onderwerp van het onderzoek. $\mathrm{Om}$ te controleren voor economische condities op regionaal niveau, hebben we macroeconomische informative over werkeloosheidscijfers en economische sectorgegevens per regio, als ook de groei in het bruto nationaal product achterhaald uit de gegevens van het Spaanse Instituut voor de Statistiek (17 autonome regio's of 52 provincies, afhankelijk welk onderzoek het betreft).

\section{Conjunctuur cyclus effecten op arbeidsmarkt transities voor oudere mensen in Spanje}

Zelfs nadat vervroegde pensioensregelingen waren afgeschaft of beperkt, vanwege hun nadelige gevolgen voor de werkgelegenheid, stegen de participatiecijfers op de arbeidsmarkt van oudere mensen niet. Deze ouderen vonden alternatieve manieren om de arbeidsmarkt te verlaten,tot ze de pensioensgerechtigde leeftijd hadden bereikt, met name door werkeloosheids en arbeidsongeschiktheids regelingen te gebruiken.

In dit hoofdstuk analyseren we de kenmerken voor de stap van werkend naar werkeloosheid, arbeidsongeschikt of niet actief op de arbeidsmarkt, voor werknemers in de leeftijdsgroep 45-59, met specifieke aandacht voor de rol van de 
conjunctuur cyclus op lokaal en nationaal niveau. Voor deze analyse gebruiken we twee modellen, te weten een 'single exit logistic hazard model' om de transitie van werkend naar alle niet werkende statussen te modelleren, en een "competing risk model" om onderscheid te maken tussen het uittreden van werkend naar werkeloos, arbeidsongeschikt of inactiviteit. We koppelden de informative over individuen uit de MCVL database met een aantal variabelen uit de data van het Nationaal Instituut voor de Statistiek van Spanje, die groei en werkgelegenheid in de verschillende regio's in Spanje weergeven.

Onze resultaten wijzen op sterke effecten van de variabelen die de conjunctuur cyclus meten op de transitie van werkend naar ontvanger van werkeloosheidsuitkeringen of arbeidsongeschiktheidsuitkeringen. Individuen hebben daarom een grotere kans om een arbeidsongeschiktheidsuitkering te ontvangen als de werkeloosheidscijfers in de regio waar ze wonenen stijgen, of als de economische groeicijfers op nationaal niveau dalen. De conclusie is dat condities gerelateerd aan de conjunctuur cyclus op zowel lokaal en nationaal niveau in Spanje sterke determinanten van de instroom van ontvangers van een arbeidsongeschiktheidsuitkering zijn. Dit kan worden geïnterpreteerd als het strategisch gebruik maken van het arbeidsongeschiktheidssysteem als alternatief middel tot verwerving van inkomen in perioden van slechte economische omstandigheden.

\section{Het promoten van werkgelegenheid voor arbeidsongeschikte vrouwen in Spanje: het evalueren van het beleid}

Het arbeidsongeschiktheidssysteem in Spanje heeft vier verschillende uitkeringsvormen. De vorm wordt bepaald door de mate van arbeidsongeschiktheid, die zowel geheel als gedeeltelijk arbeidsongeschikten in staat stelt de uitkering te combineren met het uitvoeren van werkzaamheden (die in overeenkomst zijn met de mate van arbeidsongeschiktheid). Echter uit de data blijkt dat de meerderheid van de individuen in het system geen baan heeft, zelfs in een systeem met een dergelijke mate van differentiatie in de graad van arbeidsongeschiktheid en de mogelijkheden voor het ontvangen van een uitkering terwijl men werkt.

Om die reden hebben de Spaanse autoriteiten sinds 1981 een aantal maatregelen geïntroduceerd, die de arbeidsmarkt integratie van arbeidsongeschikten bevorderen. De belangrijkste onderdelen van dit beleid zijn werknemer quota's van $2 \%$ voor bedrijven met meer dan 50 werknemers, antidiscriminatie wetgeving en kortingen in de sociale zekerheids bijdragen die betaald moeten worden door de werkgever van de arbeidsongeschikte werknemer.

In het tweede hoofdstuk analyseren we de werkgelegenheidseffecten van een beleid dat in 2004 is ingevoerd, om de relatief nadelige positie van 
arbeidsongeschikte vrouwen aan te pakken. Het beleid betrof hogere kortingen in de sociale zekerheids bijdragen voor werkgevers die arbeidsongeschikte vrouwen in dienst namen.

Om de effecten van dit beleid op de werkgelegensheids kansen van arbeidsongeschikte vrouwen in Spanje te schatten, gebruiken we een 'bivariaat probit model' waarin we twee afhankelijke variabelen schatten (het soort uitkering en de werk situatie van de arbeidsongeschikte vrouw), om rekening te houden met niet geobserveerde variabelen in beide vergelijkingen. We volgen de methodologie geintroduceerd door Autor \& Duggan (2008) en introduceren een aantal variabelen om te controleren voor de aanwezigheid van al bestaande trends in de ontwikkeling van werkgelegenheid voor vrouwen in vergelijking tot mannen.

Onze resultaten zijn redelijk stabiel, in meerdere specificaties en wijzen op positieve maar kleine effecten van het beleidsinitiatief op de werkgelegenheidsmogelijkheden voor arbeidsongeschikte vrouwen ten opzichte van mannen. Echter, dit positieve effect is sterker en significanter voor de groep individuen ouder dan 45 jaar.

Hieruit kunnen twee conclusies worden afgeleid die relevant zijn voor beleid. Ten eerste, moet er een alternatief beleidsinstrument worden gevonden dat effectief is in het promoten van werkgelegenheidsintegratie van oudere arbeidsongeschikte vrouwen $(+45)$. Ten tweede is er een bredere hervorming nodig om verstrekkende resultaten te garanderen in termen van werkgelegenheidsvooruitzichten van arbeidsongeschikte individuen aangezien kleine geïsoleerde maatregelen een positief maar slechts klein effect hebben.

\section{Werkgelegenheidseffect van stijgende arbeidsongeschiktheidsuitkeringen: een discontinue regressive analyse}

De belangrijkste kritiek op arbeidsongeschiktheidssystemen in de literatuur (met name gericht op de USA en Nederland) is dat de beleidsmaatregelen / wetgeving een negatieve impuls creëren om te werken. Dit effect is goed gedocumenteerd. Hoewel er nog geen overeenstemming is over de grootte van deze negatieve impuls, is er duidelijk consensus over het bestaan ervan.

Door beperkingen in de beschikbare data, is dit onderwerp nooit eerder bestudeerd met betrekking tot het Spaanse arbeidsongeschiktheidsbeleid. Het doel van deze studie is daarom dit gat in de literatuur te dichten, door een analyse uit te voeren naar de werkgelegenheidseffecten van één bepaalde Spaanse wet. De betreffende wet biedt een verhoging van $36 \%$ van de gedeeltelijke arbeidsongeschiktheidsuitkering voor individuen die 55 jaar of ouder zijn en die als gevolg van een gebrek aan kennis of capaciteiten in combinatie met de arbeidsmarktsituatie waarin ze zich bevinden, een kleine kans hebben om een baan te vinden. 
Door het aanwezig zijn van selectie elementen in de behandeling, kunnen we geen traditionele "difference-in-difference" schattingstechnieken toepassen. We gebruiken daarom de discontinuiteit in het beleid op 55 jarige leeftijd en passen een discontinu regressie model toe om de invloed van geobserveerde en niet geobserveerde variabelen in acht te nemen.

We gebruiken traditionele 'discontinue regressie modellen (fuzzy design)' Vanwege de aanwezigheid van niet lineaire relaties m.b.t. de covariaat "leeftijd waarop de person het arbeidsongeschiktheids system betrad', introduceren we een bepaalde specificatie waarin we de groep beperken tot individuen die voor hun $55^{\text {ste }}$ levensjaar arbeidsongeschikt waren.

Onze resultaten suggereren dat traditionele OLS en 'vaste effecten modellen' met een dummy variabele die het behandelingseffect meenemen, het effect van het beleid om arbeidsmarkt participatie van arbeidsongeschikten te beperken, significant overschat.

De resultaten uit onze traditionele 'Regression Discontinuety analyse' laten een statistisch significante daling van 3 procent punten zien in de kans om aan het werk te komen, als gevolg van de stijging van de uitkering. Echter, als we ons beperken tot een steekproef met individuen die arbeidsongeschikt werden voor leeftijd van 55 jaar, suggereren de schattingen dat het beleid een daling in de kans tot werkgelegendeid van 1 procent teweeg brengt (de gemiddelde arbeidsmarkt participatie voor deze steekproef is 12.5 procent, een 1 procent punt daling komt overeen met een 8 procent daling in de kans op werk).

In dit hoofdstuk kwantificeren we de effecten van een stijging van de arbeidsongeschiktheidsuitkeringen op de arbeidsmarkt participatie van arbeidsongeschikten in een systeem waarin het ontvangen van een uitkering niet afhankelijk is van het uitvoeren van werk. We interpreteren dit resultaat als het bewijs van het feit dat er een inkomenseffect is in plaats van een substitutieeffect, zoals Autor en Duggan (2008) concluderen. Verder komen onze resultaten zeer overeen met wat eerder is geconcludeerd in de literatuur. Dit is met name het geval voor het onderzoek van Gruber (2000) waarin hij voor Canada de elasticiteit van uitkeringen m.b.t. werk op 0.28-0.36 schat, voor een $36 \%$ stijging in de hoogte van de arbeidsongeschiktheidsuitkeringen. Onze schattingen geven een elasticiteit van 0.22 voor eenzelfde stijging van $36 \%$. 


\section{MGSoG Dissertation Series}

Keetie Roelen

False Positives or Hidden Dimentions: the definition and measurement of child poverty MGSoG Dissertation Series, nr. 8 (2010)

Denisa Maria Sologon

Earning Dynamics in Europe

MGSoG Dissertation Series, nr. 7 (2010)

Melissa Siegel

Money and Mobility: Migration and Remittances

MGSoG Dissertation Series, nr. 6 (2010)

Jessica S. Hagen-Zanker

Modest Expectations: Causes and effects of migration on migrant households in source countries

MGSoG Dissertation Series, nr. 5 (2010)

Mirtha R. Muniz Castillo

Human Development and Autonomy in Project Aid: Experiences from four

bilateral projects in Nigaragua and El Salvador

MGSoG Dissertation Series, nr. 4 (2009)

Christiane Arndt

Governance Indicators

MGSoG Dissertation Series, nr. 3 (2009)

Britta Augsburg

Microfinance - Greater Good or Lesser Evil?

MGSoG Dissertation Series, nr. 2 (2009)

Geranda Notten

Measuring and Managing Poverty Risks

MGSoG Dissertation Series, nr. 1 (2008) 


\section{Curriculum Vitae}

Judit Vall Castello was born on August 30, 1979 in Lleida, Spain. She studied Economics at Universitat Autonoma of Barcelona and graduated in 2002 with a Bachelor's in Economics. During her undergraduate studies, she spent one semester as an exchange student at the Faculty of Business and Economics of the University of Manitoba in Canada.

She then moved to England to study a Master in European Integration at the University of Essex, in Colchester, with a scholarship from the "Patronat Catala Pro-Europa" (an Institution which is part of the Catalan Government). For her Master Thesis she evaluated the Growth and Stability Pact of the EU and produced an assessment of its functioning and the potential proposals for reform.

After working as an Exports Project Coordinator at the National Economic Development Ministry of Mexico for eight months, Judit joined the Cambridge Endowment for Research in Finance (CERF) at Cambridge University in the United Kingdom as a research assistant. During her time at CERF, she was part of two projects focusing, on the one hand, on financial innovation in European and Asian countries and its effects on lending and savings behavior and economic growth and, on the other hand, on the consequences of financial flows and investment on some developing Latin-American and Asian countries.

In 2006, she joined the Maastricht Graduate School of Governance as a Marie Curie PhD fellow and started working on her dissertation which concentrates on the empirical estimation of the impact of Social Policy and the business cycle on labour market decisions of Spanish workers. As part of her dissertation, she has also studied the effects of labour promotion measures for disabled workers. During her $\mathrm{PhD}$, she has spent research visiting periods at the Institute for Economic and Social Research of the University of Essex, at the Toulouse School of Economics and at the State University of New York at Stony Brook with a Fulbright-Schuman grant.

She has presented her work on many occasions varying from academic conferences and seminars such as EALE and ESPE to faculty seminars at universities such as Cornell University or the Baruch College in New York. 
Since her studies, Judit has also taught in universities in Spain, Mexico and The Netherlands and has been involved in a number of projects for international organizations such as UNICEF or the European Commission. At the same time, she has also attended several summer schools such as the IZA summer school on labour economics, the Essex summer school or the Microeconometrics summer school at Pompeu Fabra University. 